\title{
Tratamento de eventos aplicado à composição de serviços web
}

\author{
Mauricio Chui Rodrigues
}

\author{
DisSERTAÇÃO APRESENTADA \\ $\mathrm{AO}$ \\ Instituto DE MATEmÁtica E EstatísticA \\ DA \\ UniversidAdE DE SÃO PAUlO \\ PARA \\ OBTENÇÃO DO TÍTULO \\ DE \\ Mestre em CiênCIAS
}

Programa: Ciência da Computação

Orientador: Prof. Dr. João Eduardo Ferreira 



\section{Tratamento de eventos aplicado à composição de serviços web}

Esta versão da dissertação contém as correções e alterações sugeridas pela Comissão Julgadora durante a defesa da versão original do trabalho, realizada em 29/05/2012. Uma cópia da versão original está disponível no Instituto de Matemática e Estatística da Universidade de São Paulo.

Comissão Julgadora:

- Prof. Dr. João Eduardo Ferreira (orientador) - IME-USP

- Prof. Dr. Francisco Carlos da Rocha Reverbel - IME-USP

- Prof. Dr. Luiz Camolesi Júnior - FT-UNICAMP 

Aos meus pais, Marcos e June. 



\section{Agradecimentos}

Ao meu orientador, Prof. Dr. João Eduardo Ferreira, pelas oportunidades oferecidas desde a graduação, quando me convidou para o Programa de Iniciação Científica do IME-USP, até o mestrado. Sou grato pela confiança em mim depositada ao me aceitar como orientando, ciente da minha intenção de dividir o tempo entre mestrado e trabalho.

Aos meus pais, Marcos e June, e minhas irmãs, Debora e Cristine, pelo apoio incondicional durante toda a minha vida e por tantos momentos em que abriram mão de algo por mim. Agradeço especialmente aos meus pais por todo o esforço e dedicação para que minhas irmãs e eu pudéssemos nos concentrar nos estudos em prol de uma boa formação. Tudo o que sou como indivíduo se deve à minha família e nela busco forças e inspiração para enfrentar os mais difíceis momentos.

Aos amigos e colegas de trabalho do UOL, pela compreensão e paciência em todas as ocasiões nas quais precisei cumprir horários alternativos para poder assistir a aulas, participar de seminários e, por fim, escrever esta dissertação. Admiro o incentivo do UOL à participação de seus funcionários na área de pesquisa e jamais esquecerei do apoio para que eu pudesse apresentar em meu primeiro simpósio fora do Brasil, o ACM SAC 2009. Sou grato a Rafael Plana Maranzato por acreditar em meu potencial como profissional desde 2008, ano em que iniciei tanto o mestrado quanto minha atividade na empresa.

Ao Prof. Dr. Francisco Carlos da Rocha Reverbel, um dos melhores professores com quem já tive aulas, por sua importantíssima contribuição para este trabalho ao sugerir, em meu exame de qualificação, que fosse explorada a associação entre a abordagem proposta e os serviços Web adeptos da arquitetura REST.

Aos amigos do IME-USP, especialmente os do BCC 2004, pela companhia e alegria indispensáveis para superar diversas situações de tensão durante a graduação, sem a qual não haveria o mestrado.

Aos colegas do Laboratório de Banco de Dados do IME-USP, com destaque para Kelly Rosa Braghetto e Pedro Losco Takecian, pelo conhecimento e experiência compartilhados e pela atenção dedicada sempre que precisei.

A todas as pessoas que tiveram convites negados e compromissos adiados ou até cancelados quando não consegui me fazer presente além do trabalho e do mestrado. 


\section{Resumo}

Tratamento de Eventos Aplicado à Composição de Serviços Web

Funcionalidades de software expostas como serviços Web são cada vez mais comuns e suas formas de composição e coordenação são cada vez mais imprescindíveis. Orquestração e coreografia, tradicionais abordagens de composição de serviços Web, são providas por ferramentas voltadas ao gerenciamento de processos de negócio com diferentes enfoques. Apesar do sucesso dessas abordagens, existem ainda desafios a serem superados, tais como a dificuldade de manutenção em fluxos de controle já existentes, o custo de comunicação associado às interações com os serviços Web, o conhecimento do processo de negócio por parte dos serviços e ainda a compatibilidade dos mesmos em uma composição. Como alternativa às abordagens tradicionais, esta dissertação propõe o uso da abordagem WED-flow para composição de serviços $W e b$, de modo que a execução de processos de negócio seja orientada pelas alterações do estado dos dados. Na abordagem proposta, o fluxo de controle não é um requisito, mas sim uma consequência da execução dos serviços $W e b$, o que proporciona maior flexibilidade para o desenvolvimento e a manutenção das aplicações. Mais concretamente, a primeira contribuição deste trabalho é a proposição e a avaliação de cenários possíveis de orquestração e coreografia de acordo com critérios pré-definidos. A segunda contribuição é a implementação da abordagem WED-flow para a composição de serviços $W e b$, bem como sua validação prática e sua avaliação em relação aos cenários de coreografia e orquestração. 


\section{Abstract}

Processing of Events for Web Services Composition

Features of software exposed as Web services are becoming more common and their forms of composition and coordination are increasingly essential. Orchestration and choreography, traditional approaches for Web service compositions, are provided by tools that manage business processes with different approaches. Despite the success of these approaches, there are still challenges to be overcome such as the difficulty of maintaining flows in existing control, the communication cost associated with Web service interactions, knowledge of the business process by the services and even their compatibility in service compositions. As an alternative to traditional approaches, this paper proposes the use of WED-flow approach for Web services composition, so that the execution of business processes is driven by changes in data states. In our approach, the control flow is not a requirement but a consequence of the Web service execution, which provides greater flexibility for the development and maintenance of applications. More specifically, the first contribution of this

work is to propose and evaluate possible scenarios of orchestration and choreography according to predefined criteria. The second contribution of this work is the implementation of WED-flow approach for Web service compositions, as well as its validation in the choreography and orchestration scenarios. 


\section{Sumário}

Lista de Abreviaturas $\quad$ xi

Lista de Símbolos $\quad$ xiii

Lista de Figuras $\quad$ Xv

Lista de Tabelas $\quad$ xvii

1 Introdução 1

1.1 Considerações Preliminares . . . . . . . . . . . . . . . . . . . 2

1.2 Contextualização e Trabalhos Relacionados . . . . . . . . . . . . . . . 3

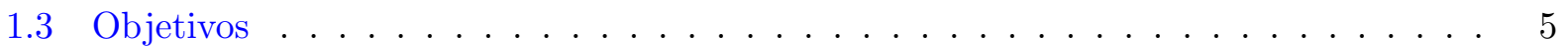

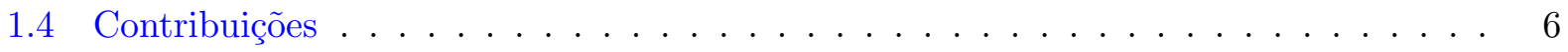

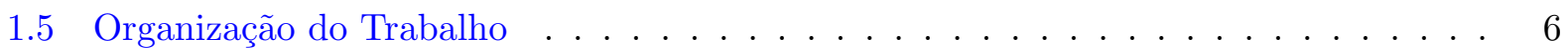

$\begin{array}{llr}2 & \text { Fundamentos } & 7\end{array}$

2.1 Teoria de Processos . . . . . . . . . . . . . . . . . . . . 7

2.2 Formalismos Clássicos . . . . . . . . . . . . . . . . . . . 8

2.2 .1 Redes de Petri . . . . . . . . . . . . . . . . . . . . 8

2.2 .2 Álgebras de Processos . . . . . . . . . . . . . . . . . . . 13

2.2.3 Redes de Petri $\times$ Álgebras de Processos . . . . . . . . . . . . . . . . 18

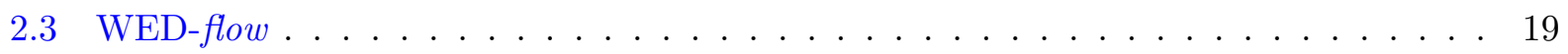

2.3 .1 Fundamentos . . . . . . . . . . . . . . . . . 20

2.3.2 Processo de Modelagem e Implementação . . . . . . . . . . . . . . . . . . . 22

2.3 .3 Exemplo de Aplicação . . . . . . . . . . . . . . . . . . . . . . . 23 


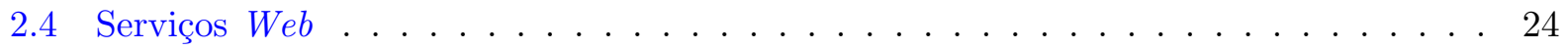

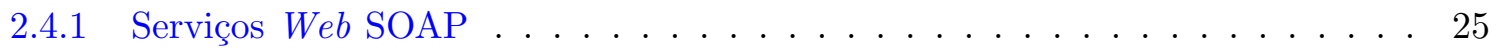

2.4.2 Serviços Web REST . . . . . . . . . . . . . . . . . 27

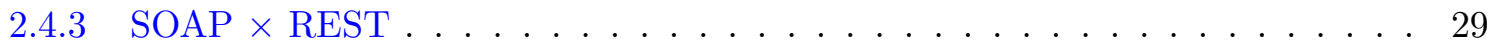

2.5 Composição de Serviços $W e b \ldots \ldots \ldots \ldots \ldots$

2.5.1 Orquestração e Coreografia . . . . . . . . . . . . . . . . 31

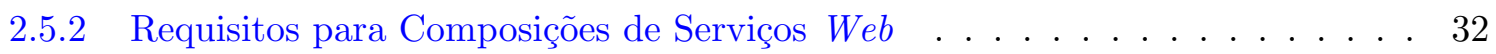

3 Proposição e Avaliação de Cenários $\quad 33$

3.1 Conceitos para Avaliação . . . . . . . . . . . . . . . . . . . 33

3.1 .1 Processos de Negócio para Simulação . . . . . . . . . . . . . . . . . . . . . 34

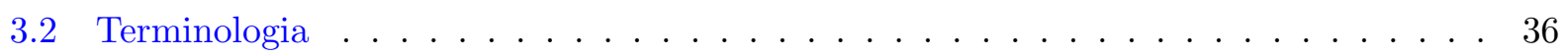

3.3 Cenários de Comunicação com Serviços $W e b \ldots \ldots \ldots$. . . . . . . . 38

3.3.1 Cenário I: Coreografia Ativa com Notificações Globais . . . . . . . . . . . . 38

3.3.2 Cenário II: Coreografia Passiva com Notificações Globais . . . . . . . . . . . 41

3.3.3 Cenário III: Coreografia Passiva com Notificações Diretas . . . . . . . . . . . 43

3.3.4 Cenário IV: Orquestração Ativa com Notificações Globais e Feedback . . . . . 45

3.3.5 Cenário V: Orquestração Passiva com Notificações Diretas e Feedback .. . 48

3.3.6 Cenário VI: Orquestração Passiva com Notificações Diretas e sem Feedback . 50

3.4 Comparativo dos Cenários Propostos . . . . . . . . . . . . . . . . 52

3.4.1 Configuração com Notificações Globais e sem Feedback . . . . . . . . . . . . . 53

3.4.2 Configuração com Notificações Globais e Feedback . . . . . . . . . . . . . 54

3.4.3 Configuração com Notificações Diretas e sem Feedback . . . . . . . . . . . . . 54

3.4.4 Configuração com Notificações Diretas e Feedback . . . . . . . . . . . . 55

4 Composição de Serviços Web com WED-flow $\quad 57$

4.1 Funcionamento do Núcleo WED-flow . . . . . . . . . . . . . . . . 57

4.2 Extensão do Núcleo WED-flow . . . . . . . . . . . . . . . . . . . 59

4.2.1 Abordagem Proposta $\times$ NPWS . . . . . . . . . . . . . 60

4.3 Implementação . . . . . . . . . . . . . . . . . . . . . . . . . . . 61 
4.3 .1 Tipos de Operações de Serviços $W e b \ldots \ldots \ldots \ldots$. . . . . . . . 62

4.3 .2 Mapeamento de Dados . . . . . . . . . . . . . . . . . . . 63

4.3.3 Integração com o Núcleo WED-flow . . . . . . . . . . . . . . . . . . 65

4.3.4 Funcionamento do Módulo de Extensão . . . . . . . . . . . . . . . . . 67

4.3.5 Requisitos para os Serviços $W e b \ldots \ldots \ldots \ldots \ldots$. . . . . . . . . . .

4.4 Exemplo de Estudo . . . . . . . . . . . . . . . . . . . . . 72

4.4 Modelagem WED-flow . . . . . . . . . . . . . . 73

4.4 .2 Simulação . . . . . . . . . . . . . . . . . . . . . . . 74

4.4 .3 Implementação . . . . . . . . . . . . . . . . . . . . . 75

4.5 Resultados Obtidos . . . . . . . . . . . . . . . . . . . 77

4.5 .1 Avaliação . . . . . . . . . . . . . . . . . 77

4.5.2 Comparação com Resultados das Configurações Propostas . . . . . . . . . . . 79

4.6 Considerações Finais . . . . . . . . . . . . . . . . . . . . . . . . 82

4.6.1 Classes de Serviços Aceitas para Composição . . . . . . . . . . . . . . . . 83

5 Conclusão $\quad 85$

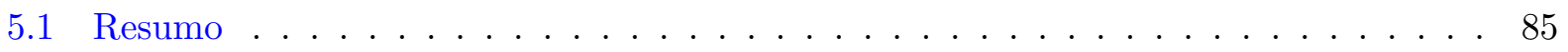

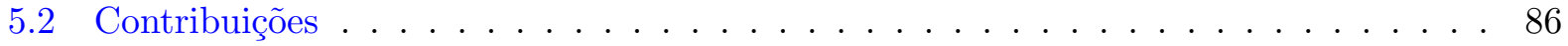

5.3 Limitações . . . . . . . . . . . . . . . . . . . . . 87

5.4 Trabalhos Futuros . . . . . . . . . . . . . . . . . . 88

5.4 .1 Gerenciamento das Informações de Serviços . . . . . . . . . . . . . . 88

5.4 .2 Tratamento de Questões de Segurança da Informação . . . . . . . . . . . . 88

$\begin{array}{lr}\text { Referências Bibliográficas } & 89\end{array}$ 


\title{
Lista de Abreviaturas
}

\author{
ACID Atomicidade, Consistência, Isolamento e Durabilidade. \\ ACP Álgebra de Processos Comunicantes (Algebra of Communicating Processes). \\ BPA Álgebra de Processos Básica (Basic Process Algebra). \\ BPEL Business Process Execution Language. \\ BPEL4WS Business Process Execution Language for Web Services. \\ BPM Gerenciamento de Processos de Negócio (Business Process Management). \\ BPMN Business Process Modelling Notation. \\ CCS Cálculo de Sistemas Comunicantes (Calculus of Communicating Systems). \\ CSP Processos Sequenciais Comunicantes (Communicating Sequential Processes). \\ ECA Evento-Condição-Ação (Event-Condition-Action). \\ FIFO First In, First Out. \\ HTTP Hypertext Transfer Protocol. \\ JSON JavaScript Object Notation. \\ LTS Sistema de Transições Rotuladas (Labelled Transition System). \\ NPDL Navigation Plan Definition Language. \\ NPWS Navigation Plan for Web Services. \\ PAP Álgebra de Processos com Paralelismo (Process Algebra with Parallelism). \\ PARIDE Process-based Framework for Orchestration of Dynamic E-Services. \\ PN Rede de Petri (Petri Net). \\ REST Transferência de Estado Representacional (Representation State Transfer). \\ SOA Arquitetura Orientada a Serviços (Service-Oriented Architecture). \\ URI Identificador Uniforme de Recursos (Uniform Resource Identifier). \\ URL Localizador Uniforme de Recursos (Uniform Resource Locator). \\ W3C World Wide Web Consortium. \\ WADL Web Application Description Language. \\ WED-flow Work/Event/Data-flow. \\ WfMC Workflow Management Coalition. \\ WS-BPEL Web Services Business Process Execution Language. \\ WS-CDL Web Services Choreography Description Language. \\ WSCI Web Services Choreography Interface.
}


WSDL Web Services Description Language.

WSTL Web Service Transaction Language.

WWW World Wide Web.

XML Extensible Markup Language. 


\section{Lista de Símbolos}

+ Operador de composição alternativa.

- $\quad$ Operador de composição sequencial.

|| Operador entrelaçamento.

$\gamma \quad$ Função de comunicação.

॥ Operador entrelaçamento à esquerda.

| Operador entrelaçamento com comunicação.

$\delta \quad$ Constante deadlock.

$\partial_{H} \quad$ Operador encapsulamento para um conjunto $H$ de ações. 


\section{Lista de Figuras}

2.1 Rede de Petri para o processo de sinistro. . . . . . . . . . . . . . . 9

2.2 Nova modelagem para o processo de sinistro. . . . . . . . . . . . . . . 10

2.3 Rede de Petri para o processamento de reclamações. . . . . . . . . . . . . . . 13

2.4 Grafo de processo com comportamento infinito. . . . . . . . . . . . 16

2.5 Grafo do processo de verificação de usuário. . . . . . . . . . . . . . . . . 18

2.6 Representação genérica de um WED-flow . . . . . . . . . . . . . . . . . . 21

2.7 WED-states do caminho normal para o exemplo da livraria online . . . . . . . . 24

2.8 Arquitetura de serviços $W e b$ SOAP. $\ldots \ldots \ldots \ldots \ldots \ldots \ldots$

2.9 Representação da arquitetura REST . . . . . . . . . . . . . . . . . . . . 28

2.10 Abordagens para composição de serviços Web: orquestração e coreografia. . . . . . . 31

2.11 Composição recursiva de serviços $W e b \ldots \ldots \ldots \ldots \ldots \ldots \ldots \ldots$

3.1 Notação gráfica utilizada neste trabalho para simulações de cenários. . . . . . . . . . 35

3.2 Rede de Petri para o subprocesso referente à composição sequencial. . . . . . . . . . 35

3.3 Rede de Petri para o subprocesso referente à composição alternativa. . . . . . . . . . 35

3.4 Rede de Petri para o subprocesso referente ao entrelaçamento. . . . . . . . . . . 36

3.5 Decomposição de processo de negócio em instâncias dos subprocessos propostos. 36

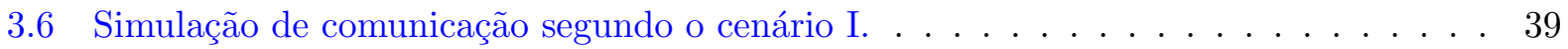

3.7 Simulação de comunicação segundo o cenário II. . . . . . . . . . . . . . . . . . 42

3.8 Simulação de comunicação segundo o cenário III. . . . . . . . . . . . . . . . . . . . 44

3.9 Simulação de comunicação segundo o cenário IV . . . . . . . . . . . . . . . . 47

3.10 Simulação de comunicação segundo o cenário V . . . . . . . . . . . . . . . . 49

3.11 Simulação de comunicação segundo o cenário VI. . . . . . . . . . . . . . . 51 
4.1 Participantes e interações em execução de processo de negócio com WED-flow. . . 58

4.2 Exemplo de distribuição de funcionalidades entre domínios de organizações distintas. 59

4.3 NPWS e sua interação com aplicações e serviços $W e b . \ldots . \ldots$

4.4 Principais entidades para integrar o módulo de extensão ao núcleo WED-flow. . . . . 64

4.5 Tratamento de parâmetros de entrada pelo módulo de extensão ao invocar um serviço

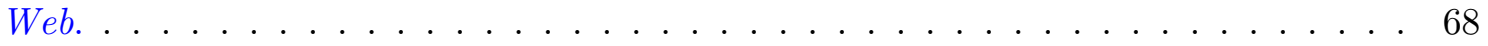

4.6 Tratamento de parâmetros de saída pelo módulo de extensão ao invocar um serviço

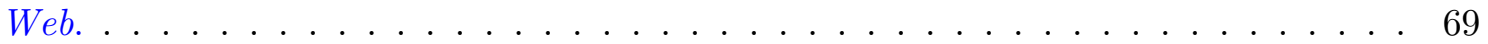

4.7 Normalização para o caminho normal da aquisição online de produtos. . . . . . . . . 73

4.8 Normalização para o caminho de cancelamento por dados inválidos de pagamento. 74

4.9 Representação do modelo WED-flow para o caminho normal. . . . . . . . . . . . . 75

4.10 Representação do modelo WED-flow para o caminho de exceção. . . . . . . . . . . . 75

4.11 Simulação do processo de negócio de aquisição online de produtos. . . . . . . . . 76

4.12 Simulação de comunicação segundo a WED-flow, somente com operações síncronas. . 78 


\section{Lista de Tabelas}

2.1 Vantagens e desvantagens na opção por serviços Web SOAP ou REST. . . . . . . . 30

3.1 Combinações entre os quatro aspectos para a nomeação de cenários. . . . . . . . . . 38

4.1 Volumes de comunicação considerados nas avaliações finais. . . . . . . . . . . . . 82 
xviii 


\section{Lista de Algoritmos}

2.1 Descrição estruturada do processo de verificação de usuário. . . . . . . . . . . . 17

4.1 Tratamento de operações REST pelo módulo de extensão. . . . . . . . . . . . . . . . 70

4.2 Tratamento de operações SOAP síncronas pelo módulo de extensão. . . 70

4.3 Tratamento de operações SOAP assíncronas pelo módulo de extensão. . . . . . . . . . 71 


\section{Capítulo 1}

\section{Introdução}

Um processo de negócio é um conjunto formado por uma ou mais atividades (passos) relacionadas que, juntas, levam ao cumprimento de um objetivo de negócio [54]. A execução de um processo de negócio apresenta condições bem definidas de início e término, e as interações entre os participantes, de duração variável, podem ou não ser formalmente definidas, bem como atividades podem ser realizadas manual ou automaticamente.

Segundo [54], definição de processo é a representação de um processo de negócio em uma forma favorável a algum tipo de manipulação automática. A definição de um processo pode conter referências a subprocessos, definidos separadamente. Define-se uma instância de processo de negócio como o artefato executável gerado a partir da definição do processo: uma definição pode originar diversas instâncias independentes. Assim, cada execução de um processo de negócio remete à execução de uma determinada instância.

O consórcio WfMC (Workflow Management Coalition) especifica ainda os conceitos de workflow $^{1}$ e de sistemas de gerenciamento de workflow [55] da seguinte forma:

- "Workflow é a automação, total ou parcial, de atividades em que documentos, informações ou tarefas são passados entre os participantes de acordo com um conjunto de regras para atingir ou contribuir com um objetivo de negócio";

- "Um sistema de gerenciamento de workflow é aquele que provê a automação procedural de um processo de negócio por meio do gerenciamento da sequência de atividades e da alocação apropriada de recursos conforme a execução dessa sequência".

A prioridade, nas definições tradicionais de workflow, é realizar as atividades referentes a um processo de negócio. Já o Gerenciamento de Processos de Negócio (BPM - Business Process Management) apresenta um escopo maior, pois oferece técnicas e ferramentas de apoio às fases de projeto, execução, gerenciamento e análise operacional dos processos de negócio [23]. Assim, o BPM propicia a proposição de melhorias para o projeto, bem como a identificação de possíveis falhas.

\footnotetext{
${ }^{1}$ Termo que, por ser bastante difundido no meio científico, não é traduzido neste texto.
} 
Diversas são as abordagens já propostas para o BPM, tal que suas vantagens e desvantagens são amplamente discutidas na área acadêmica. A área de BPM é consideravelmente ativa e novas abordagens surgem com o intuito de suprir necessidades ainda não atendidas ou mesmo atender requisitos de forma mais efetiva.

\subsection{Considerações Preliminares}

Estudos na área de BPM indicaram inicialmente a necessidade de conceitos e ferramentas com sólido embasamento teórico, o que introduziu formalismos ${ }^{2}$ clássicos como as redes de Petri e as álgebras de processos, respectivamente apresentadas nas Seções 2.2.1 e 2.2.2 deste texto.

Outras complexas questões foram posteriormente identificadas, tais quais a modelagem de sistemas com grande quantidade de atividades e a volatilidade na execução de fluxos, que apontam o tratamento de eventos como solução comum [13]. A automação desse tratamento, entretanto, é dificultada pela ampla variedade de condições sob as quais os eventos se manifestam em workflows, razão pela qual a intervenção humana, mais custosa e menos eficiente, não pode ser descartada.

São exemplos de abordagens propostas com o objetivo de transpor a rigidez na modelagem de processos: a análise essencial [27], a modelagem orientada a eventos [2], a modelagem orientada a dados [31], os artefatos de negócios [33] e as regras de Evento-Condição-Ação (ECA - EventCondition-Action) [10]. Há comum acordo entre diversas companhias e grupos de pesquisa sobre a classificação dessas e de outras técnicas de representação e execução de processos de negócio, como descrito em [12] e resumido a seguir:

- Estruturas de controle de fluxo: as tarefas são relacionadas de acordo com a passagem do controle entre as atividades, de modo que o enfoque é o fluxo de execução (i.e., um processo $a$ é executado antes de um processo $b$ ou ambos executados em paralelo);

- Estruturas de controle de dados: as ligações entre as tarefas refletem mudanças no estado dos dados de acordo com a execução de atividades (i.e., o conjunto de dados $a$ se transforma em um outro conjunto $b$ ).

Os tipos de estrutura não são mutuamente exclusivos, de forma a ser viável a existência de abordagens híbridas. Um exemplo é composto pela arquitetura Riverfish e o conceito de Plano de Navegação, propostos em [57]. Outro exemplo é a Navigation Plan Definition Language (NPDL) [6], linguagem fundamentada em uma álgebra de processos e nos conceitos de [57] e cuja implementação se denomina NavigationPlanTool.

Tanto as abordagens citadas anteriormente quanto as híbridas, entretanto, não favorecem o tratamento genérico de eventos, que tem como principal obstáculo a ausência de um mapeamento de estados para sistemas de larga escala. A abordagem WED-flow, recentemente proposta em [13]

\footnotetext{
${ }^{2} \mathrm{O}$ emprego do termo "formalismo" neste trabalho remete a "método matemático rigoroso".
} 
e descrita neste trabalho, procura superar as limitações atuais impostas ao uso de eventos e sugere um mecanismo genérico de tratamento de eventos na modelagem de workflows.

\subsection{Contextualização e Trabalhos Relacionados}

A popularidade de serviços Web como uma forma de integração, composição e reuso no desenvolvimento de aplicações distribuídas e heterogêneas cresceu com o apoio de diversos padrões da indústria. Técnicas e mecanismos de BPM, por sua vez, mostram-se essenciais para compor e coordenar serviços, de modo que o conjunto de execuções, devidamente ordenado, resulte no cumprimento dos objetivos de negócio esperados. No entanto, trabalhos como [50] e [19] afirmam que os conceitos subjacentes à composição de serviços $W e b$ ainda não foram totalmente compreendidos.

Comprova-se em [19], com base em modelos formais tais como autômatos finitos, que efeitos colaterais indesejáveis podem surgir quando determinados tipos de serviços são compostos. Os autores declaram que a composição de serviços pode apresentar mais características intrínsecas do que normalmente suposto pelos comitês de padronização. Reforçam a ideia os argumentos apresentados em [50] sobre serem raros os modelos conceituais para a especificação de serviços, bem como os estudos relacionados. É mencionada, como exemplo, a Business Process Execution Language for Web Services (BPEL4WS) [20], com a qual é possível compor serviços por meio da definição de um fluxo de controle que relaciona as atividades. Essa abordagem é vista como puramente sintática, sem qualquer possibilidade de serem extraídas propriedades do fluxo criado.

O objetivo de [50] é prover uma maneira de criar especificações para composições de serviços $W e b$ que possam ser verificadas em tempo de execução. Propõe-se um modelo de composição de serviços com multicamadas, o qual acompanha a especificação de um serviço por meio de diferentes níveis de abstração, partindo de conceitos transacionais até requisitos próximos ao provedor ou usuário final. Árvores e grafos são empregados para representar as possíveis rotas na execução do processo e suas respectivas propriedades.

Outro trabalho voltado a composições de serviços $W e b$ passíveis de verificação de propriedades é [26], em que é proposto o arcabouço Process-based Framework for Orchestration of Dynamic EServices (PARIDE). Processos são controlados por um mecanismo de orquestração que opera com fluxos de controle e de dados, sustentado por um modelo baseado em redes de Petri. Pode-se, então, especificar o comportamento externo de cada serviço e também a composição como um todo. A análise do grafo referente à rede de Petri, por sua vez, permite derivar propriedades intrínsecas, como a obtenção da configuração final esperada.

Tais quais as redes de Petri, formalismos algébricos figuram como embasamento teórico em estudos e soluções cujo intuito é o de controlar rigorosamente composições de serviços. O Navigation Plan for Web Services (NPWS) [40], também um mecanismo de orquestração, encapsula a ferramenta NavigationPlanTool por meio de um conjunto de serviços Web capazes de receber chamadas de aplicações e realizar chamadas a outros serviços. Assim, composições de serviços Web podem 
usufruir o potencial de gerenciamento de processos da ferramenta, que aplica uma extensão de álgebra de processos e conceitos da arquitetura Riverfish [57] para especificar processos e controlar a execução de suas instâncias.

O debate sobre a adoção de formalismos gráficos ou algébricos como melhor embasamento teórico no contexto das linguagens para composição de serviços Web é tratado em [46], que confronta redes de Petri e Pi Calculus para caracterizar que cada formalismo apresenta prós e contras na representação de processos. O trabalho aponta que os formalismos parecem ser mais utilizados na promoção de linguagens de composição de serviços Web, como a BPEL4WS e algumas concorrentes, do que devidamente aplicados em prol de melhorias de qualidade e solidez. Não somente é questionado o embasamento teórico dessas linguagens como são solicitadas demonstrações de que técnicas e ferramentas de análise foram aplicadas em seu desenvolvimento.

Independente da associação a formalismos, uma grande variedade de trabalhos existe para o tema de composições de serviços Web. Entre as propostas de orquestração já mencionadas, como o PARIDE, o NPWS e a BPEL4WS, o WebTransact [38] assemelha-se à última por se tratar de uma ferramenta que utiliza mediadores e uma linguagem orientada a programação, a Web Service Transaction Language (WSTL), para a composição de serviços Web.

Há também os trabalhos que visam coreografias, como a BPEL4Chor [9], proposta como uma extensão da Web Services Business Process Execution Language (WS-BPEL) [21], sucessora da BPEL4WS e também conhecida, em sua forma abreviada, por Business Process Execution Language (BPEL). A BPEL4Chor distingue-se da BPEL por habilitar a descrição do comportamento de cada participante e da topologia dos participantes, tais quais as configurações para comunicação. Em [37], propõe-se ainda uma extensão da Business Process Modeling Notation (BPMN) [34] para incorporar conceitos que viabilizem a especificação completa de coreografias com a BPEL4Chor.

Segundo [30], a representação de coreografias ainda é um desafio que não foi completamente solucionado pelas principais propostas, a Web Services Choreography Description Language (WSCDL) [22] e a BPEL. Os autores afirmam que as linguagens priorizam o aspecto procedural e sacrificam a natureza declarativa própria das coreografias, portanto propõem o uso da DecSerFlow [47], uma linguagem declarativa para a especificação dos fluxos de serviços. Ademais, [30] oferece o mapeamento da linguagem DecSerFlow para outras duas baseadas em lógica, de modo a ser possível a verificação formal dos modelos gerados.

Entre outras abordagens propostas para a composição de serviços Web em que o controle se dá de forma distribuída, constam [11] e [43]. A primeira supõe interações peer-to-peer ("ponto-aponto") entre os serviços envolvidos e utiliza diagramas de estados para mapear as ações do sistema e rastrear o fluxo de execução. Já a segunda sugere o uso do padrão de mensagens publish/subscribe para o controle transacional de processos com mínima intervenção de um coordenador central.

Com a proposta da arquitetura ${ }^{1}$ REST (Representation State Transfer) [14], descrita entre os

\footnotetext{
${ }^{1}$ Termo adotado neste texto para se referir a architectural style.
} 
fundamentos deste trabalho, e após sua adoção como um padrão alternativo ao tradicional para serviços Web, surgiram ainda estudos sobre como adaptar composições ao REST. Em [56], discutemse os desafios relacionados a essa adaptação e propõe-se um modelo formal para descrição de serviços, bem como automação de uma composição. Já [1] declara haver poucos trabalhos relacionados a composições com serviços REST, dentre os quais a maioria possui a execução de operações como prioridade, em detrimento da navegação pelos recursos disponíveis. Sugere-se uma linguagem para a descrição de serviços juntamente ao uso de redes de Petri para controle da navegação.

Ainda em relação a composições de serviços REST, há trabalhos com maior apelo prático. Um exemplo é [35], que sugere uma forma de usar a BPEL como linguagem de composição para operar tanto com os serviços tradicionais quanto com REST, segundo uma abordagem de orquestração. Outro exemplo é [39], que descreve como o Drupal, uma ferramenta de código aberto para gerenciamento de conteúdo, pode ser empregada para orquestrar serviços com base na relação entre regras e ações.

Por fim, o tópico de tratamento de exceções é bastante relevante para estudos sobre composições de serviços Web. Os autores de [8] propõem, para o BPEL4WS, uma forma de tratar fluxos excepcionais bastante similar ao encontrado em linguagens de programação. As atividades envolvidas no processo formam grupos denominados escopos, aos quais podem ser associados módulos de tratamento de exceção. Quando se identifica uma exceção, as atividades internas ao escopo cessam e avalia-se a presença de um tratador adequado: se houver, o fluxo programado para a situação é executado e o escopo é dado como completo; se não, a exceção é propagada para o escopo que o contém, e o primeiro escopo é dado como desabilitado. Somente quando nenhum escopo é capaz de tratar a exceção propagada, a execução é afetada como um todo.

A compensação transacional, por sua vez, é abordada em [42] como alternativa para o tratamento de exceções em composições de serviços Web. De acordo com essa técnica, descrita de forma detalhada em [17], a falha na execução de uma ação é substituída pela execução de outra, que pode desfazer os efeitos causados pela primeira ou prover resultados próximos disso. Os autores de [42] sugerem que, em vez de a falha de um serviço provocar o aborto da execução dos demais para que a transação seja reiniciada, haja um fluxo alternativo para compensar a falha sem interferir no restante da execução. A lógica de compensação é especificada à parte da lógica de negócio e serviços abstratos são implementados para intermediar a comunicação dos clientes com os serviços reais e viabilizar as compensações.

\subsection{Objetivos}

Os trabalhos para composição e coordenação de serviços $W e b$, sejam linguagens orientadas à programação ou propostas com sólido embasamento teórico, tradicionalmente necessitam da definição dos fluxos de controle a priori. Nota-se, como principal efeito dessa propriedade, a dificuldade em se promover mudanças na representação do processo de negócio quando este sofre alguma alteração ou identifica-se alguma falha na representação inicial. 
A abordagem proposta por este trabalho visa realizar, por meio da WED-flow, a composição de serviços $W e b$ referente a um processo de negócio com enfoque no estado dos dados associados e não em fluxos de controle, os quais abandonam o posto de requisito para assumirem o de consequência do modelo. A composição de serviços passa a ser, assim, orientada pelo tratamento de eventos identificados junto às mudanças de estado dos dados.

O principal objetivo deste trabalho é propor, avaliar e implementar uma forma de compor serviços Web com WED-flow. Como pré-requisito para isso, são avaliados cenários possíveis com abordagens tradicionais, assunto do Capítulo 3, e então elabora-se uma extensão do núcleo WEDflow, descrita no Capítulo 4. O núcleo WED-flow, por sua vez, remete a um trabalho à parte e atualmente em curso: a dissertação de mestrado de Marcela Ortega Garcia [16], sob orientação do Prof. Dr. João Eduardo Ferreira.

\subsection{Contribuições}

Este trabalho objetiva realizar duas principais contribuições. A primeira é a identificação de possíveis cenários de orquestração e coreografia, bem como sua avaliação com base no volume de chamadas remotas realizadas. Espera-se que essa contribuição disponibilize uma forma de calcular o volume de chamadas para cada cenário. Outro critério considerado na avaliação são aspectos técnicos de implementação das soluções. Ambos os critérios são detalhados no Capítulo 3.

A segunda contribuição é a proposição, a implementação e a avaliação de uma abordagem de composição de serviços Web (SOAP ou REST) orientada ao tratamento de eventos por meio da WED-flow, isto é, voltada à verificação de alterações do estado dos dados. A implementação corresponde à criação de um módulo para estender o núcleo WED-flow, já a avaliação utiliza os critérios estabelecidos junto à proposição de cenários para que seja possível apontar suas diferenças para os resultados previamente obtidos. Identificam-se, por fim, as vantagens e desvantagens da abordagem WED-flow em relação a orquestração e coreografia.

Uma vez que a realização deste trabalho ocorre de forma concorrente à do núcleo WED-flow, a real integração das implementações deve ocorrer somente após o término de ambos. Para promover a independência dos resultados, as validações práticas do módulo desenvolvido neste trabalho se dão, portanto, por meio de simulação. Propõe-se um exemplo de estudo e são desenvolvidos artefatos de testes para viabilizar essas validações. Tanto os artefatos quanto o módulo de extensão do núcleo são disponibilizados em http://www.ime.usp.br/〜 chui/wedflow.

\subsection{Organização do Trabalho}

No Capítulo 2 são apresentados os conceitos em que se baseia esta dissertação. O Capítulo 3 remete à proposição e avaliação dos cenários de comunicação em abordagens tradicionais de composição de serviços Web. Já o Capítulo 4 descreve a implementação e a avaliação da WED-flow como abordagem de composição. Por fim, o Capítulo 5 conclui esta dissertação e indica propostas para trabalhos futuros. 


\section{Capítulo 2}

\section{Fundamentos}

Este capítulo introduz os conceitos necessários para a realização deste trabalho. Inicialmente descrevem-se a Teoria de Processos, por meio de conceitos encontrados em [15], e alguns formalismos clássicos de BPM. Então a abordagem WED-flow para BPM é introduzida e, por fim, definem-se os conceitos relacionados a serviços Web, bem como são apresentadas as abordagens existentes de composição destes serviços.

\subsection{Teoria de Processos}

O comportamento de um sistema é composto pelas ações que pode realizar, bem como na probabilidade com que cada atividade ocorre e as possíveis ordens de realização, entre outros aspectos. Pode-se dizer que esse comportamento é composto por processos e dados: enquanto os processos são dinâmicos e ativos, os dados são estáticos e passivos, de modo que os processos são os responsáveis pelo controle dos dados. A tendência é que diversos processos sejam executados de forma concorrente e que esses se influenciem por meio da troca de dados.

Uma possível representação do comportamento de um processo se dá por meio do uso de um Sistema de Transições Rotuladas (LTS - Labelled Transition System). Uma transição pode ser uma tripla $\left(s, a, s^{\prime}\right)$ ou um par $(s, P)$, em que $s$ e $s^{\prime}$ pertencem a um conjunto de estados, $a$ provém de um conjunto finito de rótulos de transição e $P$ é elemento de um conjunto finito de símbolos de predicados. Cada tripla pode ser denotada por $s \stackrel{a}{\rightarrow} s^{\prime}$ e indica que um estado $s$ pode passar a $s^{\prime}$ quando uma ação a é executada; cada par, por sua vez, pode ser denotado por $s P$ e expressa a validade de um predicado $P$ no estado $s$. Define-se, assim, um LTS como um conjunto (possivelmente infinito) de transições.

O LTS que modela o comportamento de um processo em um sistema concorrente é denominado grafo de processo. Nele, o conjunto de estados corresponde aos estados possíveis para o sistema concorrente, enquanto as ações são atividades disponíveis para execução. Ademais, em um grafo de processo há um estado escolhido como raiz, ou seja, o estado inicial do processo.

Grafos de processos são distinguíveis por meio de equivalências comportamentais. Um exemplo é a equivalência por observação, que relaciona dois processos se e somente se ambos executarem 
exatamente as mesmas sequências de ações. Outro exemplo é a equivalência por bissimulação, mais refinada, que considera as sequências de ações e também a estrutura de ramificação dos grafos.

\subsection{Formalismos Clássicos}

Ainda que constituam uma forma de expressão e comparação do comportamento de sistemas, os grafos de processos podem ser representados de diferentes maneiras, de acordo com a necessidade. Dois principais formalismos são descritos nesta seção: as redes de Petri, cujas informações se baseiam em [49] e [32], e as álgebras de processos, cujos conceitos foram extraídos de [3] e [15].

\subsubsection{Redes de Petri}

O termo rede de Petri (PN - Petri Net) foi introduzido em 1962, por Carl Adam Petri, como uma ferramenta para a modelagem e a análise de processos. Embora uma de suas grandes vantagens seja a representação gráfica de fácil compreensão, essas redes se diferenciam de outras técnicas baseadas em esquemas por serem inteiramente formalizadas. A sólida base matemática associada a uma PN possibilita a verificação das propriedades do sistema modelado, tais como a sincronização e a precedência entre eventos.

Desde seu advento, essas redes foram estendidas de diferentes formas, fator que torna acessível a modelagem de processos bastante complexos. Os primeiros trabalhos sobre o seu uso para a modelagem e a análise de processos datam da década de 70 [48].

Nesta seção é abordado essencialmente o modelo original proposto por Petri, junto a sucintas explicações sobre suas principais extensões.

\section{Redes de Petri Clássicas}

Uma PN é composta por lugares e transições. Lugares são componentes passivos que permitem determinar o estado do sistema, enquanto transições são componentes ativos correspondentes a ações, eventos ou transformações que ocorrem no sistema. Graficamente, um lugar é representado como um círculo e uma transição, como um retângulo.

Um exemplo simples de PN é retratado na Figura 2.1: trata-se da modelagem do processo de sinistro (acionamento de seguro). Uma vez acionado o seguro, tal ação é registrada e tem início a análise do caso. Por fim, pode haver o pagamento ou o envio de uma notificação com as razões da rejeição. A PN possui três lugares (acionamento, processamento e encerramento) e três transições (registrar, pagar e recusar).

Lugares e transições em uma PN são relacionados por meio de arcos dirigidos, que apresentam duas variações: há os arcos que partem de um lugar para uma transição e os que partem de uma transição para um lugar. Não são permitidos arcos entre dois componentes de um mesmo tipo.

A análise dos arcos de uma PN permite a identificação dos lugares de entrada e dos lugares de saída de cada transição. Um lugar $l$ é um lugar de entrada para uma transição $t$ se e somente 


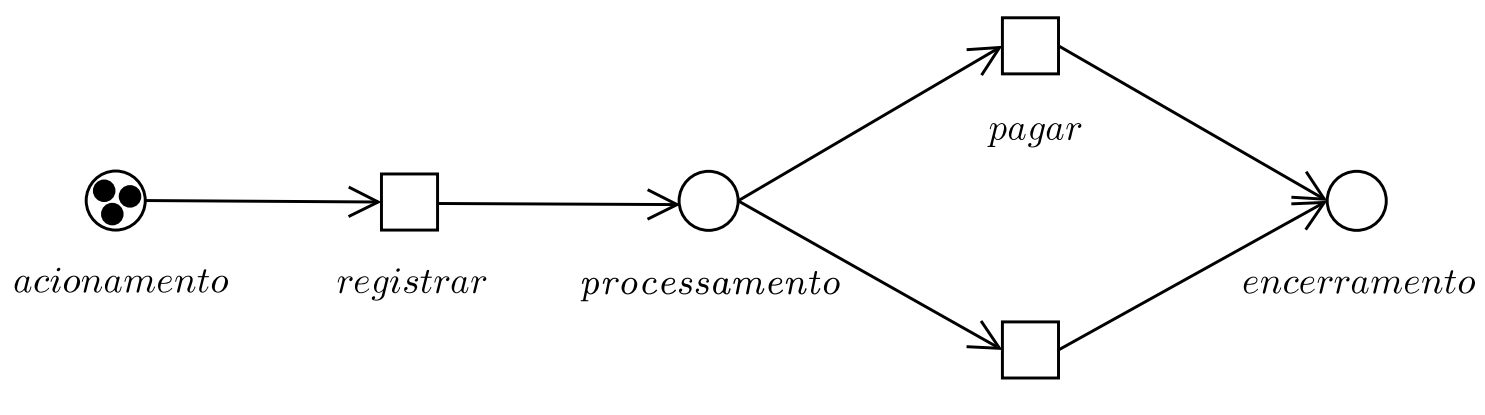

recusar

Figura 2.1: Rede de Petri para o processo de sinistro. Fonte: [49]

se existe um arco partindo de $p$ para $t$. Analogamente, um lugar $l$ é um lugar de saída para uma transição $t$ se e somente se existe um arco partindo de $t$ para $p$. Na Figura 2.1, a transição registrar possui apenas um lugar de entrada (acionamento) e um de saída (processamento).

Cada lugar contém um número não-negativo de fichas, que representam recursos física ou virtualmente disponíveis e são representadas como pontos pretos. Embora a estrutura de uma PN seja imutável, a distribuição das fichas entre os lugares tende a variar de acordo com o comportamento dinâmico do sistema. A posição das fichas determina o estado (ou marcação) da PN.

O peso de um arco determina quantas fichas uma transição consome de um lugar de entrada ou quantas produz para um lugar de saída. Quando o peso de um arco não é explicitamente definido, supõe-se seu valor como 1. Se todos os arcos de uma PN possuem peso 1, como na Figura 2.1, tal rede é classificada como ordinária.

Introduzidos os principais conceitos, define-se uma PN clássica como um grafo bipartido ${ }^{1}$ orientado em que os arcos possuem pesos e há um estado inicial. A definição formal de uma PN é dada pela quíntupla $P N=\left(L, T, A, P, E_{0}\right)$ [32], na qual:

- $L=\left\{l_{1}, l_{2}, \ldots, l_{m}\right\}$ é um conjunto finito de lugares;

- $T=\left\{t_{1}, t_{2}, \ldots, t_{n}\right\}$ é um conjunto finito de transições;

- $A \subseteq(L \times T) \cup(T \times L)$ é um conjunto de arcos;

- $P: A \rightarrow\{1,2,3, \ldots\}$ é a função peso;

- $E_{0}: L \rightarrow\{0,1,2,3, \ldots\}$ é o estado inicial;

- $L \cap T=\emptyset$ e $L \cup T \neq \emptyset$.

O disparo de uma transição é o que conduz fichas de seus lugares de entrada para os de saída. A pré-condição para um disparo é o estado da transição como ativa, isto é, todo lugar de entrada

\footnotetext{
${ }^{1} \mathrm{Um}$ grafo é bipartido se o seu conjunto $V$ de vértices pode ser dividido em dois conjuntos disjuntos $V_{1}$ e $V_{2}$ de forma que cada aresta conecte um vértice em $V_{1}$ a um em $V_{2}$.
} 
da transição deve possuir um número de fichas superior ou igual ao peso do arco que o conecta à mesma. Feito o disparo, a transição consome fichas de cada lugar de entrada de modo a produzir fichas para cada lugar de saída, respeitando os pesos dos arcos envolvidos.

A modelagem de um processo como PN pode permitir diversos progressos simultâneos, como é frequente em sistemas concorrentes. No entanto, é importante que o modelo respeite todos os limites e restrições do sistema. No exemplo da Figura 2.1, dada a presença de três fichas em acionamento, dois disparos seguidos da transição registrar resultarão em um mínimo de duas fichas em processamento. Porém, se suposta a restrição de que apenas um caso deve ser processado por vez, torna-se necessária a alteração da rede (Figura 2.2).

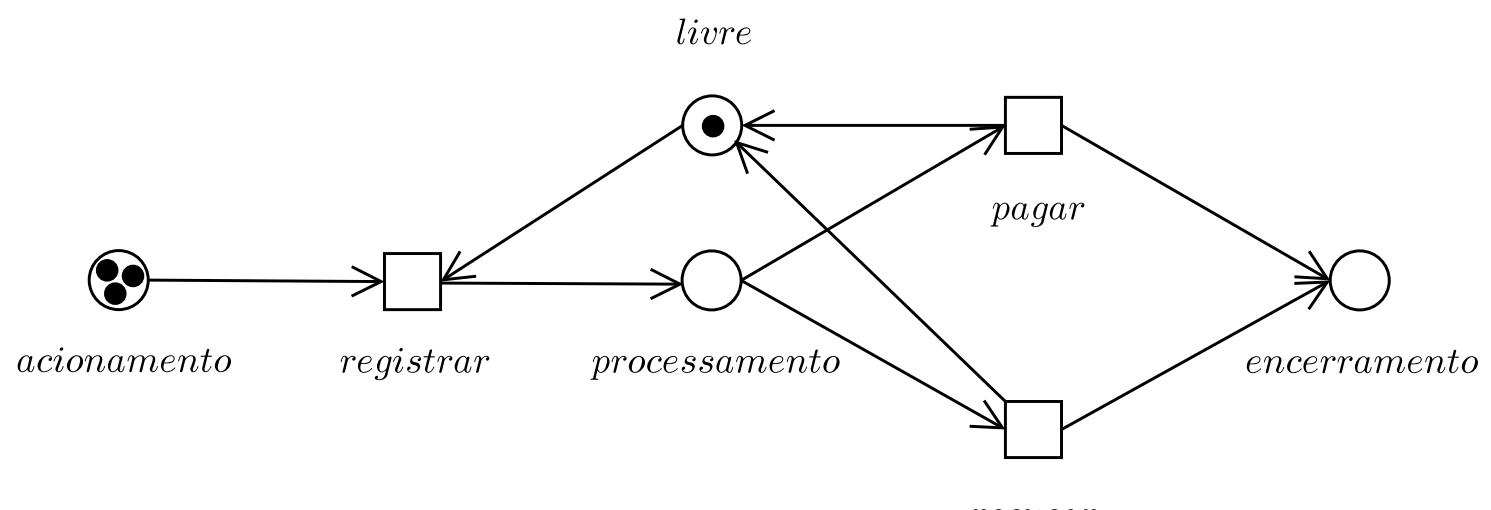

recusar

Figura 2.2: Nova modelagem para o processo de sinistro. Fonte: [49]

Adicionado o lugar livre com uma ficha, o estado inicial da PN indica que a transição registrar está ativa. Quando disparada, essa transição deixa de ser ativa para que as outras duas sejam, o que bloqueia qualquer outro acesso a processamento até o disparo de pagar ou recusar: só então será produzida uma nova ficha para livre, reativando registrar. Essa solução ainda se aplica à restrição de $n$ casos simultâneos, bastando que sejam inseridas $n$ fichas em livre.

\section{Redes de Petri de Alto Nível}

Apesar de sua simplicidade e da forte base matemática, as PN clássicas apresentam limitações em diferentes aplicações práticas, seja pelo tamanho das redes ou pela impossibilidade de modelar situações complexas de forma acessível e estruturada. Por tais razões, as redes receberam diversas extensões, dentre as quais se destacam a extensão com cores, a extensão com tempo e a hierárquica. Essas três extensões são intituladas redes de Petri de alto nível [49], apresentadas a seguir de forma simplificada.

Redes de Petri Coloridas A distinção entre duas fichas é impossível em uma PN clássica, principalmente se ocuparem um mesmo lugar. Em uma PN colorida, essa situação é evitada devido a toda ficha ser provida de cor, termo que se refere a um valor ou conjunto de valores. No processo de sinistro (Figura 2.1), cada ficha representa um seguro e, portanto, pode ser associada a um 
conjunto de valores que contém, por exemplo, um número de identificação, o nome do proprietário e atributos do veículo.

Novos fatores passam a ser considerados no disparo e na ativação de cada transição em uma PN colorida. Por exemplo, o disparo de uma transição pode produzir um número variável de fichas para cada lugar de saída, de acordo com suas cores. A representação dos dados é o que gera o contraste entre uma PN colorida e uma clássica, pois não ocorre de forma gráfica. As transições podem ser formalmente definidas ou mesmo apresentadas como um trecho de texto ou pseudocódigo.

Redes de Petri com Tempo Tanto em uma PN clássica quanto em uma colorida, há dificuldade em medir o tempo referente à simulação de um processo modelado. O diferencial em uma PN com tempo é a adição de um valor a cada ficha, indicando o momento a partir do qual ela se torna disponível, isto é, pode haver o seu consumo. Um exemplo da representação gráfica desse tipo de rede é introduzido em [49], com o intuito de modelar o funcionamento de dois conjuntos de semáforos.

Para essa extensão, define-se o conceito de tempo de ativação de uma transição: tratase do primeiro momento em que seus lugares de entrada contêm um número suficiente de fichas disponíveis. A primeira transição a atingir seu tempo de ativação é também a primeira a ser disparada, porém é necessária uma escolha não-determinística caso duas transições se tornem ativas simultaneamente. O consumo de fichas segue o princípio First In, First Out (FIFO), portanto a primeira ficha a ser consumida por uma transição é a que apresenta o menor tempo associado.

Redes de Petri Hierárquicas Embora processos complexos possam ser modelados por meio da forma clássica de PN e de suas extensões com cores e tempo, normalmente a rede resultante é incapaz de representar a estrutura hierárquica do processo em questão, dado que a modelagem gera uma única e extensa rede. A correta representação dessa estrutura é uma importante contribuição das PNs hierárquicas.

O conceito de processo, representado graficamente por um quadrado de borda dupla, é incorporado pelas redes com extensão hierárquica para indicar que a ação a ser executada não é atômica, mas sim um subprocesso, isto é, uma subrede com seus próprios lugares, transições, arcos, fichas e mesmo outros processos. As subredes são intuitivamente representadas junto à rede principal, portanto não há necessidade da descrição por outros meios.

As principais vantagens da representação gráfica de subprocessos são: o uso da estratégia de divisão-e-conquista para avaliar a complexidade do processo como um todo; e a capacidade de reaproveitamento das subredes, com o intuito de evitar a duplicação de trechos da PN. Um exemplo de PN hierárquica se encontra em [49], na modelagem de um processo de reparação. 


\section{Exemplo de Aplicação}

Para ilustrar neste texto a modelagem de um sistema como PN, utiliza-se o exemplo do processamento de reclamações em [45]. O resultado da modelagem é apresentado na Figura 2.3.

Nesse processo, primeiro há o registro de uma reclamação e então, em paralelo, ocorrem o envio de um questionário ao reclamante e a avaliação da reclamação. Se o reclamante devolver o questionário dentro do prazo de duas semanas, o questionário é processado, senão é descartado. Já a avaliação pode resultar ou não no processamento da reclamação: caso resulte no processamento, aguarda-se até que o questionário seja processado ou ocorra a expiração do prazo. Após o processamento há a sua verificação, o que pode levar a um novo processamento se for identificado algum erro. Por fim, há o arquivamento da reclamação.

Derivam-se, assim, as seguintes transições da descrição do processo:

- registrar: registro da reclamação;

- enviar_q: envio do questionário para o reclamante;

- avaliar: avaliação da reclamação;

- processar_q: processamento do questionário respondido;

- descartar_q: descarte do questionário após fim do prazo;

- processar: processamento da reclamação;

- verificar: verificação do processamento da reclamação;

- arquivar: arquivamento da reclamação.

Para considerar as duas possíveis saídas de verificar, bem como as saídas de avaliar, outras quatro transições são adicionadas ao modelo:

- proc_OK: não houve erros ao processar a reclamação;

- proc_NOK : houve algum erro durante o processamento da reclamação;

- sem proc: processamento de reclamação não realizado após a avaliação;

- proc_necessario: processamento de reclamação necessário, segundo a avaliação.

A representação dos estados entre as ações se dá por meio de condições, modeladas como lugares. Por exemplo, se o questionário for processado ou o prazo para tal expirar, o lugar $C_{5}$ passa a conter uma ficha, o que satisfaz um pré-requisito para o disparo de arquivar ou processar. As condições $I$ e $F$, por sua vez, remetem respectivamente às condições de início e fim. 


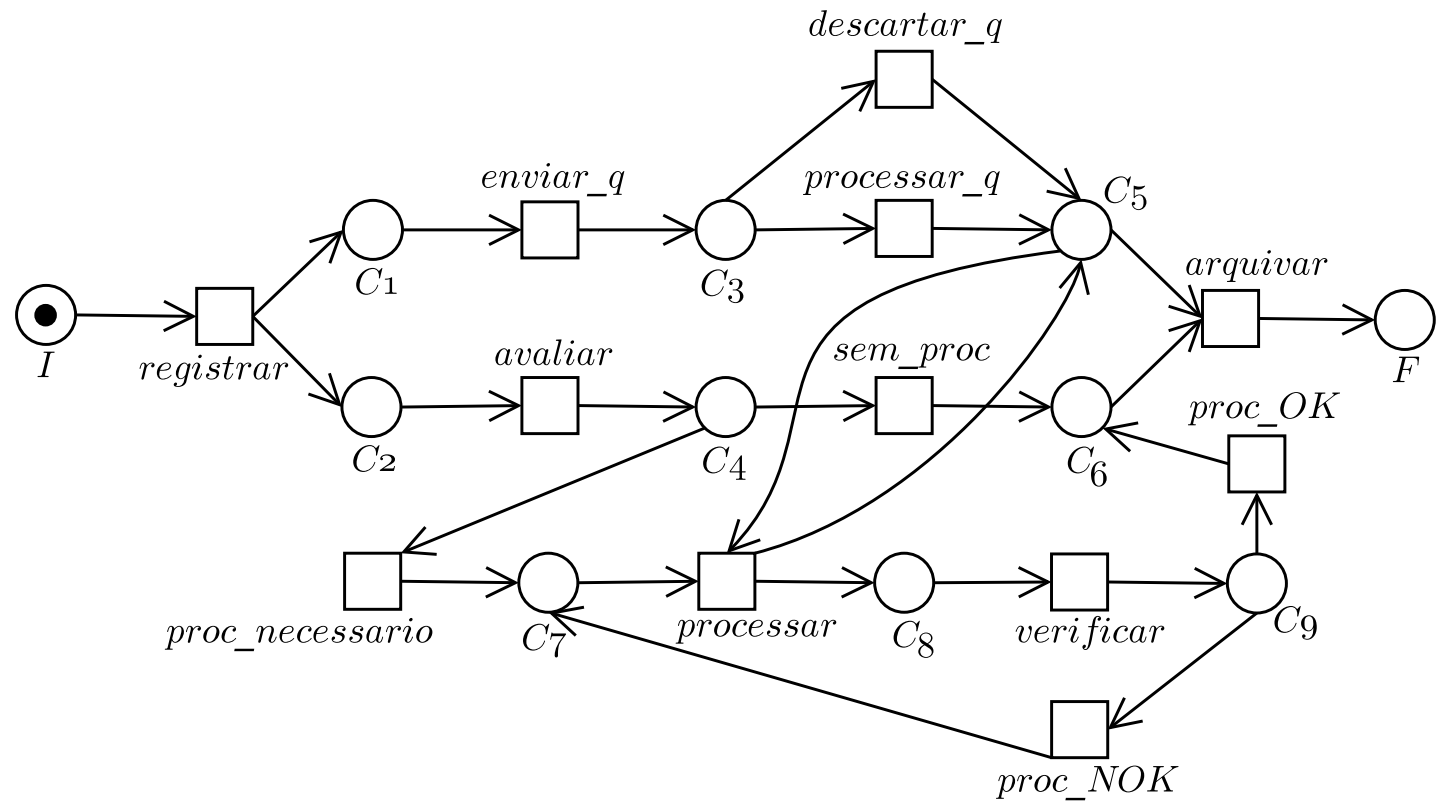

Figura 2.3: Rede de Petri para o processamento de reclamações. Fonte: [45]

\subsection{2 Álgebras de Processos}

Para o propósito do raciocínio matemático, é conveniente representar grafos de processos algebricamente, na forma de termos. As álgebras de processos constituem um arcabouço para o raciocínio formal sobre processos e dados, que visa a especificação e a manipulação de termos de processos com o uso de uma coleção de símbolos de operadores. Esse arcabouço, que enfatiza processos com execução concorrente, permite encontrar propriedades indesejáveis da especificação de um sistema, bem como possibilita a derivação formal das propriedades desejáveis.

O desenvolvimento da base das álgebras de processos teve início na década de 70 com trabalhos quase independentes que culminaram nas teorias de processos conhecidas por Cálculo de Sistemas Comunicantes (CCS - Calculus of Communicating Systems) [28] e Processos Sequenciais Comunicantes (CSP - Communicating Sequential Processes) [18]. A pouca interferência existente entre a CCS e a CSP, à época classificadas como "cálculos de processos", foi o resultado de discussões visando o amadurecimento das ideias propostas. O termo "álgebra de processos" passou a ser empregado somente a partir da década de 80, com o advento da Álgebra de Processos Comunicantes (ACP - Algebra of Communicating Processes) [4].

Toda álgebra de processos define uma lógica de equivalência sobre os termos de processos, de modo que dois termos são considerados iguais se e somente se seus grafos são comportamentalmente equivalentes. Outra propriedade comum a qualquer álgebra de processos é a capacidade de extensão com novos operadores, seja para aumentar sua expressividade ou facilitar a especificação do comportamento de um sistema.

O conteúdo restante desta seção, extraído de [15], tem como objetivo descrever sucintamente a 
gradual evolução teórica que resultou na $\mathbf{A C P}$ e na $\mathbf{A C P}$ estendida com recursão, álgebras de processos de maior relevância para esta dissertação.

\section{Álgebra de Processos Básica}

Os principais elementos que constituem a base de uma álgebra de processos para a construção de termos de processos são:

- Um conjunto finito e não vazio $A$ de ações (atômicas), representando comportamentos indivisíveis;

- Um operador binário + denominado composição alternativa. Dados dois termos $t_{1}$ e $t_{2}$ que representam respectivamente processos $p_{1}$ e $p_{2}$, então o termo $t_{1}+t_{2}$ representa o processo que executa $p_{1}$ ou $p_{2}$;

- Um operador binário - denominado composição sequencial. Dados dois termos $t_{1}$ e $t_{2}$ que representam respectivamente processos $p_{1}$ e $p_{2}$, então o termo $t_{1} \cdot t_{2}$ representa o processo que executa primeiro $p_{1}$ e finalmente executa $p_{2}$.

Cada processo finito pode ser representado a partir do conjunto $A$ de ações atômicas, do operador + e do operador $\cdot$. Os termos assim construídos são denominados termos básicos de processo e a coleção de todos esses termos recebe o nome de Álgebra de Processos Básica (BPA - Basic Process Algebra).

\section{Álgebra de Processos com Paralelismo}

Na prática, o comportamento de um processo é frequentemente determinado por diversos processadores executados em paralelo. Para modelar tais tipos de sistemas concorrentes, foi introduzido o operador binário entrelaçamento (merge) [28], representado por $\|$. Esse operador recebe dois termos de processos como argumentos e os executa de forma concorrente, o que significa que $s \| t$ pode optar por executar uma transição inicial de $s$ ou uma transição inicial de $t$.

Há ainda uma terceira opção para o entrelaçamento: executar a comunicação entre transições iniciais de $s$ e $t$. Para esse propósito, assume-se uma função de comunicação comutativa e associativa $\gamma: A \times A \rightarrow A$, tal que $A$ é o conjunto de ações atômicas. Essa função produz, para cada par de ações atômicas $a$ e $b$, sua comunicação $\gamma(a, b)$.

Após a prova, em [29], da inexistência de uma axiomatização válida e completa para a BPA estendida com o entrelaçamento, houve a definição de dois novos operadores denominados entrelaçamento à esquerda (left merge) e entrelaçamento com comunicação (communication merge) [4].

$\mathrm{O}$ entrelaçamento à esquerda é representado por $\llbracket$. Dados dois termos fechados $t_{1}$ e $t_{2}$, seu comportamento em $t_{1}\left\lfloor t_{2}\right.$ implica na realização da transição inicial de $t_{1}$ para então assumir o 
comportamento de $\|$. O entrelaçamento com comunicação, por sua vez, é representado por $\mid$. Dados dois termos fechados $t_{1}$ e $t_{2}$, seu comportamento em $t_{1} \mid t_{2}$ implica na comunicação entre as transições iniciais de $t_{1}$ e $t_{2}$ seguida do mesmo comportamento de $\|$.

Os operadores $\|, \llbracket \mathrm{e} \mid$ têm, por convenção, precedência sobre o + . Por exemplo, $a \llbracket b+a \| c$ representa $(a\lfloor b)+(a \| c)$. A BPA estendida com os três operadores de paralelismo recebe o nome Álgebra de Processos com Paralelismo (PAP - Process Algebra with Parallelism).

A combinação dos operadores entrelaçamento à esquerda e entrelaçamento com comunicação permite que seja totalmente coberto o comportamento do entrelaçamento, uma vez que

$$
s \| t=(s \llbracket t+t\lfloor s)+s \mid t
$$

para todos os termos de processo $s$ e $t$ na PAP. Informalmente, pode-se dizer que $s \| t$ é capaz de executar tanto uma transição inicial de $s$ quanto de $t$, comportamento coberto por $(s \llbracket t+t \llbracket s)$, ou ainda realizar a comunicação entre transições iniciais de $s$ e $t$, o que é satisfeito por $s \mid t$.

\section{Álgebra de Processos Comunicantes}

Há situações em que, dadas duas ações atômicas, é interessante que não possam ser executadas isoladamente, mas apenas de modo a se comunicarem entre si. Por exemplo, sejam enviar $(p)$ e receber $(p)$ duas ações atômicas: a primeira corresponde ao envio de um pacote de dados $p$ e a segunda, ao recebimento do mesmo. Seja transferir $(p)$ a ação resultante da comunicação entre enviar $(p)$ e receber $(p)$, referente à transferência do pacote $p$ por um canal. Nessas condições, é possível notar que não há sentido em executar apenas enviar $(p)$ ou receber $(p)$, a única execução permitida deve ser a comunicação que resulta em transferir $(p)$.

Para casos em que é necessário forçar a comunicação entre ações, estende-se a função de comunicação $\gamma$ com uma constante especial $\delta$ denominada deadlock, que não apresenta qualquer comportamento e portanto não pode ser executada. A extensão $\gamma: A \times A \rightarrow A \cup \delta$ permite expressar que duas ações $a$ e $b$ não se comunicam, por meio da definição $\gamma(a, b)=\delta$.

O operador unário $\partial_{H}$, para um conjunto $H$ qualquer de ações atômicas, foi introduzido com a mesma finalidade do deadlock. Denominado encapsulamento, ele renomeia como $\delta$ todas as ações do conjunto associado, o que inviabiliza a execução das mesmas.

O deadlock e o encapsulamento foram introduzidos em [28]. A extensão da PAP com esses operadores recebe o nome de Álgebra de Processos Comunicantes (ACP - Algebra of Communicating Processes).

\section{Álgebra de Processos Comunicantes com recursão}

Sistemas podem, em diversos casos, apresentar comportamento ilimitado. Por exemplo, seja o processo que infinitamente executa as ações $a$ e $b$ de forma alternada, iniciando por $a$. O grafo 
desse processo, apresentado na Figura 2.4, não pode ser representado como um termo de processo da ACP, uma vez que essa permite apenas a especificação de comportamentos finitos. No entanto, o comportamento desejado pode ser obtido por meio do uso de equações recursivas.

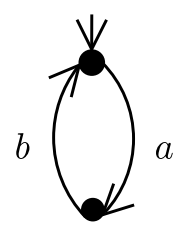

Figura 2.4: Grafo de processo com comportamento infinito.

Uma especificação recursiva é um conjunto finito de equações recursivas

$$
\begin{gathered}
X_{1}=t_{1}\left(X_{1}, \ldots, X_{n}\right) \\
\quad \vdots \\
X_{n}=t_{n}\left(X_{1}, \ldots, X_{n}\right)
\end{gathered}
$$

em que o lado esquerdo $X_{i}$ de cada equação é uma variável de recursão e o lado direito $t_{i}\left(X_{1}, \ldots, X_{n}\right)$ é um termo de processo da ACP, com possíveis ocorrências de variáveis de recursão $X_{1}, \ldots, X_{n}$. Assim, dadas duas variáveis de recursão $X$ e $Y$ representando os estados do grafo de processo na Figura 2.4, o processo em questão tem seu comportamento mapeado por duas equações recursivas:

$$
\begin{aligned}
& X=a \cdot Y \\
& Y=b \cdot X .
\end{aligned}
$$

A ACP com recursão ( $A C P$ with guarded recursion) se trata de uma extensão da ACP com as constantes $\langle X \mid E\rangle$, as quais viabilizam a representação de comportamentos recursivos como o apresentado.

\section{Exemplo de Aplicação}

O processo de Verificação de Usuário da Biblioteca do IME-USP [40] é utilizado a seguir como exemplo para ilustrar como um processo pode ser modelado em termos de álgebra de processos. A álgebra empregada é a ACP.

A verificação de um usuário na biblioteca apresenta uma série de condições segundo as quais o usuário é aprovado ou reprovado. Para que esteja apto a adquirir algum item, ele deve apresentar registro na biblioteca, constar como usuário ativo, possuir cota para a aquisição e não estar em débito. No entanto, se não houver cota suficiente, ocorre uma notificação referente a isso e o usuário ainda é considerado apto se não estiver em débito. Para melhor compreensão, o Algoritmo 2.1 introduz uma representação estruturada desta descrição do processo. 


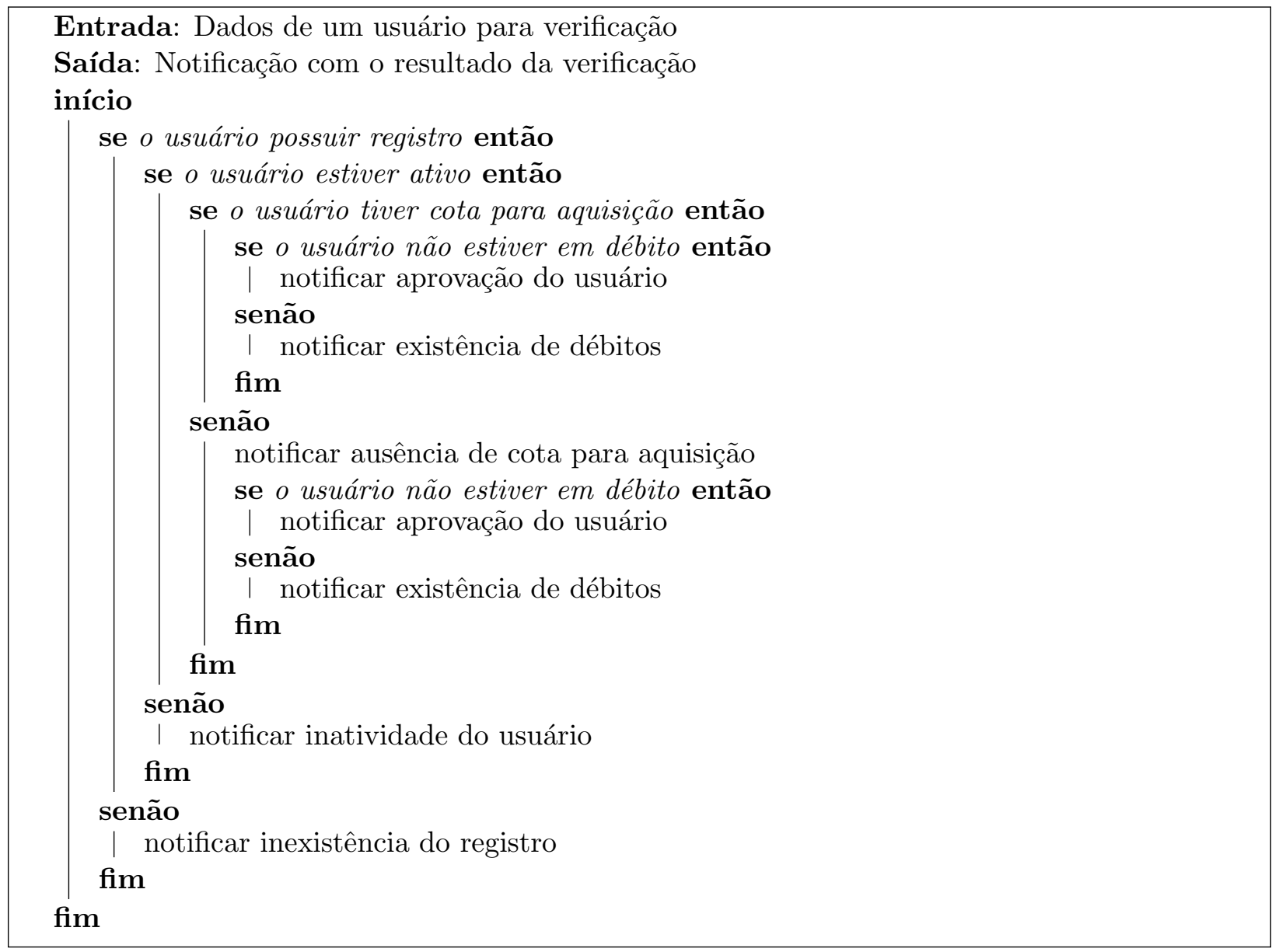

Algoritmo 2.1: Descrição estruturada do processo de verificação de usuário.

A visão simplificada do processo inclui apenas os aspectos relevantes, abstraindo comportamentos específicos como a implementação. No exemplo, pode-se notar que é suficiente representar os resultados como notificações: o processamento ou o armazenamento de dados não são parte da modelagem. O conjunto de ações possíveis no sistema é, então, definido como $A=a_{1}, \ldots, a_{9}$, tal que:

- $a_{1}$ verifica se o usuário possui registro na biblioteca;

- $a_{2}$ verifica se o usuário está ativo;

- $a_{3}$ verifica se o usuário possui cota para aquisição de item;

- $a_{4}$ verifica se o usuário está em dia com suas devoluções;

- $a_{5}$ notifica que o usuário está aprovado;

- $a_{6}$ notifica que o usuário está em débito;

- $a_{7}$ notifica que o usuário não possui cota; 
- $a_{8}$ notifica que o usuário está inativo;

- $a_{9}$ notifica que o usuário não está registrado.

O grafo de processo referente à verificação de usuário é apresentado na Figura 2.5. Os vértices correspondem aos possíveis estados do processo de verificação, já as arestas se referem às ações que o processo pode executar. Vale ressaltar que todos os vértices com mais de uma aresta são pontos de escolha, isto é, estados do processo em que apenas uma ação pode ser executada para que um novo estado seja atingido.

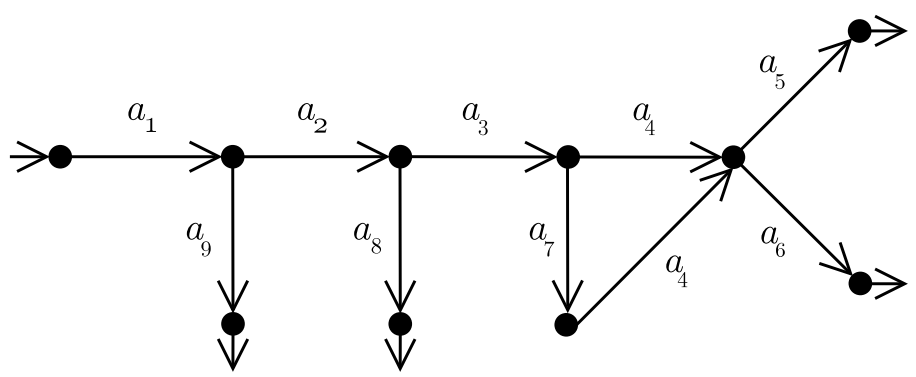

Figura 2.5: Grafo do processo de verificação de usuário.

É possível notar, no grafo do processo, que o trecho do fluxo referente à verificação de débitos pode ser atingido de duas diferentes formas. Embora não seja necessário, é possível representar tal trecho como um subprocesso $\left(P_{1}\right)$, ou seja, um processo utilizado na composição de outro. Assim, obtém-se a seguinte expressão algébrica para o processo de verificação de usuário $(P V)$ :

$$
\begin{aligned}
& P V=a_{1} \cdot\left(a_{9}+a_{2} \cdot\left(a_{8}+a_{3} \cdot\left(P_{1}+a_{7} \cdot P_{1}\right)\right)\right) \\
& P_{1}=a_{4} \cdot\left(a_{5}+a_{6}\right)
\end{aligned}
$$

\subsubsection{Redes de Petri $\times$ Álgebras de Processos}

As redes de Petri e as álgebras de processo apresentam três principais características comuns: a abundância de estudos sobre o assunto, a aplicabilidade na representação de sistemas concorrentes e a forte base matemática [6]. No entanto, são formalismos essencialmente diferentes, uma vez que a descrição das redes se dá por meio de grafos e inclui a representação dos estados do sistema, enquanto a descrição das álgebras é textual com símbolos e expressões, buscando representar o comportamento e as atividades do sistema.

As vantagens específicas de cada formalismo são discutidas em [5], das quais se destacam as seguintes sobre redes de Petri:

- A representação dos estados é explícita durante a execução e as atividades são vistas como transições entre esses estados; 
- A abordagem como grafos bipartidos oferece a possibilidade de se utilizar a teoria dos grafos para a verificação de sistemas;

- Embora apresentem forte embasamento teórico, são intuitivas e facilmente aplicadas na prática.

As álgebras de processos, por sua vez, podem ter ressaltadas as seguintes vantagens, de acordo com o mesmo estudo:

- Os conectivos utilizados aproximam as expressões algébricas e as linguagens de programação existentes, o que facilita a manipulação computacional;

- Leis algébricas, intrínsecas à adoção do formalismo, são aplicáveis na verificação de sistemas;

- São composicionais por definição, o que permite gerar sistemas complexos a partir de outros, menores e mais simples.

A maior limitação, segundo [46], das álgebras de processos em relação às redes de Petri está na modelagem de sistemas com sincronismo entre fluxos distintos de atividades. O trabalho apresenta um exemplo de processo com fluxos paralelos e mostra que, enquanto a PN pode ser facilmente alterada para modelar uma dependência entre os fluxos, a expressão algébrica precisa de sensível adaptação.

Os dois formalismos, porém, apresentam um mesmo pré-requisito que pode vir a se tornar uma limitação: todos os estados e atividades de um sistema devem ser modelados a priori. Isso requer o reconhecimento e a definição de todos os fluxos possíveis para um processo de negócio, o que não se aplica facilmente a sistemas com características reais e tende a gerar modelos extensos e complexos [13]. Outra dificuldade associada à modelagem prévia de um sistema é o impacto causado por qualquer alteração, o que pode resultar na revisão do modelo como um todo.

\subsection{WED-flow}

A abordagem WED-flow (Work/Event/Data-flow [13]) propõe um mecanismo genérico de tratamento de eventos para modelar workflows de modo a possibilitar que ocorra a verificação de propriedades de modelos sem perda de flexibilidade na alteração dos mesmos.

Baseada na adaptação e extensão de algoritmos originalmente desenvolvidos para a modelagem de transações estendidas, a WED-flow utiliza consultas contínuas (continual queries) [24] a bancos de dados relacionais para a captura e o tratamento de eventos. Emprega-se, ainda, o conceito de bancos de dados multiversionados [25], por meio do qual os resultados do processamento de eventos são registrados para a manutenção de um histórico dos dados.

Um importante aspecto dessa abordagem é a presença do fluxo de controle como consequência e não como dependência, diferente da definição a priori presente na modelagem com formalismos 
clássicos. Não é necessária a definição do fluxo de controle como ponto de partida, tal fluxo é gerado por meio da satisfação de condições no decorrer da execução. Esse aspecto é vantajoso inclusive quando são consideradas as linguagens orientadas à programação (como a BPEL), que, apesar de oferecerem alguma flexibilidade a alterações incrementais de sistemas, ainda dependem da especificação sintática dos fluxos de controle. A diferença entre o impacto de alterações na modelagem com formalismos clássicos e com WED-flow é apresentada em [12].

Por outro lado, como a WED-flow ainda não possui uma forma de mapear WED-states para um modelo formal, não há a mesma capacidade de verificação, por exemplo, de uma álgebra de processos ou uma rede de Petri, devido ao forte embasamento teórico que ambas apresentam para a derivação de propriedades.

A orientação a eventos e a separação de exceções e caminho normal, descritas na Seção 2.3.1, fazem com que a WED-flow conduza a uma forma modularizada e incremental de desenvolvimento tal que não seja preciso prever todas as exceções possíveis para que a essência do processo de negócio seja modelável. Ademais, a modelagem de uma nova exceção implica em defini-la à parte e então integrá-la ao modelo já existente. Os fundamentos, o processo de modelagem e o exemplo de implementação apresentados a seguir foram extraídos de [12] e [13].

\subsubsection{Fundamentos}

Eventos, condições, transições e dados são elementos de um processo de negócio vistos com diferentes perspectivas. Consequentemente, a abordagem WED-flow se baseia em três princípios para realizar a integração de tais elementos:

- Deve ser descrito, para cada evento, um determinado conjunto de transições que modificam o estado corrente dos dados;

- Qualquer estado dos dados que seja consultado, modificado ou gerado por uma transição deve ser explicitamente representado e permanentemente armazenado;

- Todas as transições de um estado de dados para outro devem ser disparadas por um evento, de modo a serem executadas apenas quando um determinado conjunto de condições for satisfeito.

Conceitualmente, a definição e a captura de eventos por meio de triggers (monitores) compõem o ponto de partida para a WED-flow. Os eventos iniciam a validação de um conjunto de condições sobre valores de atributos que devem ser satisfeitas para que uma transição seja executada. Tais valores devem ser representados como estados de dados antes e após o tratamento de cada evento. Uma instância de um processo de negócio é, portanto, disparada por um evento, o qual inicia a captura do estado dos dados, a verificação de condições e, quando apropriado, promove-se a transição para um novo estado. 


\section{Definições}

As definições a seguir introduzem conceitos essenciais para o entendimento da abordagem WEDflow. A Figura 2.6 contém a representação de um modelo gerado a partir desses conceitos.

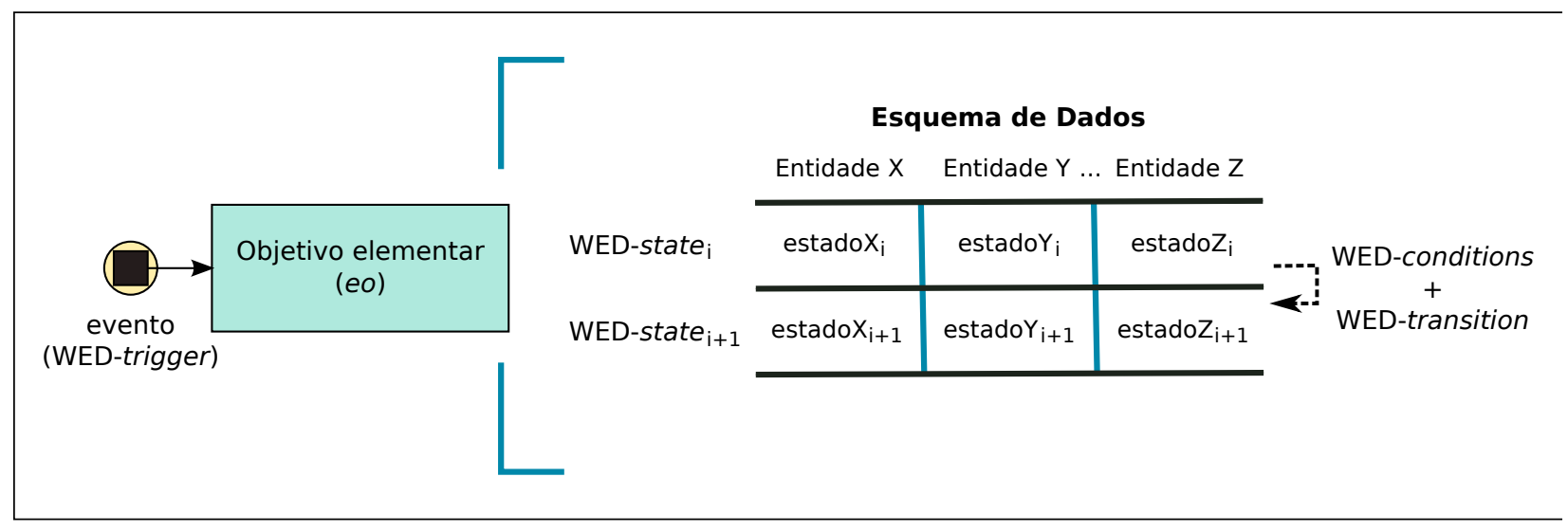

Figura 2.6: Representação genérica de um modelo WED-flow. Fonte: [12]

- Definição 1. WED-state. Um estado WED, denotado por WED-state, é um conjunto de valores de atributos capturados de algumas aplicações;

- Definição 2. WED-condition. Uma condição WED, denotada por WED-condition, é um conjunto de predicados definidos sobre um conjunto específico de WED-states;

- Definição 3. WED-transition. Uma transição WED, denotada por WED-transition, transforma um conjunto de WED-states (entrada) em outro conjunto de WED-states (saída). Essa transformação é realizada por meio de um conjunto de ações atômicas;

- Definição 4. WED-trigger. Um monitor WED, denotado por WED-trigger, inicia uma WED-transition quando uma WED-condition é satisfeita;

- Definição 5. WED-flow. Um fluxo de trabalho, eventos e dados, denotado por WED-flow, é um conjunto de WED-states, WED-conditions, WED-triggers e WED-transitions.

- Definição 6. eo. Um objetivo elementar, denotado por eo (elementary objective), é descrito como uma quádrupla que combina um WED-trigger com os domínios e condições do WEDstate correspondente. A quádrupla assume a seguinte forma:

$$
e o=<D\left(W E D-\text { state }_{i-1}\right), W E D-\text { cond }_{i}, W E D-\text { transition }_{i}, D\left(W E D-\text { state }_{i}\right)>
$$

- Definição 7. history $(W F)$. Um histórico de execução de um WED-flow $W F$ é uma sequência de execuções de eo. Denotado por history $(W F)$, parte do estado inicial WED-state 0 e contém WED-transition $_{1}$, WED-state $1, \ldots$, até WED-transition ${ }_{n}$ e WED-state ${ }_{n}$, estado final de $W F$. 


\section{Caminho Normal e Tratamento de Exceções}

A modelagem de um processo de negócio parte do princípio de que esse deve ser separado em duas partes: o caminho normal e as exceções. Essa separação resulta da observação de que a maioria dos processos de negócio apresenta um objetivo de negócio bem definido e, assim, um caminho ideal que permite atingi-lo por meio de uma sequência de transições de estados.

A abordagem WED-flow define eventos normais como o menor conjunto de eventos necessários para se atingir o principal objetivo de um processo de negócio. O caminho normal é uma sequência, ordenada por tempo, dos eventos normais e dos respectivos estados que, portanto, equivale ao caminho ideal previamente citado. Já as exceções correspondem aos eventos de exceção, isto é, situações secundárias que podem surgir ao longo do caminho normal, sejam casos mais complexos e incomuns ou erros.

Procedimentos devem ser estabelecidos para o tratamento das exceções, de forma que o sistema possa ser restaurado e retorne a um estado consistente. Devido à diversidade de situações que podem ocorrer, o esforço gasto em seu tratamento tende a ser muito maior do que o necessário para o caminho normal. Consequência direta disso é a existência de processos de negócio em que boa parte dos casos excepcionais permanecem indefinidos e, quando ocorrem, é necessária a intervenção humana (por exemplo, em centrais de atendimento).

A WED-flow é capaz de reduzir a complexidade do tratamento de exceções por meio da representação explícita do estado dos dados e das transições entre os estados, com base em condições e eventos.

\subsubsection{Processo de Modelagem e Implementação}

A modelagem e a implementação de um processo de negócio como WED-flow é composta por três fases, discriminadas a seguir. A noção de evento é essencial do início ao fim desse processo trifásico.

\section{Identificação dos Principais Eventos (Fase I)}

Na primeira fase, há a identificação dos principais eventos referentes ao processo de negócio em questão. Os eventos são, então, classificados como normais ou como de exceção, conforme descrito na Seção 2.3.1.

\section{Aplicação dos Conceitos WED-flow (Fase II)}

A segunda fase remete à modelagem propriamente dita, por meio da composição de eventos, dados, condições e transições. Para todo evento, normal ou de exceção, devem ser descritos os respectivos WED-states, WED-conditions e WED-transitions. Essa fase se divide em quatro principais etapas, descritas a seguir. 
Normalização das sequências de estados Os eventos normais envolvem diversas entidades ou classes de dados, cada qual com sua própria sequência de estados. As sequências podem não ser compatíveis entre si devido às durações dos estados que contêm, portanto é necessário um processo de normalização para vincular os estados das diferentes entidades e alinhar as sequências segundo a ordenação temporal.

Representação do caminho normal Cada grupo de estados vinculados produz um diferente WED-state, de modo que todos os WED-states são encadeados em ordem crescente de tempo para compor uma visão do caminho normal baseada no estado dos dados. Todo evento normal tem sua condição de ocorrência e sua transição resultante modeladas respectivamente como WED-condition e WED-transition, bem como é modelado o WED-trigger que associa a transição à condição.

Representação de exceções Cada exceção recebe tratamento similar ao do caminho normal, com três diferenças: (1) devem ser localizados os WED-states do caminho normal a partir dos quais a exceção pode ser disparada; (2) WED-states existentes podem ser incrementados com informações adquiridas junto à exceção, embora isso não afete o caminho normal nem outros fluxos excepcionais; e (3) um novo fluxo pode terminar em um WED-state da exceção, dado que o retorno ao caminho normal só é viável quando o tratamento da exceção conduz a algum estado válido.

Vinculação de elementos Distribuem-se todos os WED-triggers, WED-conditions e WEDtransitions entre o WED-state inicial e os finais. Isso complementa o vínculo temporal entre os WED-states e completa a visão orientada ao estado dos dados, criando um modelo WED-flow.

\section{Especificação (Fase III)}

A última fase do processo é a fase de implementação. Realiza-se a tradução do modelo WED-flow em uma linguagem concreta de especificação: isso se dá em duas etapas, uma visando apenas o caminho normal e outra voltada às exceções. Uma vez traduzido para a linguagem de especificação, o modelo pode enfim ser interpretado e convertido em programas executáveis por meio de ferramentas automatizadas.

\subsubsection{Exemplo de Aplicação}

O processo de negócio de solicitação de livros em uma livraria online é utilizado por [12] para exemplificar a criação de um modelo WED-flow. Identificam-se três entidades distintas (o cliente, a livraria e o pedido), cada qual com sua sequência de estados, bem como os seguintes eventos normais:

1. Solicitação de livros por um cliente;

2. Validação do pedido pela livraria;

3. Pagamento do pedido pelo cliente; 
4. Envio dos livros pela livraria;

5. Recebimento dos livros pelo cliente.

O modelo obtido para o caminho normal desse processo de negócio é ilustrado na Figura 2.7. A representação do processo de modelagem como um todo é omitido neste trabalho, porém pode ser consultada em [12], bem como exemplos referentes à modelagem de exceções.

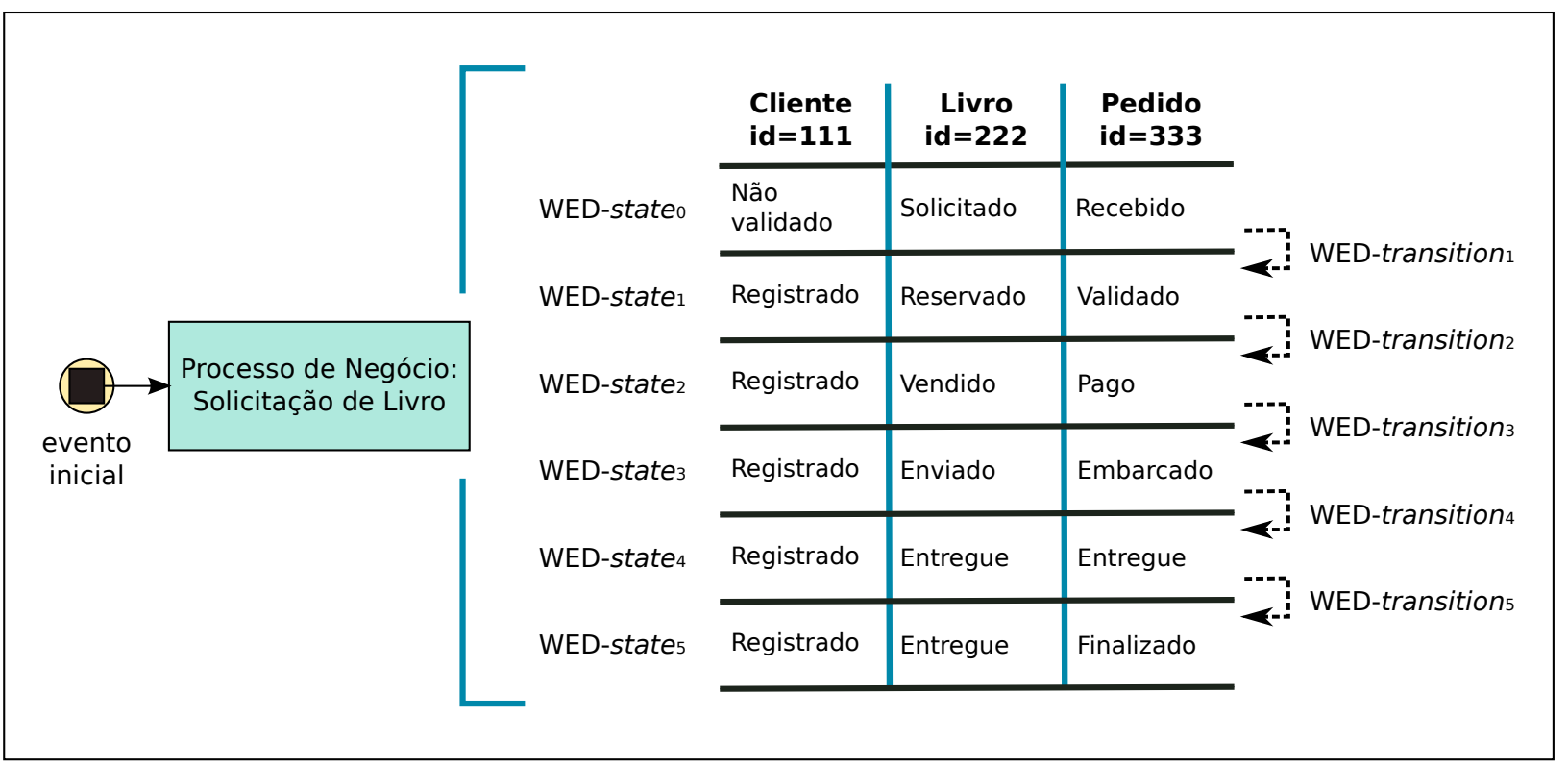

Figura 2.7: WED-states do caminho normal para o exemplo da livraria online. Fonte: [12]

\subsection{Serviços $W e b$}

Um serviço pode ser definido como uma entidade autônoma constituída por um ou mais componentes relacionados cuja função é realizar atividades em prol de um objetivo comum [41]. Esse conceito é essencial para as arquiteturas orientadas a serviços (SOA - Service-Oriented Architectures), paradigma segundo o qual toda funcionalidade se encontra disponível como serviço, em um alto nível de abstração. Em uma SOA, cada serviço é capaz de interagir com outros serviços, apesar de eventuais diferenças de implementação.

Um serviço $\boldsymbol{W} \boldsymbol{e} \boldsymbol{b}$ é um serviço disponível em uma rede, pública ou privada, com o qual é possível interagir de acordo com padrões pré-definidos de comunicação [7]. Já a comunidade World Wide Web Consortium (W3C) define o termo como um sistema de software desenvolvido para permitir a interação entre máquinas via uma rede e o qual pode ser acionado por outros sistemas, por meio de mensagens em um protocolo comum e de acordo com a descrição especificada em sua interface [53].

A World Wide Web (WWW), ou simplesmente Web, opera como um sistema de informações interligadas no qual componentes de software (ou agentes, termo normalmente utilizado na literatura 
W3C) identificam objetos, denominados recursos, por meio dos Identificadores Uniformes de Recursos (URIs - Uniform Resource Identifiers) [52]. Esses componentes utilizam vários formatos de dados, como documentos e imagens, para representar o estado dos recursos. Tais representações, por sua vez, são trocadas via protocolos que empregam URIs no endereçamento direto ou indireto dos componentes e recursos, por exemplo o Hypertext Transfer Protocol (HTTP). Os serviços Web são, assim, componentes desse grande sistema.

Com a proposta, em [14], da arquitetura intitulada Transferência de Estado Representacional (REST - Representation State Transfer), aplicável a sistemas distribuídos de hipermídia, como a WWW, surgiu uma nova especificação possível para a construção de serviços Web. Os serviços, então, passaram a ser classificados como serviços Web REST ou serviços Web SOAP, de acordo com a adesão aos princípios de REST.

As Seções 2.4.1 e 2.4.2 apresentam, respectivamente, os principais conceitos associados aos serviços Web SOAP e REST, segundo [52] e [14]. A arquitetura REST é descrita na Seção 2.4.2, também de acordo com [14].

\subsubsection{Serviços Web SOAP}

Essa classe de serviços $W e b$ pode ser considerada a abordagem tradicional, pois precede a proposta de REST e, além de representar todos os serviços criados até então, sua popularidade ainda é grande entre os provedores de serviços, principalmente por toda a estrutura oferecida. Embora exista uma vasta quantidade de tecnologias relacionadas aos serviços Web SOAP, três são avaliadas como fundamentais:

- Extensible Markup Language (XML): mais do que uma linguagem, é um conjunto de regras rigorosas para a elaboração de documentos interpretáveis por máquinas e contribui com um formato de dados textual padronizado, flexível e extensível, importante para a especificação e para o uso dos serviços.

- SOAP: originalmente um acrônimo para Simple Object Access Protocol, trata-se de uma especificação de protocolo que provê uma forma padrão, extensível e composicional para o empacotamento e a troca de informações estruturadas como mensagens em XML. A troca de mensagens via SOAP é viável em diversos protocolos de rede, como o HTTP.

- Web Services Description Language (WSDL): linguagem baseada em XML empregada na descrição de um serviço Web. As operações e respectivas mensagens são descritas de forma abstrata e então associadas a um protocolo concreto de rede e a um formato esperado de mensagem. As definições podem ser mapeadas para qualquer linguagem de programação, plataforma, modelo de objetos ou sistema de mensagens.

Juntas, as três tecnologias mencionadas serviram como pilares para sustentar, durante bastante tempo e até os dias atuais, o mais difundido padrão para troca de mensagens baseadas em XML. 
Ademais, devido à extensibilidade do SOAP, diversos outros padrões foram criados e a ele integrados, por exemplo para a segurança e a atomicidade de transações. O tratamento de erros, em particular, é nativamente oferecido pelo SOAP.

Os serviços Web SOAP são assim intitulados por utilizarem a especificação homônima de protocolo para a troca de mensagens em XML. Cada mensagem possui seus dados armazenados na forma de um elemento denominado envelope SOAP. Após o advento de REST, também passaram a ser conhecidos como arbitrários por disponibilizarem conjuntos arbitrários de operações, isto é, que não se comprometem a seguir os princípios de REST. Cada serviço declara suas operações por meio da WSDL e cabe às aplicações clientes a realização de chamadas com base no que se encontra declarado.

A declaração das operações via WSDL serve como um rígido contrato de comunicação que orienta os interessados em interagir com o serviço. O contrato define os tipos dos parâmetros esperados para cada operação, o tipo esperado para a saída e, assim, estabelece as regras a serem seguidas pelas mensagens XML. Alterações nesse contrato, portanto, só devem ser concretizadas com o consentimento de todos os envolvidos.
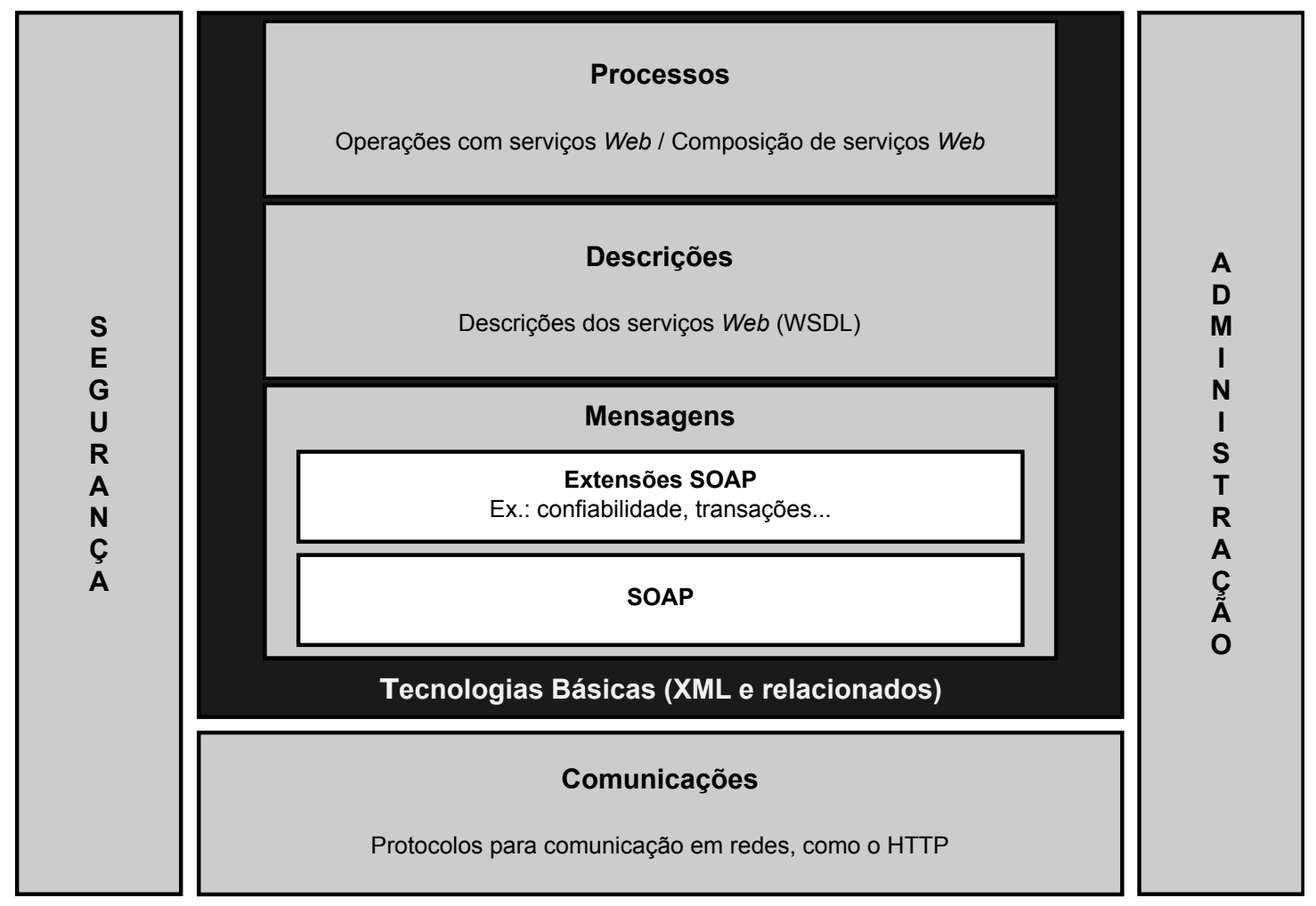

Figura 2.8: Arquitetura de serviços Web SOAP. Fonte: [52]

A Figura 2.8 provê uma representação da arquitetura de serviços Web SOAP construída com a abordagem bottom-up, isto é, primeiro são especificados os elementos básicos, em camadas inferiores, e então determinam-se os elementos de níveis mais altos. 
Nota-se que, independente das camadas formadas por tecnologias que se interoperam, há módulos da arquitetura voltados especificamente a segurança e a administração dos serviços. O módulo de segurança remete a uma série de requisitos e políticas para o uso de serviços Web que visam proteger o tráfego de dados da ação mal intencionada de terceiros. Já o módulo administrativo se refere ao controle e à monitoração do ciclo de vida e da qualidade dos serviços disponíveis.

\subsubsection{Serviços Web REST}

A arquitetura REST para sistemas distribuídos de hipermídia é uma forma híbrida derivada de outras, baseadas em redes, e combinada a restrições adicionais que definem uma interface uniforme de conexão. A Figura 2.9 ilustra a REST como originalmente proposta, arquitetura dotada das seguintes propriedades:

- Cliente-servidor: cada componente denominado servidor oferece um conjunto de serviços e aguarda por requisições, enquanto todo componente cliente, para utilizar um serviço, envia requisições ao servidor correspondente por meio de um conector;

- Sem estado: cada requisição deve conter todas as informações necessárias para ser interpretada, sem depender de qualquer contexto armazenado no servidor;

- Habilitado ao uso de cache: os dados em cada requisição são rotuláveis quanto ao uso ou não de cache, isto é, quanto à possibilidade de os dados de uma resposta serem reaproveitados para requisições equivalentes, de modo a eliminar algumas interações e proporcionar maior eficiência na comunicação;

- Multicamadas: permite que a arquitetura seja composta por camadas hierárquicas, com a restrição comportamental de que um componente não conhece o que existe além da camada com a qual interage diretamente;

- Uniforme: o princípio de generalidade e uma série de restrições definidas fazem com que os componentes exponham interfaces uniformes;

- Código sob demanda: a capacidade de clientes pode ser estendida por meio da transferência e execução de código em forma de applets ou scripts, porém, por reduzir a visibilidade, trata-se de uma propriedade opcional de REST.

O princípio de generalidade é a principal característica de REST, pois a arquitetura é simplificada como um todo e as interações adquirem maior visibilidade. Por outro lado, perde-se em eficiência, uma vez que a padronização do modo como as informações são transferidas deixam de ser adaptáveis de acordo com as necessidades de uma aplicação específica.

A arquitetura REST abstrai elementos arquiteturais, como a implementação de componentes ou a sintaxe de protocolos, de modo que tenham destaque, para cada componente, o seu papel, 


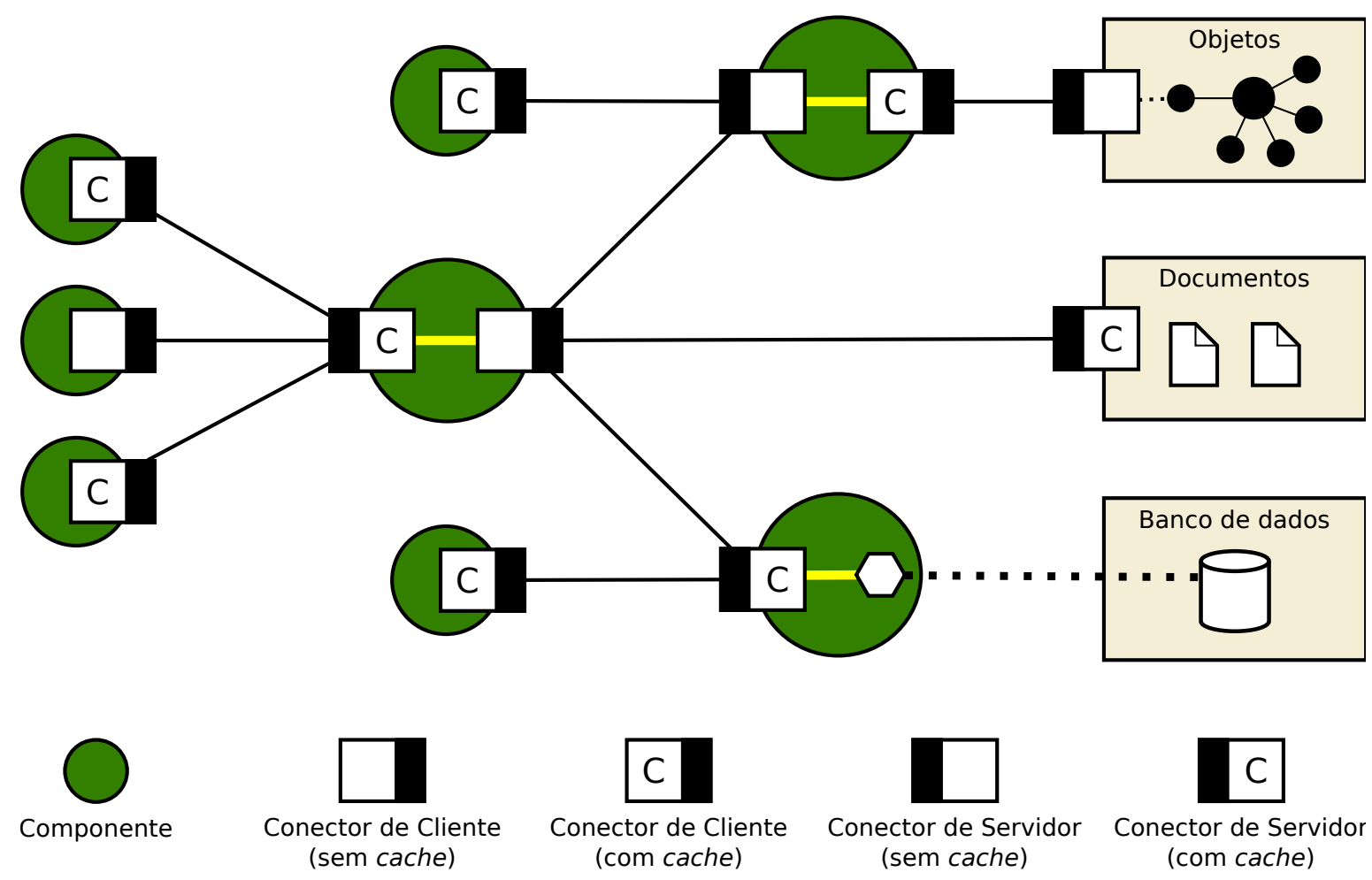

Figura 2.9: Representação da arquitetura REST. Fonte: [14]

suas restrições na interação com outros componentes e sua interpretação dos dados. Os tipos de dados, por sua vez, são compartilhados em associação a metadados, porém com escopo restrito à interface padronizada.

A comunicação entre componentes se dá pela transferência da representação de recursos (informações) em algum formato compatível com os tipos de dados disponíveis. As mensagens, autodescritivas, têm seus tamanhos definidos dinamicamente: enquanto mensagens com semântica de controle geralmente são pequenas ou médias, aquelas voltadas à recuperação de informações tendem a ser bem maiores, devido à devolução de representações completas de recursos.

Serviços Web REST (ou RESTful) são aqueles que seguem os princípios de REST e, portanto, possuem um conjunto uniforme de operações sem estado para manipular a representação de recursos. As operações essenciais se resumem a criação, recuperação, atualização e remoção, enquanto a manipulação de recursos se dá apenas pela troca de representações.

O protocolo adotado para a interação com serviços Web REST é o próprio HTTP, protocolo base para a Web. As operações disponíveis, provenientes do HTTP 1.1, são discriminadas a seguir, associadas a seus principais propósitos:

- GET: recuperação de uma representação;

- POST: criação de uma representação; 
- PUT: atualização de uma representação;

- DELETE: remoção de uma representação.

As quatro operações se aplicam às representações de recursos por meio de suas URIs. Por exemplo, suposto um serviço fictício de gerenciamento de usuários disponível em http://www. exemplo.org/usuarios/, um HTTP POST realizado com uma representação de usuário a tornaria disponível sob uma URI própria, enquanto um HTTP PUT para tal URI permitiria atualizar suas informações. Já um HTTP GET devolveria a representação associada à URI e um HTTP DELETE promoveria a desassociação.

Embora cada operação seja marcada por um papel principal, funções auxiliares podem ser assumidas, como é o exemplo do HTTP PUT. Se essa operação for invocada para atualizar dados de uma URI que ainda não estiver associada a uma representação, um recurso é criado com os dados informados e passa a constar como associado à URI.

Não é necessário o uso de XML nas interações com serviços Web REST. Uma alternativa comumente utilizada é a JavaScript Object Notation (JSON), padrão caracterizado principalmente por sua concisão na representação de informações.

\subsubsection{SOAP $\times$ REST}

Embora os serviços Web SOAP usufruam vantagens das tecnologias que os sustentam, como o rígido contrato imposto via WSDL e a robustez e extensibilidade do SOAP, todos os artefatos associados à existência e ao consumo desses serviços fazem com que normalmente sejam considerados complexos ("pesados"). Por exemplo, as mensagens XML devem estar de acordo com cada regra do SOAP, enquanto a declaração em WSDL precisa ser minuciosamente elaborada e frequentemente é mapeada para alguma linguagem de programação. Isso justifica a grande quantidade de ferramentas desenvolvidas com a finalidade de facilitar ou mesmo automatizar a criação desses artefatos.

A facilidade de criação, a clareza dos resultados e a concisão na declaração e no uso de serviços Web REST fazem com que sejam classificados como simples ("leves"). Reforça essa ideia, inclusive, a possibilidade de se transmitir dados com JSON em vez de XML. Essa classe de serviços, todavia, traz consigo algumas desvantagens. Segundo [44], uma é a falta de padrões para suprir necessidades de serviços mais sofisticados, como segurança e confiabilidade. Outra é a forte associação ao HTTP como protocolo de rede, pois não há camada de abstração como a oferecida pelo SOAP aos serviços $W e b$ arbitrários.

A falta de um contrato rígido, anteriormente lembrada como grande desvantagem dos serviços Web REST, foi tratada com o advento da WSDL 2.0 e com a emergência da Web Application Description Language (WADL). Enquanto a primeira linguagem lida com todos os métodos HTTP, e não apenas GET e POST, como fazia sua antecessora (WSDL 1.1), a segunda é uma linguagem alternativa à WSDL e voltada especificamente a serviços Web REST. 
As vantagens e desvantagens referentes a cada classe de serviços Web constam na tabela a seguir, com base em [44].

\begin{tabular}{|l|l|l|}
\hline Classe de serviços & SOAP & REST \\
\hline \multirow{5}{*}{ Vantagens } & - Maior consolidação; & - Curva menor de aprendizado; \\
& - Padrões auxiliares (ex: segurança); & - Simplicidade de desenvolvimento; \\
& - Apoio de ferramentas; & - Pouca dependência de ferramentas; \\
& - Extensibilidade; & - Concisão; \\
& - Tratamento nativo de falhas; & - Proximidade da filosofia de Web \\
& - Isolamento da camada de transporte & \\
\hline \multirow{2}{*}{ Desvantagens } & - Curva maior de aprendizado; & - Falta de padrões auxiliares; \\
& - Declaração extensa; & - Transporte restrito a HTTP \\
\hline
\end{tabular}

Tabela 2.1: Vantagens e desvantagens na opção por serviços Web SOAP ou REST.

\subsection{Composição de Serviços Web}

O cumprimento de um objetivo de negócio é diretamente associado à execução de passos prédefinidos que compõem o processo de negócio. Representados de forma abstrata durante o processo de modelagem, esses passos podem corresponder a quaisquer atividades, associadas a diferentes tipos de execução. São exemplos válidos de passos:

- A retirada de um livro da estante pelo funcionário de uma biblioteca, em um processo de empréstimo de obras;

- O armazenamento de sequências de código genético por um aplicativo, em um processo de análise de mutações;

- A solicitação de compra de um determinado item que acaba de se esgotar, em um processo de gerenciamento de estoque.

A execução de um passo pode ser automatizada ou depender da intervenção humana, bem como pode se tratar apenas de uma atividade local ou então requerer uma atividade remota por meio de alguma forma de comunicação. Embora haja muitas formas de se definir um passo em um processo de negócio, uma adquiriu considerável relevância tanto em estudos acadêmicos quanto na aplicação prática: a definição como serviço Web.

Funcionalidades expostas como serviços são de grande interesse devido à reutilização proporcionada e por seu alto poder composicional. Uma vez disponível, um serviço pode vir a ser a solução para um problema comum, de modo a interessados apenas integrarem suas aplicações ao serviço em vez de planejar, investir e desenvolver uma solução equivalente. A funcionalidade, por sua vez, pode ser combinada às oferecidas por outros serviços mediante uma ordenação qualquer. A combinação de serviços $W e b$ visando atingir um objetivo pré-definido se denomina composição. 
A tendência do aumento na disponibilidade de atividades como serviços independentes é um fator importante na implementação de qualquer abordagem de BPM. Não somente é necessário identificar quais serviços devem participar da execução, como deve-se controlar o fluxo de execução de forma correta e eficaz, estabelecendo regras para a comunicação entre todas as partes envolvidas.

\subsubsection{Orquestração e Coreografia}

Existem diversos padrões para a composição de serviços Web com o intuito de representar processos de negócio. Duas são as abordagens possíveis para a classificação desses padrões: a orquestração e a coreografia. Os conceitos utilizados nesta seção são provenientes de [36].

A composição dos serviços $W e b$ em uma orquestração se dá com a presença de um participante mestre intitulado orquestrador, que contém a lógica do processo de negócio e determina a ordem das atuações dos demais participantes. Esses, por sua vez, sequer têm conhecimento de que fazem parte de uma composição. As interações são capazes de relacionar aplicações de diferentes organizações em um modelo de processo transacional, de longa duração e com vários passos. A orquestração possui a BPEL [21] entre seus padrões conhecidos.

A abordagem de coreografia possui um maior fator colaborativo, o que induz cada um dos participantes a descrever seu papel nas interações. Não há uma figura central responsável por toda a lógica, de modo que cada serviço $W e b$ está ciente sobre fazer parte de uma composição e da necessidade de interagir com outros, bem como tem conhecimento da reação que deve apresentar quando acionado. A lógica do processo de negócio corresponde à união das informações conhecidas por cada participante. A Web Services Choreography Interface (WSCI) [51] é um exemplo de padrão dessa abordagem.

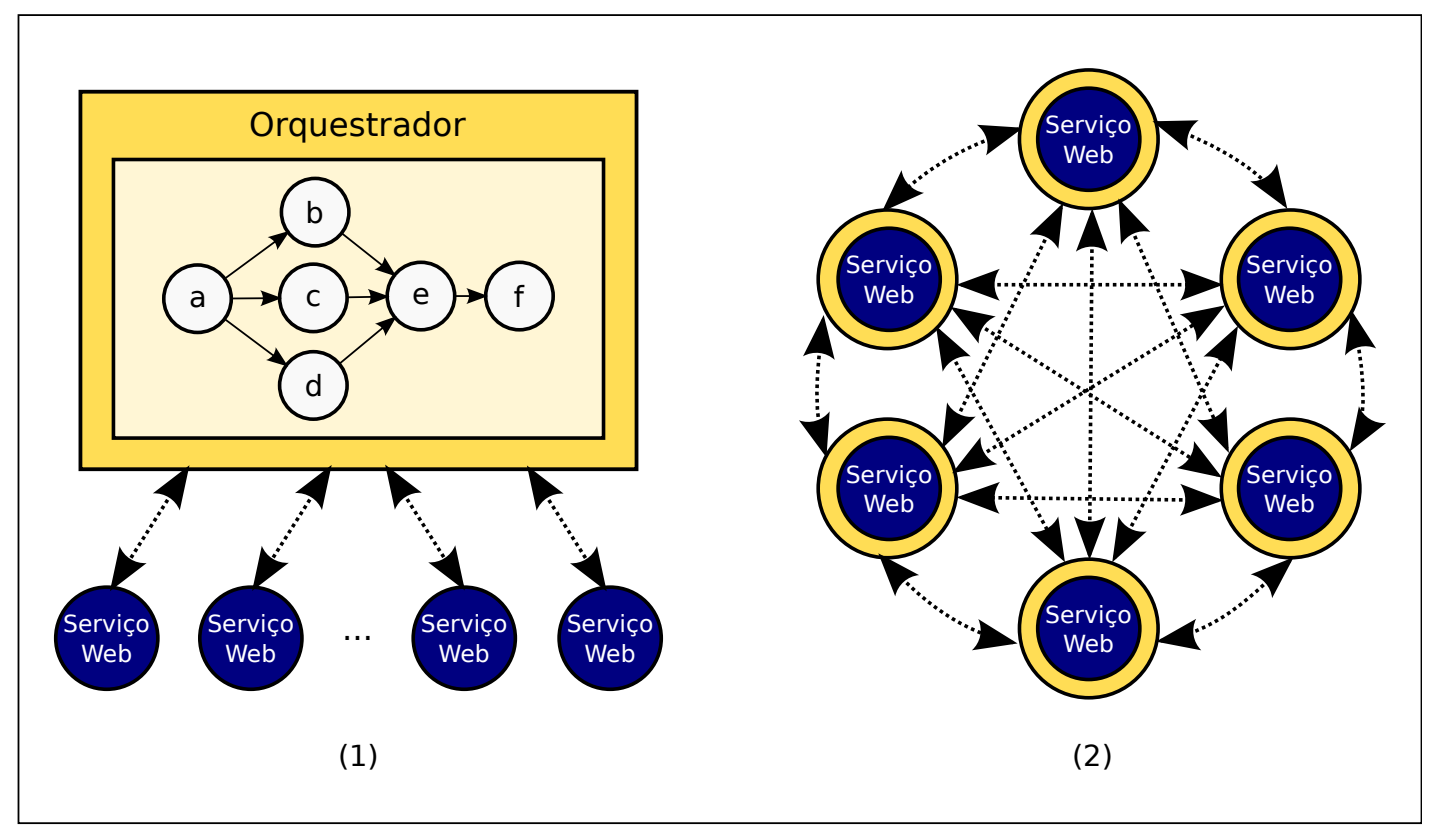

Figura 2.10: Abordagens para composição de serviços Web: orquestração (1) e coreografia (2). 
A Figura 2.10 ilustra as diferenças entre as duas abordagens, da dependência ou não de uma figura central até as possíveis interações envolvendo os participantes.

\subsubsection{Requisitos para Composições de Serviços Web}

Os padrões de composição de serviços $W e b$ estão sujeitos a requisitos técnicos desde a linguagem de descrição do processo de negócio até a infraestrutura para viabilizar sua execução. Aspectos essenciais são a comunicação assíncrona, necessária para a confiabilidade e a escalabilidade dos ambientes, e a capacidade de realizar chamadas concorrentes, útil para otimizações de performance. Ademais, é preciso um mecanismo capaz de relacionar devidamente as requisições assíncronas.

A arquitetura para execução do processo deve, ainda, oferecer tratamento de erros e integridade transacional. O tempo de espera pela resposta de um serviço $W e b$ pode ser longo, o que inviabiliza transações tradicionais do tipo ACID (Atomicidade, Consistência, Isolamento e Durabilidade), pois não há como reservar os recursos até o fim da execução. Uma alternativa é o uso de transações com compensação, nas quais cada operação apresenta uma forma de anular seu próprio efeito em caso de erro.

A orquestração de serviços Web, em particular, deve ser dinâmica, flexível e adaptável a novas decisões de negócios. Incentiva-se uma nítida separação entre lógica de processo e serviços Web, o que promove a flexibilidade. Por fim, deve ser possível criar serviços Web de alto nível a partir de processos orquestrados, visando outras composições por orquestração ou mesmo coreografia, conforme apresentado na Figura 2.11.

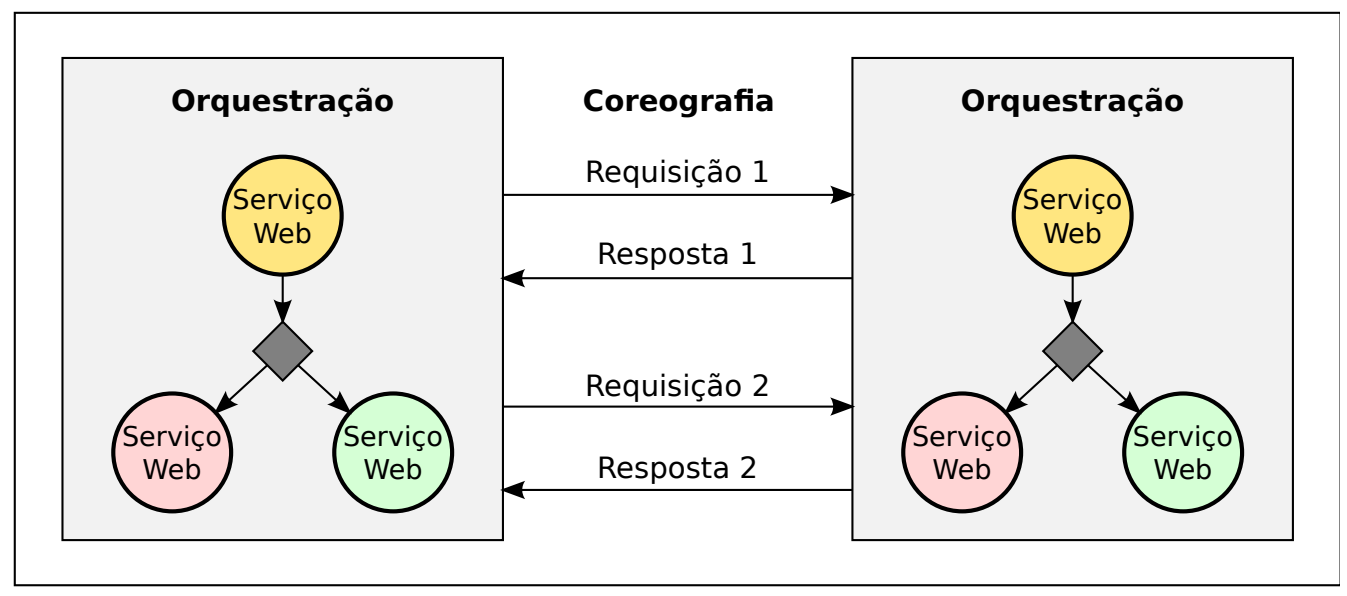

Figura 2.11: Composição recursiva de serviços Web. Fonte: [36] 


\section{Capítulo 3}

\section{Proposição e Avaliação de Cenários}

Este capítulo apresenta a primeira contribuição desta dissertação. São propostos e avaliados diferentes cenários de comunicação com Serviços Web referentes a coreografia e orquestração, de forma a prover meios de verificar o comportamento da solução apresentada para composição de serviços $W e b$.

A avaliação dos cenários se concentra na quantidade de chamadas a serviços Web necessárias para que todos os estados de uma execução de processo de negócio sejam reconhecidos. Isso se dá mediante a determinados critérios, suposições e definições, bem como uma terminologia proposta para atribuir nomes aos cenários. Avaliam-se ainda aspectos técnicos dos cenários, de modo a definir suas propriedades e requisitos.

Cada cenário avaliado resulta na obtenção de uma expressão matemática que permite estimar seu respectivo número de chamadas, de modo que tais expressões possam, por fim, ser confrontadas dentro de configurações pré-definidas.

\subsection{Conceitos para Avaliação}

Todos os cenários de comunicação propostos neste trabalho são avaliados segundo dois critérios. O primeiro critério é o volume de comunicação, isto é, a quantidade de chamadas a serviços $W e b$ necessárias para que todos os estados de uma execução de processo de negócio sejam reconhecidos. Já o segundo representa aspectos técnicos da implementação do cenário. O processo de avaliação dos cenários ainda está sujeito às seguintes suposições:

- Cada serviço Web desempenha somente uma atividade: casos em que um mesmo serviço desempenharia mais de uma atividade devem ser tratados com a separação das atividades em serviços distintos;

- Cada chamada representa a interação com um serviço Web, independente da compatibilidade com os princípios REST;

- Toda interação entre os participantes é instantânea, o que implica em uma chamada a serviço $W e b$ ser recebida no mesmo momento em que é enviada; 
- Não há qualquer interferência externa, portanto não devem ser tratadas questões de segurança na comunicação entre os envolvidos;

- A perda de chamadas e a ocorrência de instabilidades na rede não são consideradas na avaliação do volume de comunicação, somente na descrição de aspectos técnicos.

É preciso ainda declarar as seguintes definições para uso nas expressões matemáticas referentes ao volume de comunicação de cada cenário, bem como na posterior comparação entre cenários.

- $C$ : conjunto formado por todos os serviços Web disponíveis na composição;

- $E$ : conjunto com passos executados, isto é, registros das execuções dos serviços $W e b$ ocorridas ao longo da execução de uma instância do processo de negócio (por exemplo, se um mesmo serviço foi acionado duas vezes, dois registros devem constar nesse conjunto);

- T: tempo total gasto na execução de uma instância do processo de negócio, do início do primeiro passo até o término do último;

- exe $_{i}$ : tempo da execução de uma atividade pelo respectivo serviço, associado a um registro de execução $i \in E$;

- $s u c_{i}$ : número de sucessores diretos após a execução de $i \in E$, tal que $0 \leq s u c_{i} \leq|C|-1$, dado que um serviço nunca se autonotifica e que o último a atuar em uma composição não possui sucessores;

- int $_{i}$ : intervalo de tempo entre duas consultas subsequentes realizadas pelo serviço $i$, tal que $i \in C$, caso o conceito seja aplicável ao cenário;

- $a t r_{i j}$ : possível atraso na consulta de um serviço $W e b i \in C$ sobre o estado da execução de um passo $j \in E$, o que ocorre quando tal consulta sucede um intervalo de espera durante o qual $j$ teve início, de forma que $0 \leq a t r_{i j}<i n t_{i}$ (quando o conceito for aplicável).

Os conjuntos $C$ e $E$ são supostos não-vazios, pois não são relevantes para este trabalho os processos de negócio sem passos ou cujos passos nunca são executados. Já os termos relacionados a tempo, quando aplicáveis, assumem apenas valores positivos, sem referência a unidades de tempo.

Por fim, introduz-se a notação proposta para as ilustrações que exemplificam simulações dos cenários. Os elementos gráficos empregados nas ilustrações são descritos na Figura 3.1.

\subsubsection{Processos de Negócio para Simulação}

Para cada cenário proposto, as simulações de comunicação entre os serviços $W e b$ são ilustradas e remetem a subprocessos genéricos que exploram propriedades dos três principais operadores das álgebras de processos. Tais subprocessos podem ser compostos para construir representações 


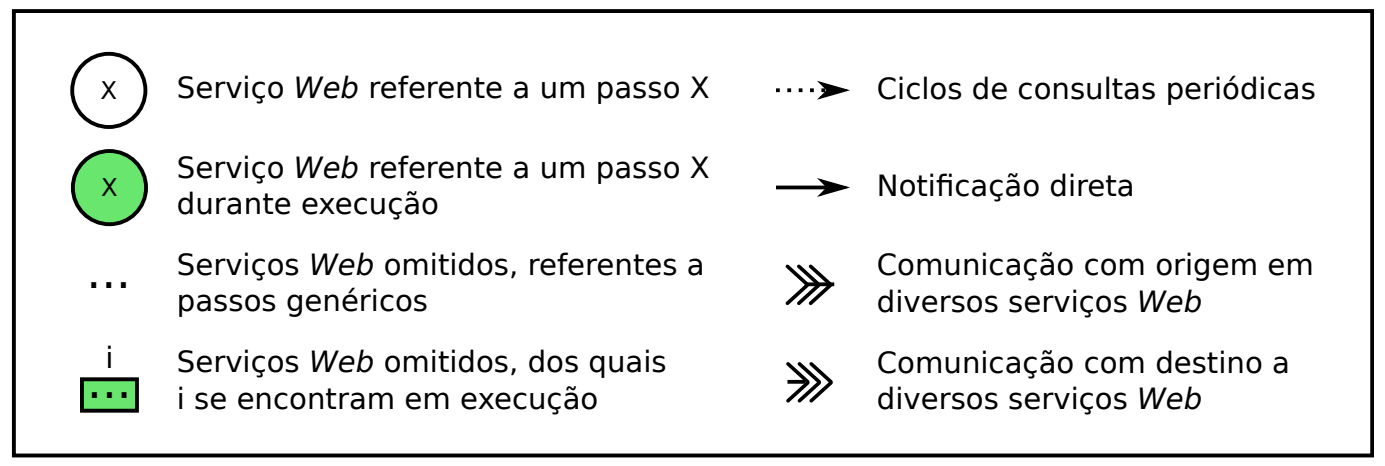

Figura 3.1: Notação gráfica utilizada neste trabalho para simulações de cenários.

mais complexas de outros processos de negócio, cujas simulações completas passam a ser, portanto, composições das simulações apresentadas. Toda simulação de cenário pressupõe que os passos dos subprocessos propostos sejam serviços Web.

Composição sequencial $\mathrm{O}$ subprocesso possui $n>1$ passos, de forma que todos devem ser executados sequencialmente a partir do primeiro. A Figura 3.2 possui a representação desse subprocesso como uma rede de Petri cujos lugares são $L 1, \ldots, L(n+1)$ e transições são $T 1, \ldots, T n$.

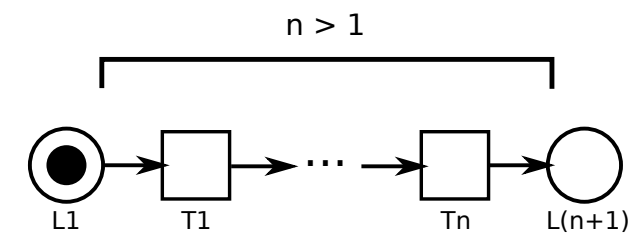

Figura 3.2: Rede de Petri para o subprocesso referente à composição sequencial.

Composição alternativa O subprocesso possui um passo inicial que, quando executado, é sucedido por apenas um dentre $m>1$ candidatos. Qualquer candidato pode vir a ser o sucessor, de acordo com uma condição pré-definida. A Figura 3.3 contém uma rede de Petri possível para esse subprocesso, na qual os lugares são $L I$, Lalt, $L F$ e as transições são $T, T 1, \ldots, T m$.

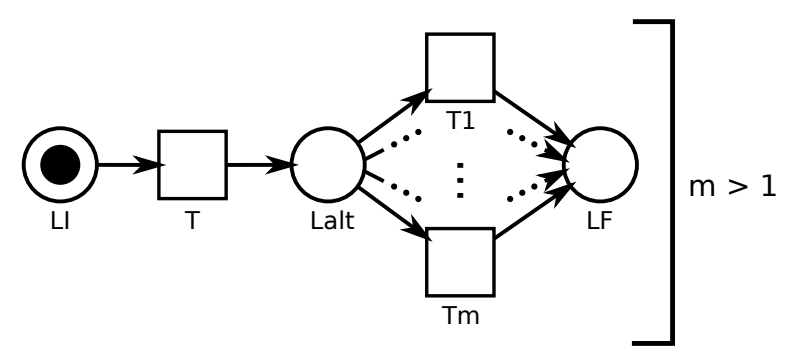

Figura 3.3: Rede de Petri para o subprocesso referente à composição alternativa.

Entrelaçamento O subprocesso para o entrelaçamento é similar ao proposto para a composição alternativa, exceto por todos os $m>1$ candidatos à sucessão se tornarem sucessores, isto é, serem 
executados após o passo inicial. Uma possível representação como rede de Petri é apresentada na Figura 3.4, tal que os lugares são $L I, L 1, \ldots, L m, L F$ e as transições são $T, T 1, \ldots, T m$.

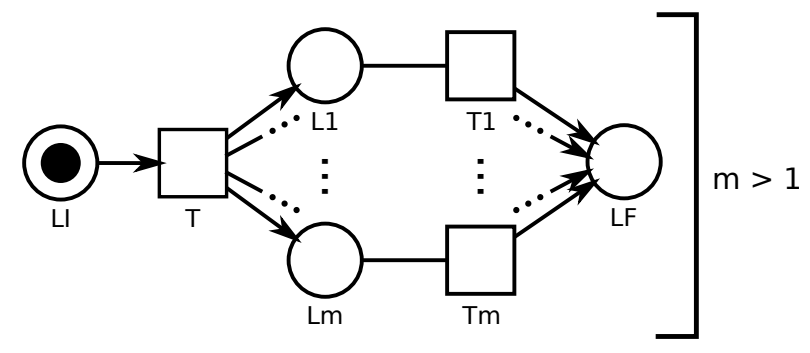

Figura 3.4: Rede de Petri para o subprocesso referente ao entrelaçamento.

O processo a. $((b .(c+d)) \|(e . f))$ é representado na Figura 3.5 para ilustrar como processos de negócio podem ser compostos pelos três subprocessos propostos. Nesse exemplo, apenas uma instância de cada subprocesso foi suficiente para a composição; para processos mais complexos, podem ser utilizadas quantas instâncias forem necessárias.

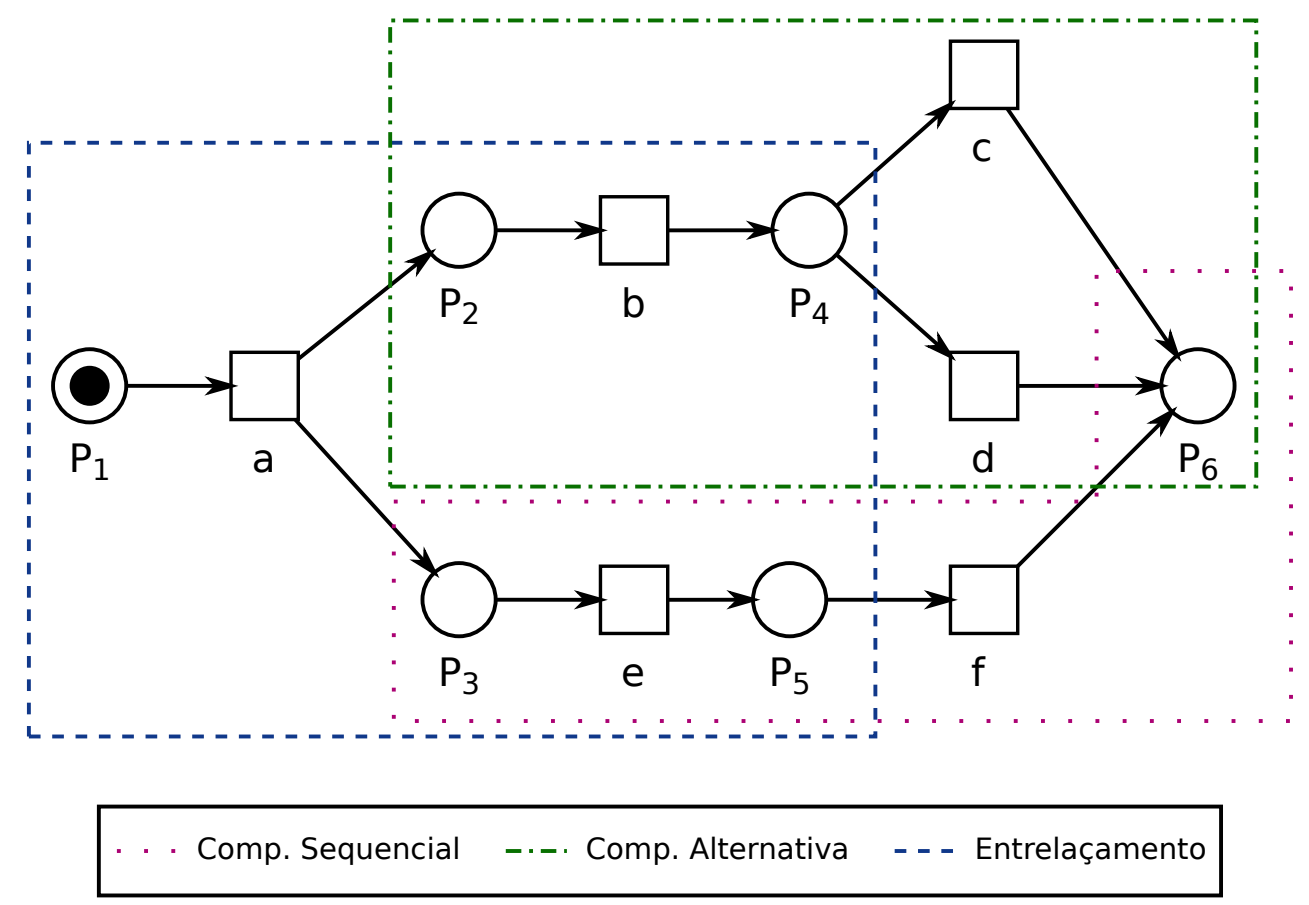

Figura 3.5: Decomposição de processo de negócio em instâncias dos subprocessos propostos.

\subsection{Terminologia}

Os nomes atribuídos aos cenários não são padrões nem seguem qualquer terminologia proposta por outros trabalhos, somente há a intenção de intitular cada cenário de forma a ser facilmente distinguível dos demais. Os nomes são compostos a partir da combinação entre quatro aspectos, descritos a seguir: 
1. Abordagem de composição de serviços Web (Seção 2.5.1):

- Coreografia: lógica de execução distribuída entre os envolvidos, sem uma figura central;

- Orquestração: presença de uma figura central para coordenação, o orquestrador, que detém todo o conhecimento sobre a execução.

2. Tipo de participação dos envolvidos à espera do momento de executar suas atividades:

- Ativa: os participantes consultam o(s) detentor(es) de informações sobre o estado da execução até que identifiquem seus momentos de atuar;

- Passiva: cada participante aguarda até que seja acionado por uma chamada, que corresponde a um aviso de que deve iniciar suas atividades.

3. Tipo de notificação realizada pelo participante que efetua uma alteração de estado durante a execução:

- Notificações globais: todos os demais participantes adquirem informações sobre o novo estado;

- Notificações diretas: apenas os participantes que podem atuar no novo estado, após a alteração, adquirem as informações.

4. Necessidade do envio de notificações de término de atividade por um participante a outro que mantém o estado da execução do processo, para que essa tenha continuidade:

- Sem feedback: aqueles que possuem conhecimento global sobre a execução devem buscar informações sobre o término de atividades junto aos demais participantes para mantê-lo atualizado;

- Com feedback: os participantes devem se encarregar da tarefa de reportar o término de suas atividades aos que conhecem o estado global da execução.

Vale ressaltar que nem todas as combinações entre os aspectos são válidas. O último aspecto, por exemplo, se aplica basicamente a orquestrações, dado que em coreografias não há participantes responsáveis por manter e atualizar uma representação do estado da execução do processo como um todo. Assim, coreografias não podem operar com feedback; por outro lado, em orquestrações, essa é uma importante função associada ao orquestrador.

Já o segundo aspecto restringe o terceiro, pois a participação ativa dos serviços $W e b$ pode ocorrer somente por meio de notificações globais. Isso se deve à necessidade de cada serviço reconhecer o momento em que deve atuar: em uma orquestração, tornam-se necessárias consultas frequentes ao orquestrador, enquanto em coreografias a constante interação se dá entre os próprios participantes. Assim, todos os serviços da composição passam a adquirir alguma informação sobre o estado atual. 
Ademais, orquestrações com participação passiva e notificações globais não são viáveis, pois teriam como princípio o constante envio de mensagens do orquestrador para os participantes, de modo aos últimos avaliarem o conteúdo recebido com o intuito de descobrir se devem ou não realizar atividades. Isso violaria a propriedade da orquestração segundo a qual a composição deve ser imperceptível para os serviços envolvidos (Seção 2.5.1).

Uma última suposição diz respeito a um caso particular da restrição anterior: sempre deve haver feedback na combinação entre orquestração e participação ativa. Uma vez que os serviços $W e b$ cuidam de toda a comunicação com o orquestrador, não há razão para que o último precise buscar informações sobre o término das atividades.

\begin{tabular}{|l|c|c||c|c|}
\cline { 2 - 5 } \multicolumn{1}{c|}{} & \multicolumn{2}{c||}{ Coreografia } & \multicolumn{2}{c|}{ Orquestração } \\
\cline { 2 - 5 } \multicolumn{1}{c|}{} & Ativa & Passiva & Ativa & Passiva \\
\hline Notificações globais sem feedback & $\sqrt{ }$ & $\sqrt{ }$ & $\times$ & $\times$ \\
\hline Notificações globais com feedback & $\times$ & $\times$ & $\sqrt{ }$ & $\times$ \\
\hline Notificações diretas sem feedback & $\times$ & $\sqrt{ }$ & $\times$ & $\sqrt{ }$ \\
\hline Notificações diretas com feedback & $\times$ & $\times$ & $\times$ & $\sqrt{ }$ \\
\hline
\end{tabular}

Tabela 3.1: Combinações entre os quatro aspectos para a nomeação de cenários.

A Tabela 3.1 contém as combinações válidas entre os aspectos propostos. Cada linha da tabela representa uma configuração, portanto são quatro configurações possíveis.

\subsection{Cenários de Comunicação com Serviços Web}

Nesta seção são introduzidos seis cenários de comunicação para a composição de serviços Web. Cada cenário corresponde a uma combinação válida presente na Tabela 3.1, de forma que os três primeiros cenários são de coreografia e os demais, de orquestração.

Todo cenário é primeiramente descrito para então ter seu volume de comunicação avaliado matematicamente. Por fim, avaliam-se os aspectos técnicos de implementação.

\subsubsection{Cenário I: Coreografia Ativa com Notificações Globais}

Neste cenário, cada serviço $W e b$ da composição consulta a situação de outros serviços até que identifique ser o seu momento de atuação. Supõe-se que haja algum serviço $W e b$ reconhecido como o primeiro a participar, de modo que os demais possam iniciar suas consultas a partir dele. Caso contrário, todos os serviços precisariam se comunicar entre si para descobrir essa informação.

Inicialmente e a cada passo concluído na execução de uma instância de processo de negócio, os serviços $W e b$ avaliam o estado atual e verificam se é o momento de realizar uma atividade:

- Se o serviço não tem função a realizar no estado corrente, ele promove consultas periódicas (i.e., ciclos intervalados de consultas) aos que estão responsáveis por alguma operação, até que se atinja um estado do qual possa participar ou a execução termine, seja com sucesso ou 
por falha;

- Se o serviço identifica uma função a realizar, ele inicia a execução da operação esperada e informa o seu andamento aos demais quando consultado. Já as consultas periódicas a outros serviços continuam sendo realizadas, se houver outros serviços atuando paralelamente;

- Ao encerrar com sucesso uma atividade, um serviço deve informar, como resposta às consultas, quais os serviços que o sucederam, para que as próximas consultas sejam direcionadas aos mesmos.

O intervalo de tempo entre duas consultas subsequentes pode ser fixo e comum a todos os serviços $W e b$, bem como cada um pode definir seu próprio valor para a duração. A Figura 3.6 ilustra uma simulação da execução dos subprocessos descritos na Seção 3.1.1. A notação gráfica segue a proposta da Figura 3.1.

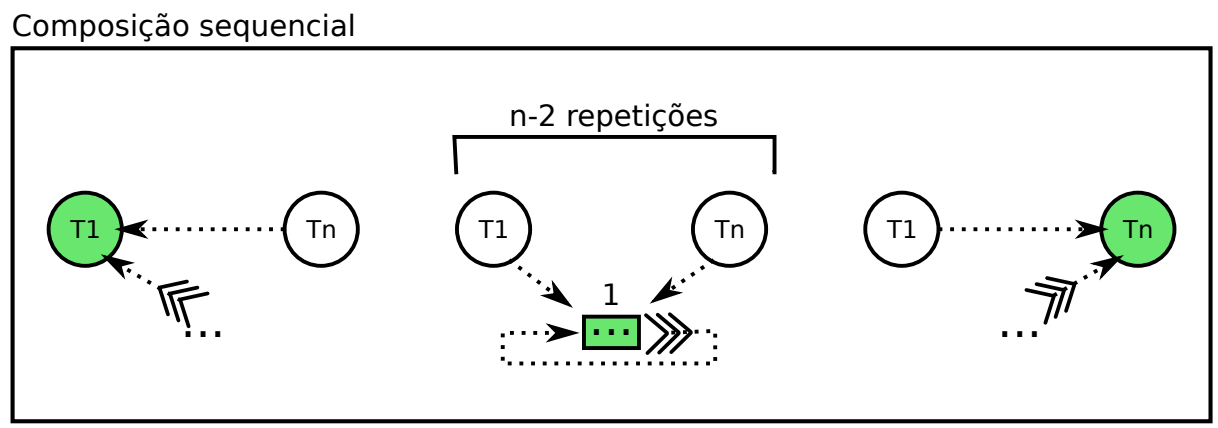

Composição alternativa
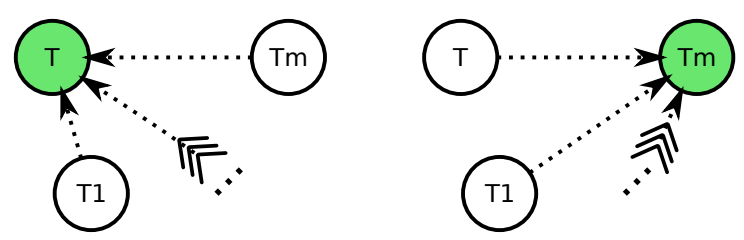

Entrelaçamento

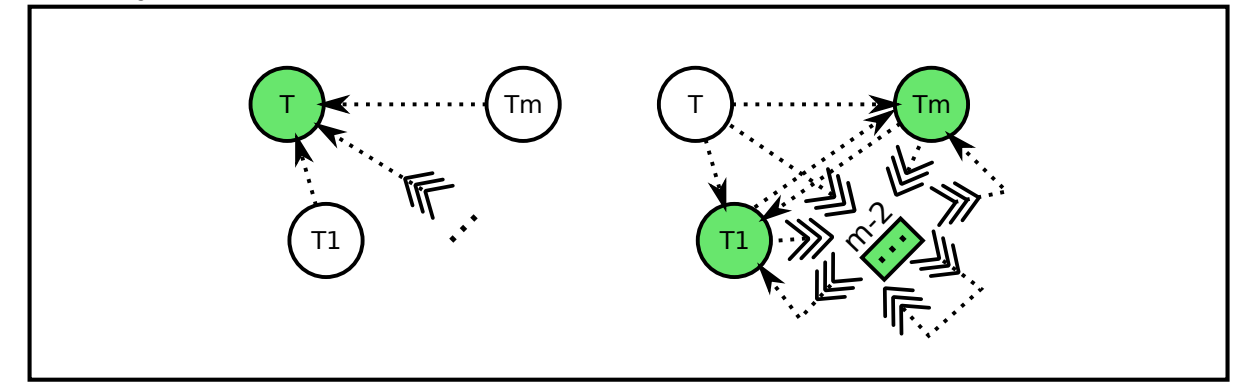

Figura 3.6: Simulação de comunicação segundo o cenário I. 


\section{Volume de Comunicação}

Todos os serviços Web da composição se comportam da mesma maneira ao consultar um serviço responsável por realizar sua atividade em um dado estado da execução: cada um promove a primeira consulta e, enquanto a atividade não termina, entra em um ciclo de consultas periódicas no qual cada iteração é composta por um intervalo de espera seguido de uma nova consulta.

Para cada serviço $j$ executado, o número de consultas que recebe dos demais serviços da composição se traduz em

$$
\sum_{i \in C \backslash\{j\}}\left(1+\left\lceil\frac{e x e_{j}}{i n t_{i}}\right\rceil\right)
$$

Considerados todos os serviços executados, o total de chamadas referente a consultas se dá, então, por

$$
\sum_{j \in E} \sum_{i \in C \backslash\{j\}}\left(1+\left\lceil\frac{e x e_{j}}{i n t_{i}}\right\rceil\right)
$$

O ciclo de consultas periódicas se mantém até que seja identificado o fim da atividade, o que pode ocorrer no momento exato do encerramento, caso esse coincida com a realização de uma consulta, ou em qualquer momento posterior, caso haja o término durante um intervalo e isso seja reconhecido apenas na consulta seguinte. Devem-se considerar, então, os atrasos $a t r_{i j}$ nas consultas, caso a atividade $j$ tenha início durante um intervalo de $i$. Assim, subtraem-se os atrasos dos tempos de execução.

O volume $V_{1}$ de comunicação neste cenário é dado, então, por

$$
\begin{aligned}
V_{1} & =\sum_{j \in E} \sum_{i \in C \backslash\{j\}}\left(1+\left\lceil\frac{e x e_{j}-a t r_{i j}}{i n t_{i}}\right\rceil\right) \\
& =\sum_{j \in E}\left(|C|-1+\sum_{i \in C \backslash\{j\}}\left\lceil\frac{e x e_{j}-a t r_{i j}}{i n t_{i}}\right\rceil\right) \\
& =|E|(|C|-1)+\sum_{j \in E} \sum_{i \in C \backslash\{j\}}\left\lceil\frac{e x e_{j}-a t r_{i j}}{i n t_{i}}\right\rceil
\end{aligned}
$$

\section{Aspectos Técnicos da Implementação}

Dado que os serviços conhecem a composição e têm controle das notificações que os interessam, diversas medidas podem ser aplicadas na otimização das consultas periódicas. Um serviço $W e b$ pode, por exemplo, encurtar seu intervalo de espera com o passar do tempo ou mesmo customizá-lo 
de acordo com o serviço a ser consultado, desde que possua alguma informação sobre o tempo médio de execução dos outros serviços.

O conteúdo de cada chamada correspondente a uma consulta periódica pode ser informalmente definido como:

- identificador da instância de processo: 12345

- identificador do passo em execução: 123

O serviço $W e b$ consultado, por sua vez, responde à chamada com o estado atual da execução. Espera-se que, após o término de uma atividade, constem referências aos serviços que o sucederam.

- estado do passo consultado: em execução / finalizado / falhou

- outros dados relevantes: ... (ex.: serviços que o sucederam)

Outro aspecto interessante diz respeito ao tratamento de instabilidades na rede. Devido ao uso de consultas periódicas, se uma consulta falhar por causa de uma instabilidade momentânea, a seguinte ocorrerá automaticamente e suprirá sua antecessora. Ademais, ainda há a oportunidade de tratar casos como esse para que sejam feitas retentativas independentes do intervalo de espera.

A flexibilidade proporcionada pelas consultas periódicas, entretanto, é contrabalanceada pela indefinição sobre o tratamento de casos de falha ou aborto de execução. Por exemplo, se uma falha de rede persistir e um serviço $W e b$ concluir que deve haver o aborto após inúmeras consultas sem sucesso, os demais não podem ser informados e sincronizados, devido ao tipo de participação.

Por fim, a ativação dos serviços Web é mais um ponto de atenção neste cenário. Uma solução precisa ser adotada para que os serviços tenham ciência do momento em que devem iniciar suas consultas, seja por meio da definição de horário ou pela atribuição de um novo papel ao primeiro serviço a atuar: o de estabelecer comunicação preparatória com os demais. A última alternativa, entretanto, implica no aumento do volume de chamadas se adotada.

\subsubsection{Cenário II: Coreografia Passiva com Notificações Globais}

Analogamente ao cenário I, os serviços $W e b$ conhecem a composição de que fazem parte e são capazes de se comunicar entre si. Porém, neste cenário, os serviços só agem quando notificados por aqueles que de fato realizaram alguma atividade.

Quando a execução do processo tem início, os serviços $W e b$ verificam o estado inicial e aqueles com alguma função disponível começam a atuar, enquanto os demais apenas aguardam. Forma-se, então, um padrão de interações que é mantido até o encerramento da execução: cada serviço $W e b$ realiza sua atividade e notifica a todos quando terminar, com falha ou sucesso.

A Figura 3.7 ilustra uma simulação da execução dos subprocessos descritos na Seção 3.1.1. A notação gráfica segue a proposta da Figura 3.1. 


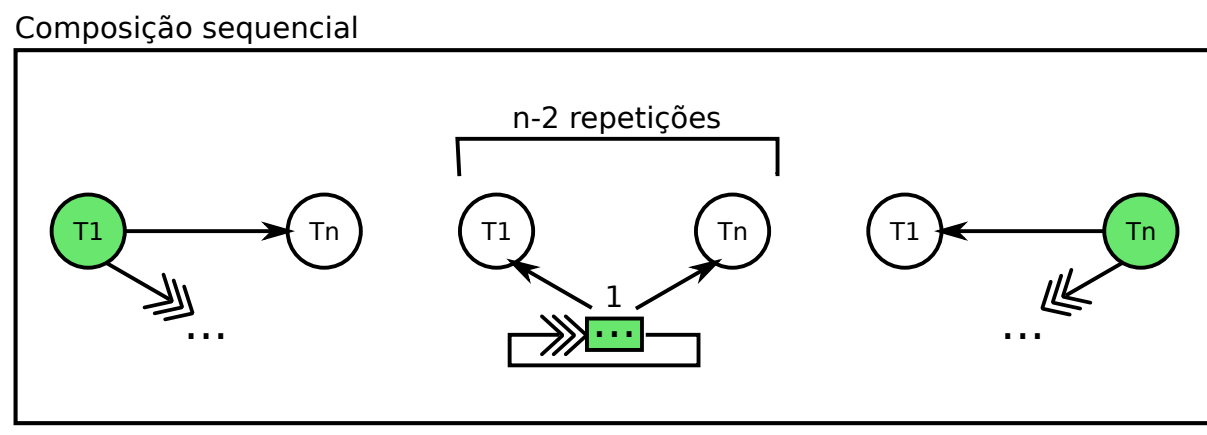

Composição alternativa

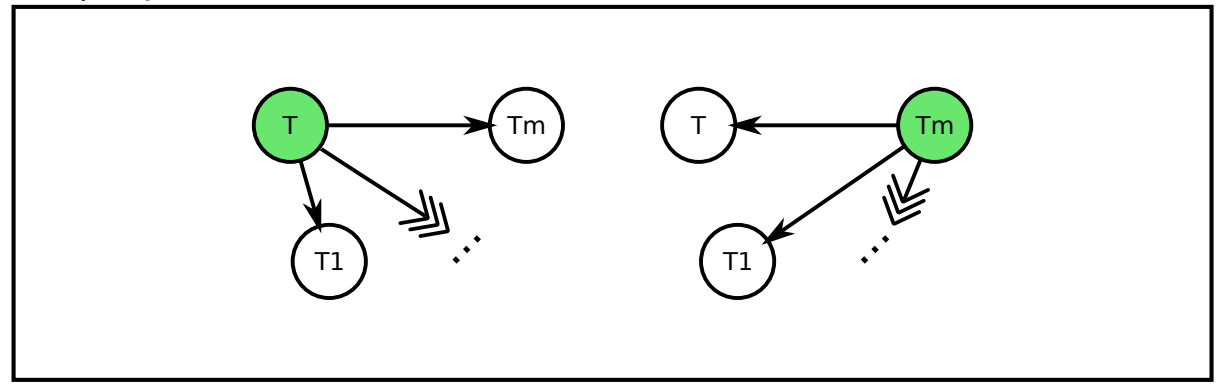

Entrelaçamento
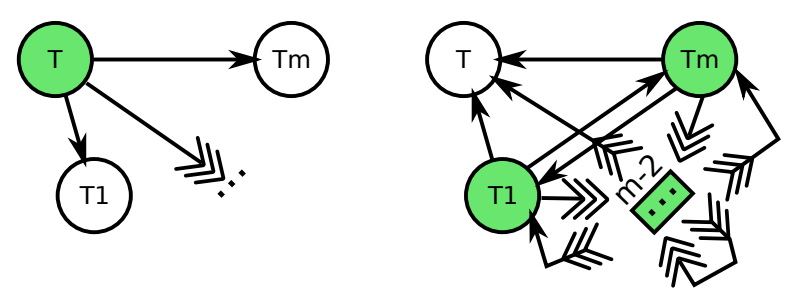

Figura 3.7: Simulação de comunicação segundo o cenário II.

\section{Volume de Comunicação}

A avaliação se concentra nos serviços $W e b$ que participam da execução do processo de negócio. Conforme descrito, um serviço envia, por atividade realizada, uma notificação de término para cada um dos demais serviços da composição, portanto uma atividade resulta no envio de $|C|-1$ mensagens.

As chamadas se repetem a cada passo durante a execução da instância de processo, isto é, $|E|$ vezes. Assim, o volume $V_{2}$ de chamadas realizadas corresponde a

$$
V_{2}=|E|(|C|-1)
$$

\section{Aspectos Técnicos da Implementação}

O conhecimento de informações sobre a composição se mantém como propriedade dos serviços $W e b$, analogamente ao cenário anterior. A ausência de consultas periódicas oferece o benefício de 
não ser preciso tratar atrasos nem promover o cálculo de intervalos de espera, bem como cada serviço está livre de consumir recursos computacionais para manter o ciclo de consultas.

Cada notificação feita por um serviço remete a uma mensagem com o formato informalmente descrito abaixo:

- identificador da instância de processo: 12345

- identificador do passo em execução: 123

- resultado da execução: sucesso / falha

- outros dados relevantes: ...

Por outro lado, com o fim das consultas periódicas, perde-se parcialmente o controle sobre a transmissão de informações e o tratamento de casos excepcionais na comunicação se torna relevante. Por exemplo, todo serviço $W e b$ da composição deve controlar retentativas de chamadas em caso de instabilidade na rede.

\subsubsection{Cenário III: Coreografia Passiva com Notificações Diretas}

Este cenário se assemelha ao anterior na forma como ocorre a comunicação, exceto pelos destinatários das chamadas quando um serviço $W e b$ desempenha o seu papel na composição. No cenário II, cada serviço deve informar a todos os demais sobre o fim de sua atividade. Neste cenário, apenas os reais sucessores na execução são notificados, enquanto os demais seguem à espera de contato.

Um serviço $W e b$, ao iniciar sua atividade, deve ser capaz de avaliar quais são seus possíveis sucessores segundo o conhecimento que possui sobre a composição. Ao terminar de atuar, deve avaliar quais candidatos à sucessão serão notificados, se houver, e então lhes transmitir o estado da execução.

O conteúdo de cada notificação é o que mais diferencia este cenário dos outros propostos para coreografia. Nos cenários I e II, todo serviço Web conhece o resultado de cada serviço já executado, seja de forma ativa ou passiva, o que permite que um serviço atue de acordo com o contexto da execução, se necessário. Neste cenário, um serviço $W e b$ apenas se torna ciente da execução do processo quando é reconhecido por outro como sucessor, então qualquer conhecimento do contexto que se mostre necessário deve ser transferido juntamente às chamadas.

A Figura 3.8 ilustra uma simulação da execução dos subprocessos descritos na Seção 3.1.1. A notação gráfica segue a proposta da Figura 3.1. 


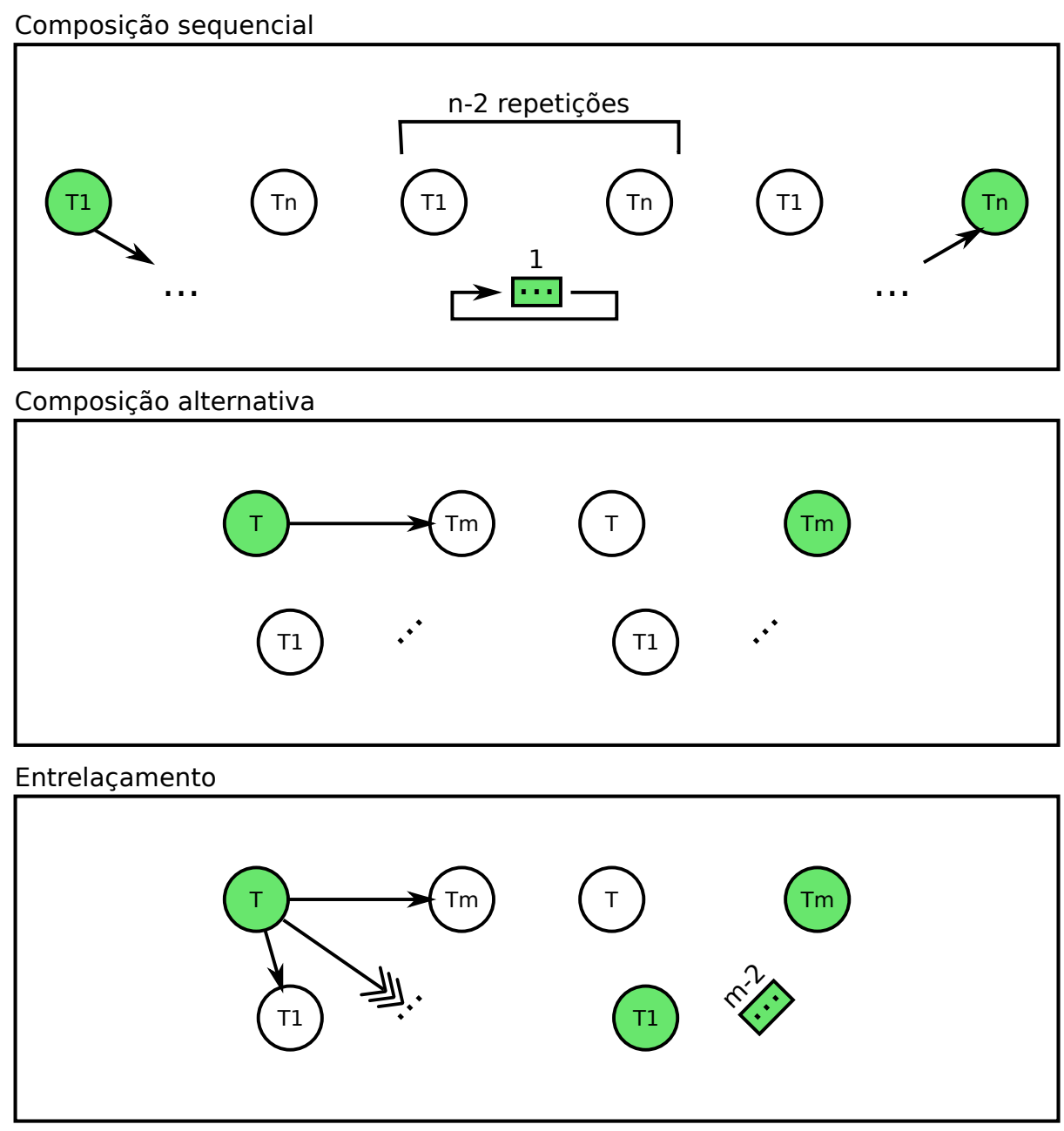

Figura 3.8: Simulação de comunicação segundo o cenário III.

\section{Volume de Comunicação}

Para avaliar o volume $V_{3}$ da troca de mensagens neste cenário, é essencial o uso do termo $s u c_{i}$, para $i \in E$, como definido na Seção 3.1. Todas as chamadas são feitas por serviços executados a seus sucessores, então calcula-se $V_{3}$ como

$$
V_{3}=\sum_{i \in E} s u c_{i}
$$

\section{Aspectos Técnicos da Implementação}

A definição dos aspectos técnicos depende da importância do contexto da execução para a identificação dos sucessores de cada serviço Web que atua na composição.

Se todo serviço da composição for livre de contexto para identificar seus sucessores na execução, isto é, toda notificação recebida implica nos mesmos sucessores, então a implementação é prati- 
camente a mesma descrita para o cenário II. A única diferença está no conhecimento dos serviços Web: em vez de manter referências para todos os outros serviços, basta que consiga se comunicar com seus sucessores.

Contudo, se o contexto da execução influenciar na escolha dos sucessores de um serviço Web, então este deve conhecer no mínimo todos os seus possíveis sucessores e ser capaz de diferenciá-los de acordo com o contexto. Assim, tende a haver maior complexidade lógica na implementação dos serviços. Ademais, o conteúdo das chamadas deve ser incrementado, o que implica em dois requisitos:

1. Deve haver um formato pré-definido das notificações para sustentar o incremento do contexto a cada passo executado no processo de negócio;

2. Todo serviço $W e b$ precisa ser capaz de interpretar corretamente cada contexto recebido, de forma a criar uma representação do estado corrente em alguma estrutura de dados ou mesmo em um banco de dados.

Encontra-se a seguir um exemplo de possível formato de notificação para habilitar a transmissão do conhecimento ao longo da execução: a propagação incremental dos resultados de todas as atividades realizadas até o momento.

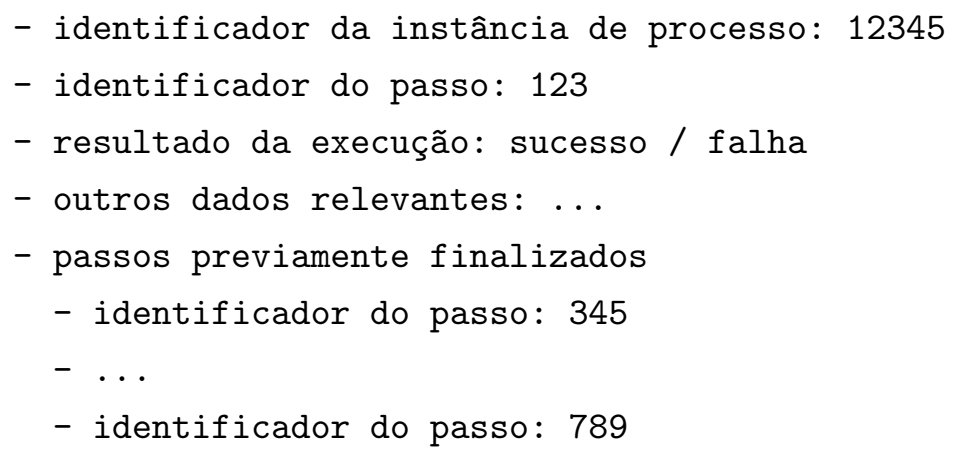

Assim como no cenário anterior, o uso de retentativas também deve ser considerado no envio de notificações, caso ocorram problemas como instabilidade da rede.

\subsubsection{Cenário IV: Orquestração Ativa com Notificações Globais e Feedback}

Segundo as propriedades de orquestração, apenas o orquestrador tem ciência da existência da composição e o conhecimento sobre a lógica da execução do processo de negócio. Assim, em orquestrações há condições propícias para a adoção de alguma abordagem de BPM para o controle da execução pelo orquestrador. Espera-se o seguinte comportamento dos serviços orquestrados:

- O serviço $W e b$ deve consultar periodicamente o orquestrador, questionando se o estado atual da execução demanda que sua respectiva atividade seja realizada; 
- Identificado um estado em que deve atuar, o serviço Web inicia suas operações, mantendo as consultas periódicas, pois nada impede que seu trabalho seja novamente solicitado durante uma atividade (por exemplo, em processos de negócio dotados de paralelismo);

- Terminadas as suas operações, o serviço $W e b$ deve reportar o resultado ao orquestrador, para que esse possa rever o estado da execução.

O intervalo de tempo entre duas consultas subsequentes, assim como no cenário I, pode ser fixo e comum a todos os serviços $W e b$ ou cada um pode definir um valor distinto. O orquestrador, por sua vez, deve exercer três papéis:

- O orquestrador deve notificar todos os serviços Web quando a execução de uma instância do processo de negócio tiver início, para que possam iniciar suas consultas;

- O orquestrador deve informar os serviços Web sobre precisarem atuar ou não, quando consultado pelos mesmos, de acordo com as informações que armazena sobre a execução da instância do processo de negócio;

- Sempre que receber uma notificação de encerramento de atividade, o orquestrador é encarregado de atualizar suas informações e, em caso de alteração no estado da execução, deve modificar o conjunto de serviços Web cujas participações são esperadas (após o término da execução da instância de processo, quaisquer consultas devem receber a informação do encerramento).

A Figura 3.9 ilustra uma simulação da execução dos subprocessos descritos na Seção 3.1.1. A notação gráfica segue a proposta da Figura 3.1.

\section{Volume de Comunicação}

O orquestrador inicialmente informa a todos os serviços $W e b$ sobre o início da execução, para que passem a consultar o estado da mesma. O resultado são $|C|$ notificações iniciais por parte do orquestrador.

Antes de iniciar o ciclo de consultas periódicas, no qual cada iteração é formada por um intervalo de espera e uma nova consulta, cada serviço $W e b$ promove uma consulta inicial ao orquestrador. Contabilizam-se, então, $|C|$ consultas iniciais. Já as consultas periódicas de todos os serviços orquestrados prosseguem de maneira uniforme durante toda a execução da instância do processo de negócio, em um total determinado por

$$
\sum_{i \in C}\left\lceil\frac{T}{i n t_{i}}\right\rceil
$$


Composição sequencial

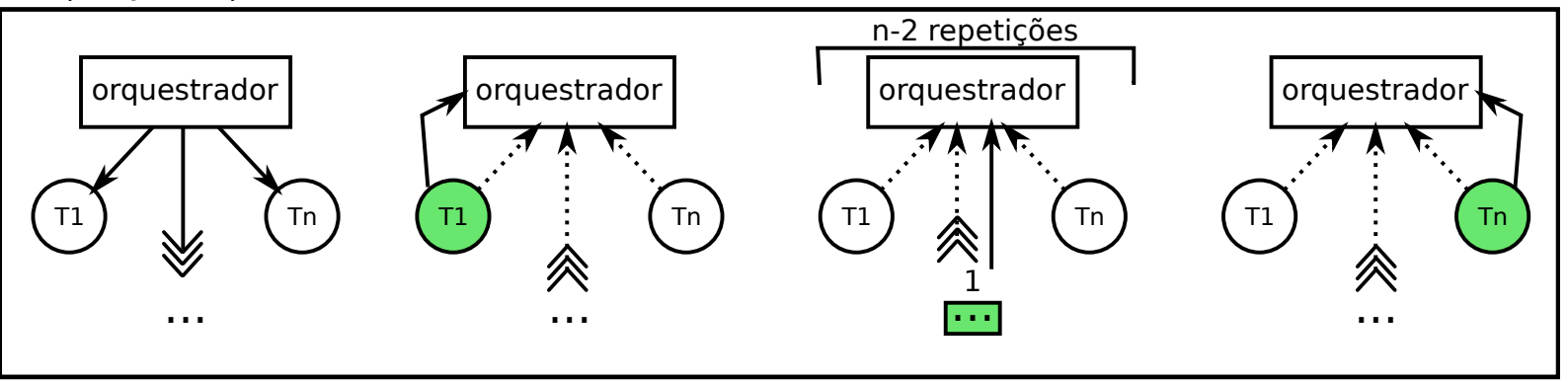

Composição alternativa

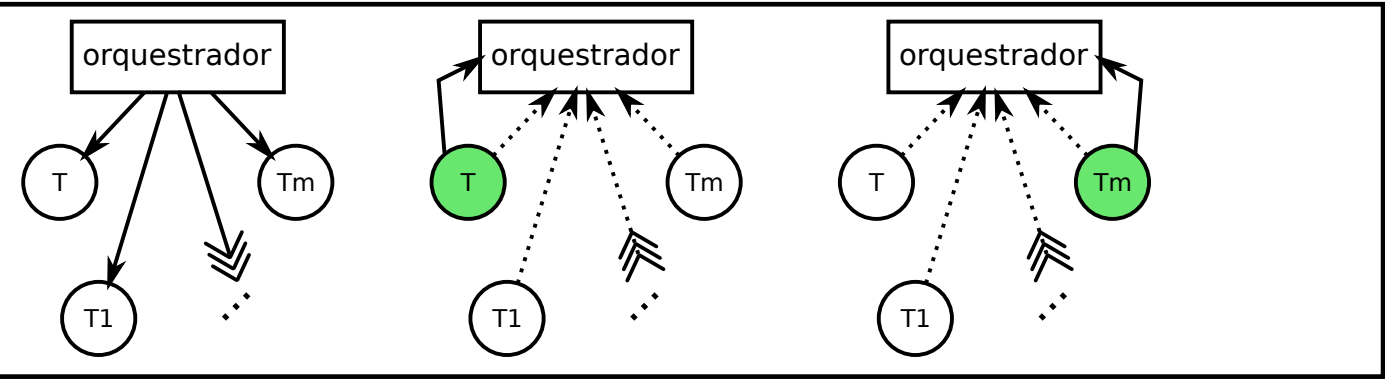

Entrelaçamento
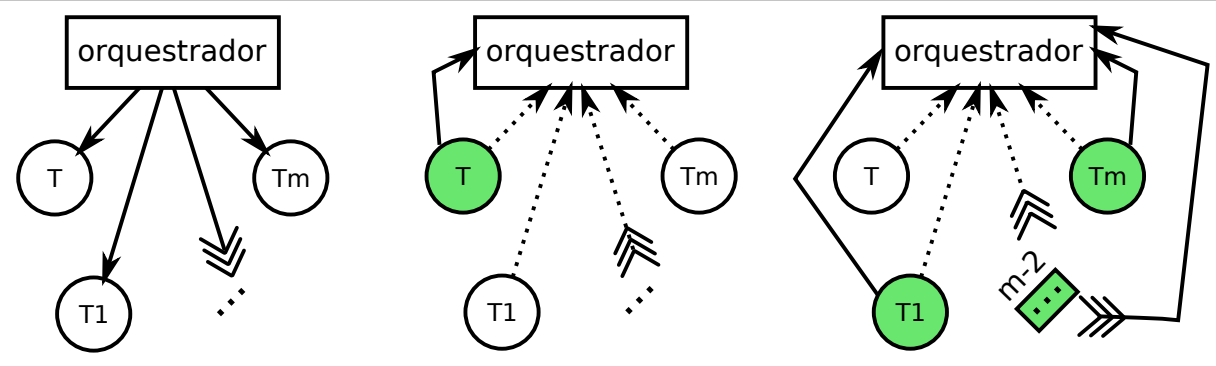

Figura 3.9: Simulação de comunicação segundo o cenário IV.

Por fim, deve-se contabilizar o número de notificações de término de atividade. Trata-se de uma chamada por atividade realizada, portanto um total de $|E|$ notificações. O volume $V_{4}$ de comunicação, por fim, é a soma de todas as expressões descritas:

$$
V_{4}=2|C|+|E|+\sum_{i \in C}\left\lceil\frac{T}{i n t_{i}}\right\rceil
$$

\section{Aspectos Técnicos da Implementação}

Uma interface $W e b$ deve ser disponibilizada pelo orquestrador para as consultas solicitadas pelos serviços da composição. O mesmo deve, ainda, disponibilizar uma forma de ser notificado pelos serviços que encerram suas atividades. A maior parte da complexidade técnica do orquestrador está, entretanto, no controle da execução por meio de alguma abordagem de BPM.

As respostas do orquestrador aos serviços podem se limitar a um valor booleano representando a 
negação quando ainda não puderem atuar; caso contrário, se puderem atuar, devem ser informados com os identificadores do passo e da instância de processo em execução:

- identificador da instância de processo: 12345

- identificador do passo em execução: 123

A complexidade da implementação dos serviços $W e b$, por outro lado, corresponde somente às operações que precisam realizar, às consultas periódicas e ao envio de notificações, dado que o conhecimento do processo de negócio e da composição é restrito ao orquestrador. Cada notificação deve indicar os identificadores previamente recebidos do orquestrador, o resultado das atividades e ainda eventuais dados relevantes para a continuidade da execução:

- identificador da instância de processo: 12345

- identificador do passo em execução: 123

- resultado da execução: sucesso / falha

- outros dados relevantes: ...

A flexibilidade proporcionada pelas consultas periódicas se mantém neste cenário, de forma que cada serviço pode alterar livremente seus intervalos entre consultas em busca de otimização. Como descrito na Seção 3.3.1, a falha de uma consulta pode ser compensada automaticamente por sua sucessora. Porém, as notificações de término não são consultas periódicas e devem ser consideradas retentativas de envio em caso de falhas.

Abortos de execução por falhas ou outras regras, como expiração de tempo, são definidos junto ao orquestrador e nada precisa ser atualizado nos serviços orquestrados.

\subsubsection{Cenário V: Orquestração Passiva com Notificações Diretas e Feedback}

O orquestrador da composição segue a mesma proposição do cenário anterior e expõe uma interface para interagir com os serviços $W e b$. Sua interface, contudo, somente é acionada pelos serviços da composição quando informam o término de atividades, visto que neste cenário participam de forma passiva na aquisição de informações.

Os papéis exercidos pelos serviços $W e b$ orquestrados e também os papéis atribuídos ao orquestrador são descritos a seguir:

- A cada estado da execução do processo de negócio, o orquestrador avalia quais serviços Web devem ser notificados para dar continuidade à execução. São enviadas tantas notificações quanto necessário, de modo que um mesmo serviço deve ser chamado mais de uma vez em caso de repetição de atividades;

- Os serviços Web aguardam alguma notificação do orquestrador: quando isso acontece, cada serviço inicia suas operações e posteriormente informa o resultado ao orquestrador. 

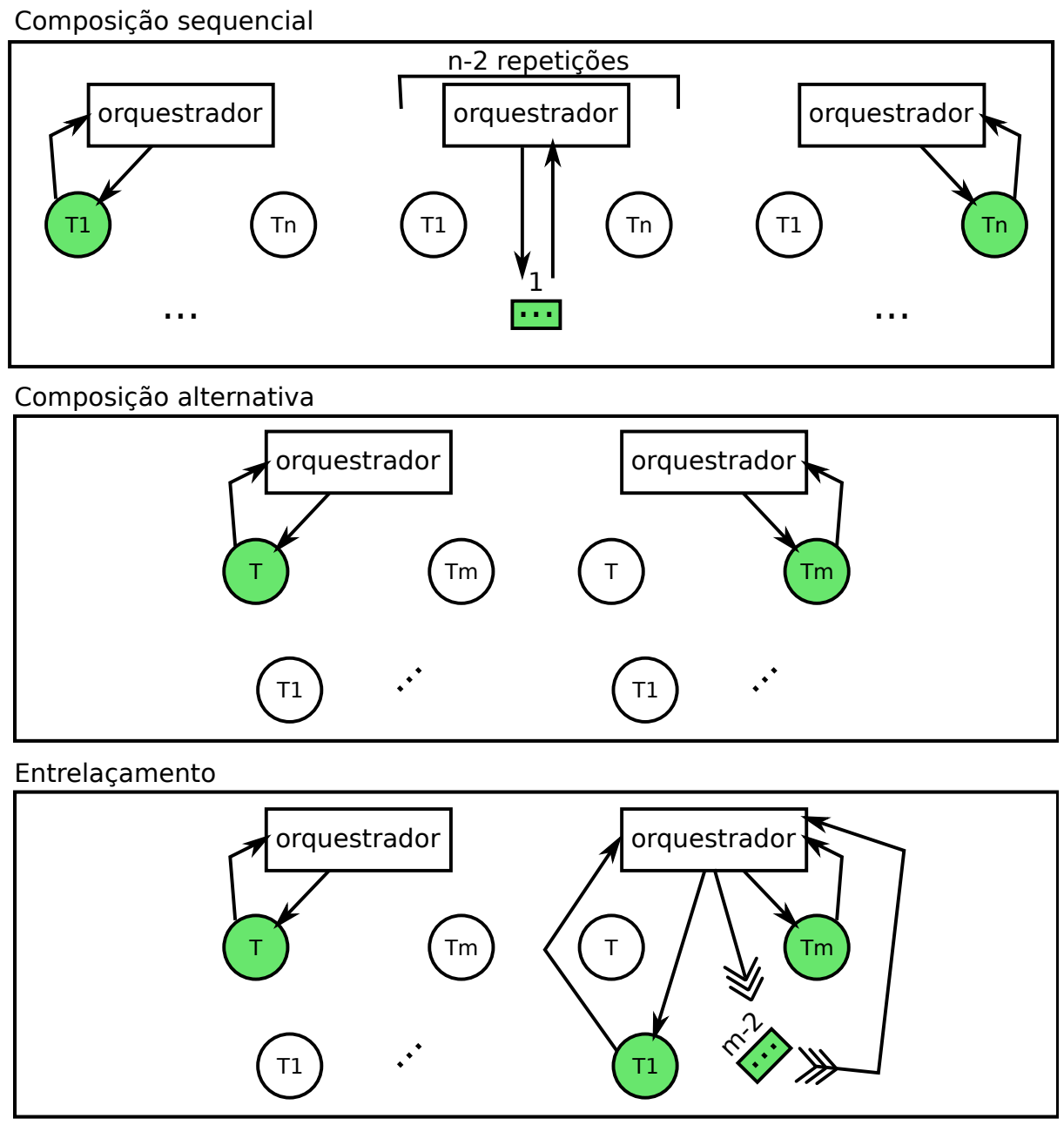

Figura 3.10: Simulação de comunicação segundo o cenário V.

A Figura 3.10 ilustra uma simulação da execução dos subprocessos descritos na Seção 3.1.1. A notação gráfica segue a proposta da Figura 3.1.

\section{Volume de Comunicação}

O orquestrador avalia os participantes que devem ser notificados desde o início da execução, de forma que cada chamada realizada corresponde ao início de uma atividade por um serviço Web. Esse, por sua vez, informa o término da atividade ao orquestrador por meio de outra chamada.

Dado o envio de duas notificações por passo executado na instância de processo de negócio, o volume $V_{5}$ de comunicação corresponde a

$$
V_{5}=2|E|
$$

Vale notar que, se imposta a restrição de que a execução de toda atividade é sempre síncrona, a chamada de término passa a ser desnecessária e tem-se que $V_{5}=|E|$. No entanto, devido à perda 
de generalidade, esse valor não é considerado neste trabalho.

\section{Aspectos Técnicos da Implementação}

O orquestrador possui a função de percorrer a lista de serviços Web a serem acionados e notificálos, um a um. As chamadas são simples mensagens enviadas aos serviços, os quais devem ser implementados de modo a iniciar suas atividades assim que solicitados. Abaixo é sugerido um formato para as notificações enviadas aos serviços para o início de atividades:

- identificador da instância de processo: 12345

- identificador do passo a ser executado: 123

O formato esperado para as notificações de término, por sua vez, é o mesmo abordado na Seção 3.3.4.

- identificador da instância de processo: 12345

- identificador do passo em execução: 123

- resultado da execução: sucesso / falha

- outros dados relevantes: ...

A complexidade da implementação dos serviços Web é menor do que a presente no cenário anterior, pois deixam de realizar consultas periódicas. Porém, isso faz com que o orquestrador precise considerar o uso de retentativas em caso de falhas ao notificar serviços.

\subsubsection{Cenário VI: Orquestração Passiva com Notificações Diretas e sem Feedback}

Uma propriedade diferencia este cenário de seu antecessor: a necessidade do orquestrador coletar informações sobre as atividades em execução em vez de ser notificado sobre o término das mesmas pelos respectivos serviços $W e b$. Ou seja, a cada passo iniciado, ele deve consultar o respectivo serviço $W e b$ periodicamente até identificar o término da atividade, momento em que atualiza os dados sobre a execução.

O ciclo de consultas periódicas do orquestrador não é constante ao longo da execução do processo como um todo: há um ciclo a cada serviço $W e b$ acionado, cujo início se dá junto ao início da atividade em questão e prossegue até que ela termine.

A Figura 3.11 ilustra uma simulação da execução dos subprocessos descritos na Seção 3.1.1. A notação gráfica segue a proposta da Figura 3.1.

\section{Volume de Comunicação}

O volume $V_{6}$ de comunicação corresponde ao volume $V_{5}$ com uma alteração: as $|E|$ mensagens de término enviadas pelos serviços $W e b$ que atuam na composição são substituídas pelo total de consultas periódicas realizadas pelo orquestrador a cada um desses serviços. 


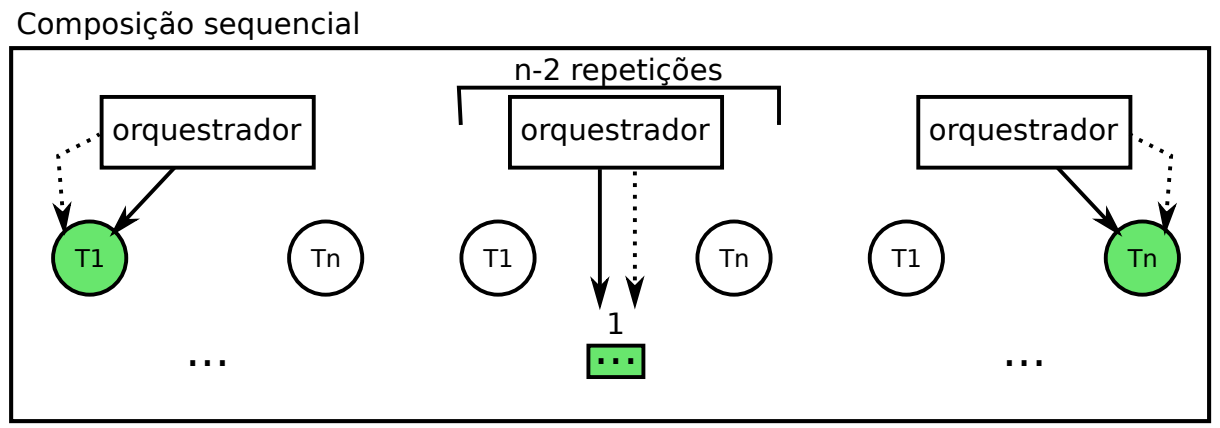

Composição alternativa

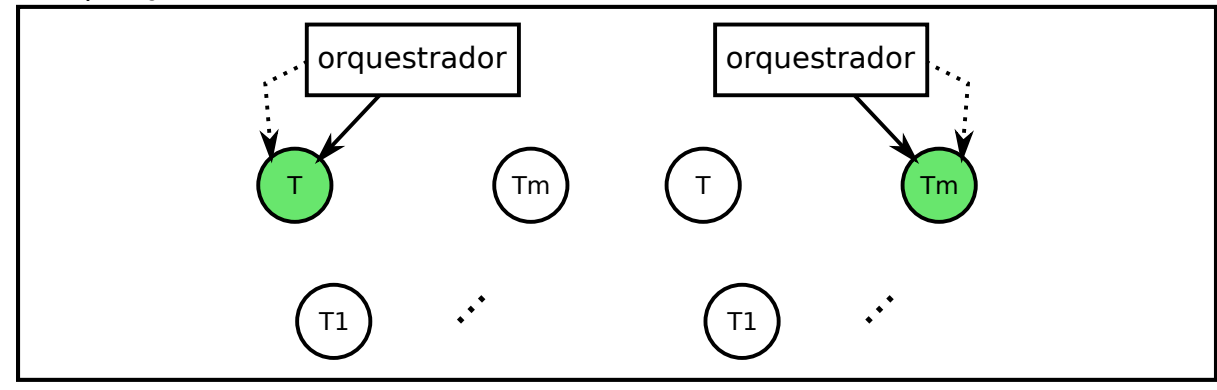

Entrelaçamento

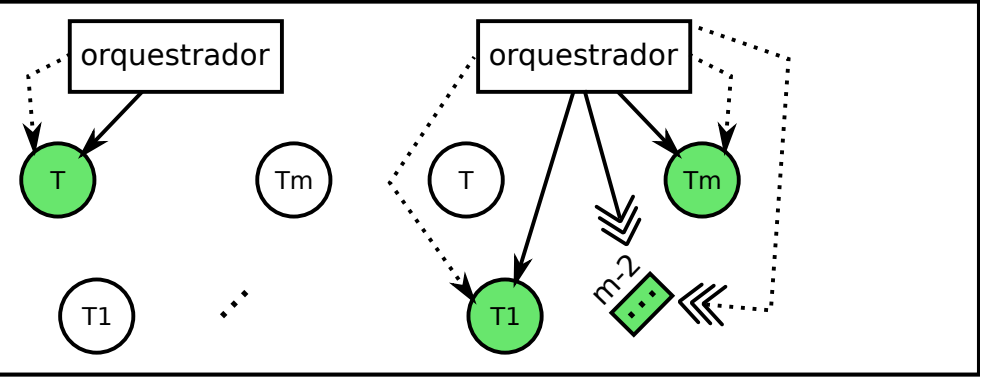

Figura 3.11: Simulação de comunicação segundo o cenário VI.

Dado que cada ciclo de consultas periódicas é composto por uma consulta inicial seguida de uma série de consultas intervaladas,

$$
\begin{aligned}
V_{6} & =|E|+\sum_{i \in E}\left(1+\left\lceil\frac{\text { exe }_{i}}{\text { int }_{\text {orq }}}\right\rceil\right) \\
& =2|E|+\sum_{i \in E}\left\lceil\frac{\text { exe }_{i}}{\text { int }_{\text {orq }}}\right\rceil
\end{aligned}
$$

tal que $i n t_{\text {orq }}$ é o intervalo entre duas consultas subsequentes do orquestrador. Visto que cada ciclo de consultas tem início assim que o orquestrador aciona o serviço Web a ser monitorado, atrasos não são relevantes para a avaliação.

Assim como no cenário $\mathrm{V}$, se imposta a restrição de que a execução de toda atividade é sempre síncrona, tem-se que $V_{6}=|E|$. Porém o valor não é considerado neste trabalho devido à perda de generalidade. 


\section{Aspectos Técnicos da Implementação}

Os aspectos técnicos deste cenário são bastante similares aos do cenário V. O orquestrador, contudo, deve ser implementado de forma a realizar as consultas periódicas em vez de aguardar notificações diretas. Já o envio das notificações pelo orquestrador mantém o conteúdo proposto para o cenário anterior:

- identificador da instância de processo: 12345

- identificador do passo a ser executado: 123

É comum que serviços Web disponibilizem operações de consulta em suas interfaces, o que pode até ser incorporado ao conhecimento do orquestrador. Caso um serviço não apresente operações nativas de consulta, o orquestrador deve supor o uso de uma chamada padrão com conteúdo prédefinido, dotada das mesmas informações da notificação de início de atividades:

- identificador da instância de processo: 12345

- identificador do passo em execução: 123

O mesmo aspecto da interface de consulta deve ser avaliado no que diz respeito aos serviços Web. Caso algum serviço da composição não disponibilize alguma operação desse tipo que possa ser integrada ao orquestrador, sua interface deve ser adaptada para receber as chamadas padrões do mesmo. Nesse caso, eis um possível conteúdo para as respostas às consultas periódicas padrões:

- estado do passo consultado: em execução / finalizado / falhou

- outros dados relevantes: ...

Se o serviço Web estiver associado a alguma forma de armazenamento de dados ou for capaz de avaliar o andamento de suas execuções na ausência de dados armazenados, a criação da interface é suficiente para atender ao cenário. Caso contrário, ainda é necessária a implementação de um meio de recuperar essas informações.

\subsection{Comparativo dos Cenários Propostos}

Dadas as configurações introduzidas na Seção 3.2, nota-se que cada uma proporciona condições distintas para composições. Comparam-se, nesta seção, apenas os cenários propostos que pertencem a uma mesma configuração, com o intuito de identificar os melhor avaliados e aproveitar esses resultados posteriormente neste trabalho, na avaliação de composições de serviços Web com a WED-flow. 


\subsubsection{Configuração com Notificações Globais e sem Feedback}

Os cenários I e II se enquadram nesta configuração, ambos retratando a abordagem de coreografia. Suas respectivas expressões para o cálculo do volume de comunicação são:

$$
\begin{aligned}
& V_{1}=|E|(|C|-1)+\sum_{j \in E} \sum_{i \in C \backslash\{j\}}\left\lceil\frac{e x e_{j}-a t r_{i j}}{\text { int }_{i}}\right\rceil \\
& V_{2}=|E|(|C|-1)
\end{aligned}
$$

\section{Volume de Comunicação}

É intuitivo que o volume de comunicação do cenário I tende a ser maior do que o apresentado pelo cenário II. Para que a afirmação seja válida, basta que ocorra no mínimo uma consulta periódica, isto é,

$$
\sum_{j \in E} \sum_{i \in C \backslash\{j\}}\left\lceil\frac{e x e_{j}-a t r_{i j}}{i n t_{i}}\right\rceil>0
$$

É pouco provável, no cenário I, que um serviço $W e b$ consulte o estado da execução de outro no exato momento do término das atividades. É ainda menos provável que todos os serviços de uma composição apresentem esse comportamento de forma simultânea a cada passo executado, de modo a não haver qualquer consulta periódica. Conclui-se, então, que o cenário II é mais vantajoso do que o cenário I no critério de volume de comunicação.

\section{Aspectos Técnicos}

Por serem cenários relacionados à coreografia, ambos contêm serviços Web dotados de um certo grau de complexidade, por não desempenharem apenas o papel de cumprir ordens recebidas de outros serviços, e sim interpretarem a situação para identificar o que fazer quando invocados.

O uso de consultas periódicas torna o cenário I mais flexível, visto que cada serviço Web pode apresentar uma maneira distinta de calcular os intervalos entre cada consulta, e tolerante a falhas, pois a falha em uma chamada geralmente é compensada por uma de suas sucessoras. Contudo é preciso que todo serviço dedique recursos computacionais às chamadas recorrentes que precisa realizar.

Por outro lado, o cenário II utiliza menos recursos computacionais devido à forma passiva de participação dos serviços, mas esses devem tratar situações atípicas, como falhas de comunicação: se uma chamada falhar, é preciso considerar retentativas de envio. 
Uma possível solução para a desvantagem do cenário II é realizar retentativas periódicas em momentos de falha, até que haja sucesso na chamada. Tal comportamento é análogo às consultas periódicas do cenário I e supre o tratamento de situações atípicas sem sacrificar a vantagem no volume de comunicação, suposta a ocorrência esporádica de falhas.

\subsubsection{Configuração com Notificações Globais e Feedback}

Esta configuração inclui apenas o cenário IV, cujo volume corresponde a $V_{4}=2|C|+|E|+$ $\sum_{i \in C}\left\lceil\frac{T}{\text { int }_{i}}\right\rceil$. Não há, portanto, comparações possíveis nesta configuração.

\subsubsection{Configuração com Notificações Diretas e sem Feedback}

Constituem esta configuração o cenário III, representando a abordagem de coreografia, e o cenário VI, representando a orquestração. Seus volumes de comunicação são descritos, respectivamente, pelas expressões

$$
\begin{aligned}
& V_{3}=\sum_{i \in E} s u c_{i} \\
& V_{6}=2|E|+\sum_{i \in E}\left\lceil\frac{e x e_{i}}{\text { int }_{\text {orq }}}\right\rceil
\end{aligned}
$$

\section{Volume de Comunicação}

Enquanto o cenário III depende dos números de potenciais serviços Web sucessores ao longo da execução, o cenário VI está associado a consultas periódicas. Sejam $k \geq 0$ o número médio de consultas periódicas e $s \geq 0$ o número médio de sucessores por serviço executado, $k, s \in \mathbb{Z}$, tais que

$$
\begin{aligned}
\sum_{i \in E}\left\lceil\frac{\text { exe }_{i}}{\text { int }_{\text {orq }}}\right\rceil & \approx \sum_{i \in E} k=|E| k \\
\sum_{i \in E} s u c_{i} & \approx \sum_{i \in E} s=|E| s
\end{aligned}
$$

Para comparar os volumes de comunicação dos dois cenários, pode-se avaliar qual a condição necessária para que um deles seja tão ou menos custoso que o outro. Seja $V_{3} \leq V_{6}$ tal suposição, então, dados os valores médios previamente descritos,

$$
\begin{gathered}
|E| s \leq 2|E|+|E| k \\
s \leq 2+k
\end{gathered}
$$

Nota-se que a inequação resultante tende a ser válida, uma vez que vale $s \leq 1$ para processos de negócio em que não há paralelismo de atividades, isto é, há no máximo um sucessor por passo. O número médio de consultas periódicas é, então, o que limita o grau de paralelismo permitido para 
que processos de negócio tenham o cenário III como mais favorável.

Mesmo na ausência de consultas periódicas, quando $k=0$, a inequação vale para processos de negócio em que todo passo executado dispara outros dois em paralelo. Esse grau médio de paralelismo já está acima do que se encontra normalmente, pois retrata processos de negócio compostos essencialmente por operações executadas de forma concorrente, sem fluxos sequenciais nem alternativos.

Todavia, conforme descrito na Seção 3.4.1, são improváveis as condições necessárias para que não haja consultas periódicas, então tende a valer que $k>0$ e a vantagem do cenário III se torna ainda mais ampla sobre o cenário VI quanto ao volume de comunicação.

\section{Aspectos Técnicos}

A diferença entre as abordagens de composição de serviços Web impacta diretamente na implementação. Como previamente discriminado na Seção 3.4.1, os serviços $W e b$ tendem a ser mais complexos em coreografias. Já o cenário VI, associado à abordagem de orquestração, transfere a complexidade dos serviços para o orquestrador, uma vez que todo o estado da execução deve ser mantido e controlado de forma centralizada, geralmente por meio da adoção de algum mecanismo de BPM e da definição e manutenção de um modelo para o processo de negócio em questão.

O cenário VI impõe um requisito a todo serviço da composição: a disponibilidade de uma interface para a consulta do estado da execução, necessária para que o orquestrador possa monitorála devidamente. Tal estado deve ser mantido de alguma forma pelos serviços orquestrados. As chamadas realizadas na comunicação, entretanto, são simplificadas.

Caso os serviços Web independam do contexto de execução para atuar conforme a definição do cenário III, as chamadas são simplificadas e os serviços demandam complexidade inferior à requisitada pelo cenário VI, visto que o serviço depende apenas de si para acionar seus sucessores, os quais não variam pois não há condições a serem consideradas.

Contudo, se o contexto for necessário para a continuidade da execução, o cenário III impõe que ocorra a transmissão, a cada mensagem, de todo o estado da execução, o que implica no sucessivo aumento do conteúdo propagado pelas notificações e ainda exige uma maior complexidade dos serviços para que sejam capazes de interpretar as informações. Ademais, a avaliação do contexto passa a influir diretamente na decisão de um serviço sobre seus sucessores. A adoção do cenário III, nesse caso, impõe mais restrições técnicas do que a de seu concorrente.

\subsubsection{Configuração com Notificações Diretas e Feedback}

Apenas um cenário é viável para esta configuração, o cenário $\mathrm{V}$, cujo volume de mensagens se dá por $V_{5}=2|E|$. Assim, não há qualquer comparação a ser realizada nesta configuração. 


\section{Capítulo 4}

\section{Composição de Serviços Web com WED-flow}

Descreve-se, neste capítulo, a segunda contribuição deste trabalho: o módulo de extensão do núcleo WED-flow, bem como aspectos do núcleo relevantes para o seu desenvolvimento. A linguagem Ruby ${ }^{1}$ e o arcabouço Ruby on Rails ${ }^{2}$ foram adotados para a implementação, dado o seu uso na criação do núcleo. Espera-se, portanto, total compatibilidade entre o núcleo, abordado de forma detalhada em [16], e o módulo de extensão.

Detalhes técnicos da implementação não são apresentados nesta dissertação, tais como blocos do código ou bibliotecas. Abordam-se noções gerais, algoritmos e decisões necessárias, de forma que informações técnicas podem ser consultadas junto ao resultado da implementação, no endereço http://www.ime.usp.br/ chui/wedflow.

Um exemplo de estudo também é proposto para retratar como a abordagem WED-flow pode ser utilizada. Os artefatos implementados para simulação e testes do módulo criado são descritos de modo a comprovar a viabilidade prática da solução e se encontram disponíveis no mesmo endereço mencionado.

Por fim, realiza-se a avaliação da WED-flow como abordagem para composição de serviços $W e b$, segundo os mesmos critérios utilizados para avaliar os cenários de orquestração e coreografia. Os resultados da avaliação são, então, confrontados com os obtidos no Capítulo 3.

\subsection{Funcionamento do Núcleo WED-flow}

Como apresentado na Seção 2.3, a execução de um processo de negócio segundo a abordagem WED-flow se dá pelas transições entre WED-states, as quais ocorrem quando o estado dos dados satisfaz suas respectivas WED-conditions. Cada WED-state, portanto, é apto a tornar disponíveis funcionalidades capazes de alterar o estado dos dados e satisfazer alguma WED-condition que conduza a outro WED-state. A combinação de condições a transições ocorre por meio de monitores e a execução de atividades deve se estender até que se atinja um estado final.

Diferentes organizações podem ser relacionadas por um mesmo processo de negócio, de modo a

\footnotetext{
${ }^{1}$ A especificação da linguagem Ruby pode ser encontrada em http://www.ruby-lang.org.

${ }^{2}$ Informações sobre Ruby on Rails estão disponíveis em http://www.rubyonrails.org.
} 
serem compostas funcionalidades de domínios diversos em sua execução. Porém, a única forma de os monitores acionarem funcionalidades é com a concessão de acesso direto ao interior dos domínios, o que frequentemente não é conveniente às organizações.

Vale ressaltar que os dados que pertencem a WED-states originados de sistemas externos ao WED-flow não devem ser atualizados diretamente. Toda alteração realizada em um WED-state deve ser feita junto ao WED-flow e então ser propagada para o respectivo sistema fonte. A Figura 4.1 ilustra essa propriedade e também as interações existentes entre os participantes.

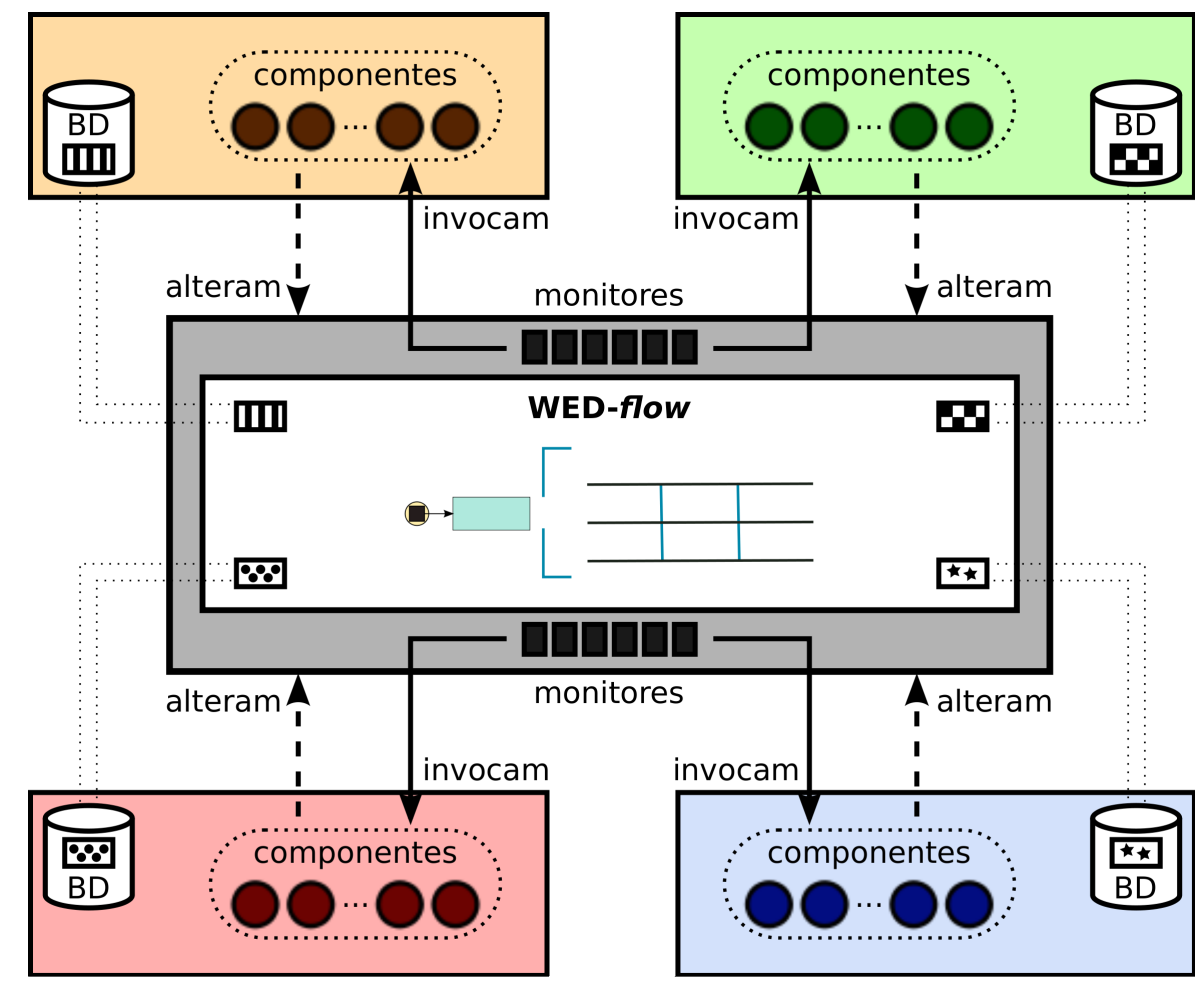

Figura 4.1: Participantes e interações em execução de processo de negócio com WED-flow.

Outro potencial problema para a execução de funcionalidades por monitores está na integração de tecnologias. Mesmo que cada organização conceda o acesso necessário ao seu domínio, os monitores devem ser capazes de interagir com os componentes externos. Surgem, assim, questões sobre como operar com diferentes plataformas e linguagens, bem como a viabilidade prática de serem implementados adaptadores para a comunicação com o sistema de toda organização envolvida.

O uso de serviços $\boldsymbol{W e b}$, conforme apresentado na Seção 2.4, é uma solução para esse problema de integração, pois elimina a necessidade de fortes vínculos com os domínios por meio da adoção de uma interface pública e baseada em padrões estabelecidos. Apenas funcionalidades necessárias são expostas, sem que a organização responsável por um determinado domínio precise liberar o acesso a todas as demais nem tenha que revelar detalhes sobre configurações e soluções técnicas adotadas. 


\subsection{Extensão do Núcleo WED-flow}

Este trabalho propõe e promove a criação de um módulo de extensão para a implementação do núcleo WED-flow, de modo que os monitores possam usufruir a forma de integração proporcionada pelos serviços Web. Isso permite que o tratamento de eventos seja, então, empregado para compor os serviços de forma análoga à que combina funcionalidades sob um mesmo domínio, isto é, por meio da avaliação do estado dos dados.

A essência da WED-flow é mantida na abordagem proposta para composição de serviços Web, bem como seus requisitos. Todo serviço Web deve ser, assim, capaz de acessar e alterar o estado dos dados. Ademais, por se tratar de uma extensão do núcleo WED-flow, mesmo funcionalidades locais restritas aos domínios podem ser combinadas às expostas como serviços Web.

A Figura 4.2 ilustra uma possível distribuição de funcionalidades entre domínios diversos, algumas expostas como serviços Web. Vale notar que, caso uma organização permita acesso ao interior de seu domínio, suas funcionalidades podem ser acessadas tanto diretamente quanto por meio de chamadas $W e b$.

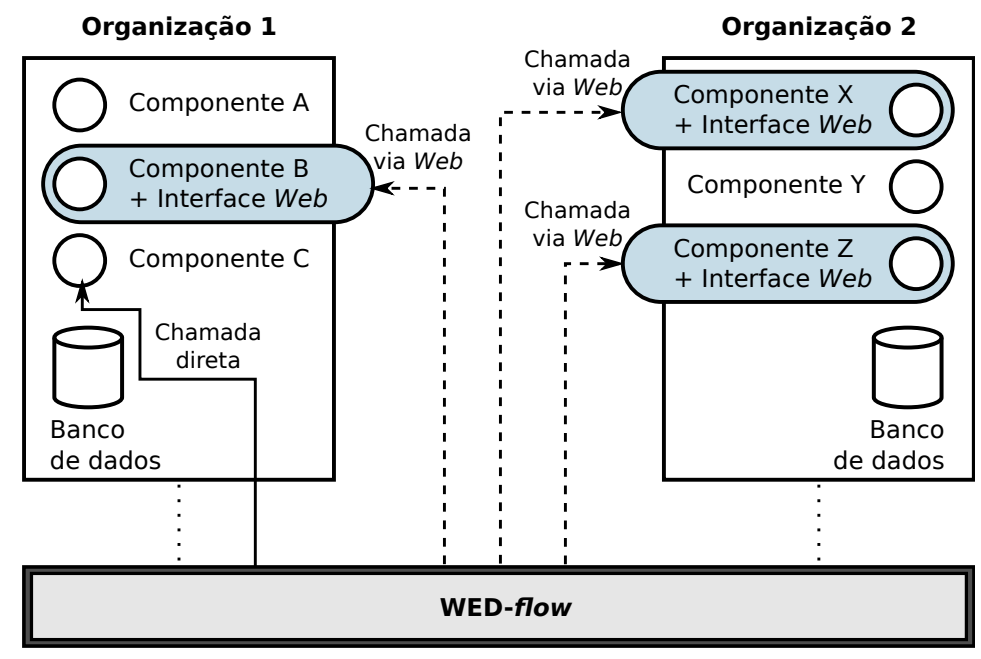

Figura 4.2: Exemplo de distribuição de funcionalidades entre domínios de organizações distintas.

Uma importante propriedade da composição de serviços Web com WED-flow é sua compatibilidade com serviços REST. Como descrito na Seção 2.4.2, tal classe de serviços trabalha com operações que operam com o estado de recursos. Se esses forem interpretados como representações de dados disponíveis para consultas por monitores, então o propósito de REST se aplica exatamente ao que se espera para a abordagem proposta.

Contudo, não é sacrificada a compatibilidade com serviços SOAP. Uma vez que essa classe de serviços permite a existência de conjuntos arbitrários de operações, conforme apresentado na Seção 2.4.1, basta que a interação com dados conste entre as atividades realizadas pelas operações disponíveis para composição. O que se espera dessa interação com dados, porém, depende das propriedades específicas de cada serviço SOAP. 


\subsubsection{Abordagem Proposta $\times$ NPWS}

O Navigation Plan for Web Services (NPWS) [40], um dos trabalhos mencionados na Seção 1.2, está diretamente vinculado a este trabalho. Desenvolvido em 2007, durante iniciação científica, pelo mesmo autor desta dissertação, o NPWS possibilitou a avaliação prática de uma forma de orquestração de componentes dotados ou não de interface $W e b$.

Analogamente à implementação proposta por este trabalho, o NPWS encapsula uma ferramenta de gerenciamento de processos de negócio, denominada NavigationPlanTool ou NPTool, para prover a capacidade de compor serviços Web. Enquanto a ferramenta interage diretamente com os dados da execução, segundo um elaborado modelo de dados, o NPWS disponibiliza seis serviços Web para consultar, definir, gerenciar e executar processos de negócio (o que inclui chamadas a serviços Web cadastrados para composição), como ilustrado na Figura 4.3.

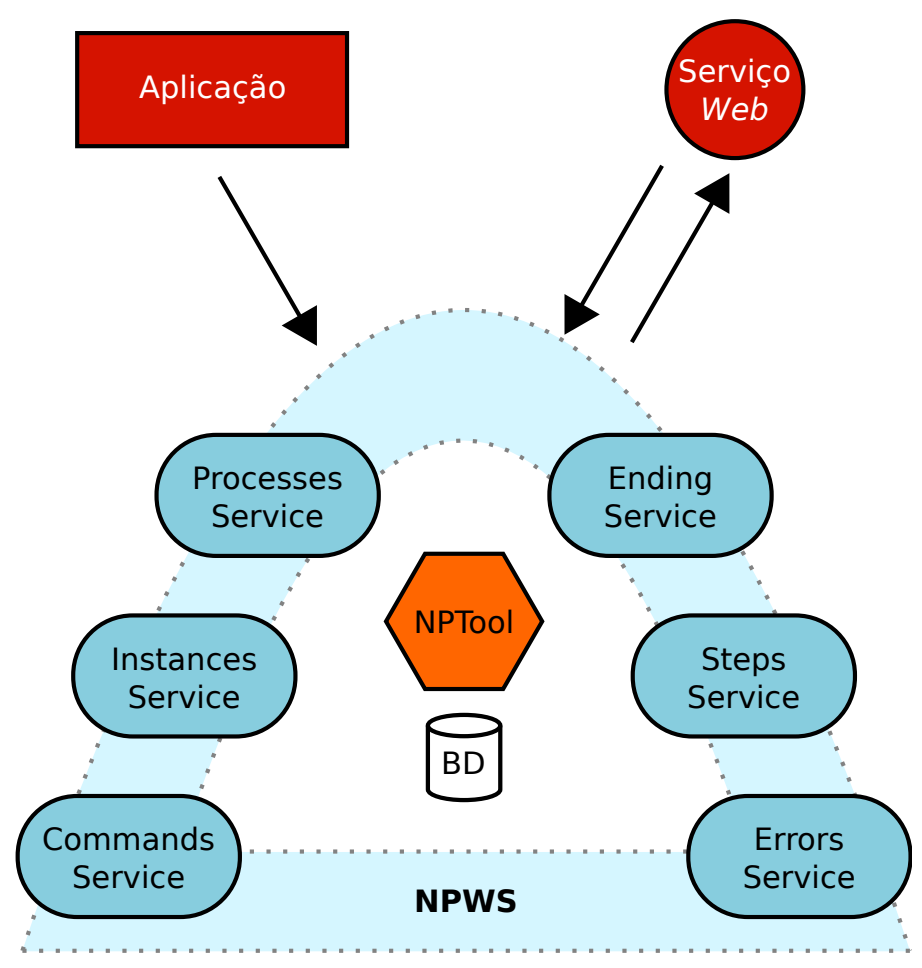

Figura 4.3: NPWS e sua interação com aplicações e serviços Web.

A principal diferença do NPWS em relação a este trabalho está na abordagem que emprega, a qual se trata de uma orquestração cujo arcabouço de BPM é uma extensão de álgebra de processos. A quantidade de funções acumuladas pelo NPWS se deve justamente ao fato de assumir o papel de orquestrador: todos os dados da execução se encontram centralizados e, então, serve como único ponto de acesso remoto a tais informações. Difere, portanto, da abordagem WED-flow, segundo a qual os dados são acessíveis a partir de diversos pontos.

As aplicações clientes do NPWS ainda precisam de adaptação, pois são responsáveis por consultar continuamente o orquestrador para conhecer o estado da execução e as atividades disponíveis. 
Caso uma atividade seja uma funcionalidade local, a aplicação também se responsabiliza por executá-la e então notificar o término ao orquestrador; por outro lado, se a atividade corresponder a um serviço $W e b$, a aplicação solicita sua execução ao NPWS, que aciona o serviço e espera por uma posterior notificação sobre o fim da execução. O comportamento do NPWS e da ferramenta que encapsula, assim, é passivo: cabe a alguma aplicação ou indivíduo consultá-los e determinar o que deve ser feito em cada situação.

Os serviços $W e b$, por sua vez, devem obedecer a diversas restrições impostas pelo NPWS. Para pertencer a uma orquestração, cada serviço deve:

- Disponibilizar uma operação padrão em sua interface para que possa ser acionado pelo NPWS;

- Independer de parâmetros de entrada para sua execução, pois não há transmissão de dados do NPWS para os serviços;

- Chamar o NPWS após encerrar suas atividades, para notificar o término e permitir que o estado da execução seja atualizado;

- Devolver apenas dados específicos e em situações previstas na modelagem do processo de negócio.

Nota-se, portanto, que serviços REST não podem ser compostos com o NPWS. Os requisitos não só impõem a existência de uma operação específica na interface de todo serviço como impedem a transmissão livre de dados, de forma que somente serviços SOAP são aptos a obedecer às restrições.

O perfil passivo e a série de requisitos impostos aos serviços Web pelo NPWS contrastam com a abordagem proposta nesta dissertação e detalhada nas próximas seções. Espera-se, portanto, que este trabalho se diferencie do antecessor pela autonomia na composição de serviços $W e b$ e também pela maior abrangência de serviços.

\subsection{Implementação}

As modificações necessárias para prover a extensão do núcleo WED-flow são apresentadas a seguir, bem como as decisões que as motivaram. A seção se divide em cinco tópicos principais:

- Tipos de operações de serviços Web admitidas para composição;

- Mapeamento dos dados necessários para a extensão;

- Interações previstas do núcleo com o módulo desenvolvido;

- Funcionamento do módulo desenvolvido;

- Requisitos para os serviços $W e b$ participantes de composições. 
É importante frisar que, nesta seção, somente aspectos do núcleo WED-flow relevantes para o módulo desenvolvido são mencionados. Detalhes sobre o funcionamento e a implementação do primeiro devem ser consultados em [16].

\subsubsection{Tipos de Operações de Serviços Web}

O módulo de extensão visa compor tanto serviços SOAP quanto os compatíveis com REST, como descrito na Seção 4.2. As duas classes de serviços $W e b$ originam três tipos de operações de serviços admitidas para composição com WED-flow:

1. Operações de serviços REST;

2. Operações síncronas de serviços SOAP;

3. Operações assíncronas de serviços SOAP.

Uma operação síncrona é aquela cuja resposta o módulo implementado deve aguardar após invocá-la na interface do respectivo serviço. Por outro lado, uma operação assíncrona é aquela que, uma vez invocada pelo módulo, não deve implicar na espera pelo fim das respectivas atividades. Isso significa que, após solicitar a execução de uma operação assícrona, o módulo somente deve esperar que seja iniciada; após o término da execução, o serviço deve registrar o ocorrido por meio de uma nova chamada ao módulo.

A condição de sincronização é determinada junto ao módulo de extensão, isto é, não se trata de um aspecto imposto à implementação dos serviços, mas de um conhecimento derivado de suas propriedades. Dadas as operações padronizadas dos serviços REST para interagir com recursos, entende-se que tais operações sejam sempre síncronas. O módulo deve, assim, solicitar uma operação sobre um determinado recurso, aguardar que ocorra e então receber um eventual resultado.

Todas as operações de serviços REST são admitidas para a composição de serviços Web proposta. Embora PUT, POST e DELETE sejam as operações HTTP que implicam em alterações de dados, a operação GET pode ser útil para a aquisição de dados relevantes para uma dada execução de processo de negócio.

Por outro lado, operações de serviços SOAP, por serem arbitrárias, estão sujeitas à configuração da condição de sincronização. Um fator que pode ser determinante para essa definição é o tempo esperado de execução da operação:

- Caso a operação em questão seja instantânea ou sua duração estimada seja curta o suficiente para que o módulo de extensão possa aguardar uma resposta, então deve ser configurada como síncrona;

- Caso a duração estimada da operação seja longa ou no mínimo impactante para que o módulo aguarde seu término, então deve ser configurada como assíncrona. 
Devido à inviabilidade de espera por resultados de operações assíncronas, essas devem estar de acordo com alguns requisitos para proporcionar o correto funcionamento do módulo de extensão. Esses requisitos são determinados na Seção 4.3.5.

\subsubsection{Mapeamento de Dados}

O módulo desenvolvido precisa ter conhecimento sobre os serviços $W e b$ disponíveis para composição e suas respectivas operações, bem como deve ser capaz de diferenciá-las de acordo com os tipos apresentados. O mapeamento desses dados é, portanto, essencial para que o módulo tenha a noção do que executar e de que forma isso deve ocorrer.

O modelo de dados proposto inclui três entidades de dados relacionadas às operações de serviços Web. As entidades e seus atributos são explicados a seguir.

Entidade: Operação de Serviço

Representa: operação qualquer de serviço $W e b$ a ser chamada

Atributos:

- Identificador: chave que representa uma operação;

- Descrição: define e esclarece a serventia da operação;

- Classe do serviço: indica se a operação pertence a um serviço SOAP ou REST.

Entidade: Operação REST (especialização de operação de serviço)

Representa: operação específica de serviço REST

Atributos:

- Identificador: chave que representa uma operação;

- Método HTTP: indica se a operação é GET, POST, PUT ou DELETE;

- Formato de documento: indica o padrão a ser utilizado para representar informações enviadas, como JSON ou XML;

- Máscara de URL: contém o endereço de localização do serviço na rede (URL - Uniform Resource Locator), já preparado com lacunas a serem preenchidas com os valores esperados em uma chamada. No exemplo http://exemplo.com.br/recursos/<lacuna>, deve-se preencher o termo "<lacuna $>$ " com um identificador de recurso.

Entidade: Operação SOAP (especialização de operação de serviço)

Representa: operação específica de serviço SOAP

Atributos: 
- Identificador: chave que representa uma operação;

- Nome da operação: nome da função correspondente na interface do serviço em questão;

- URL para WSDL: contém o endereço de localização do arquivo de descrição do serviço (vide Seção 2.4.1);

- Sincronização: determina se a operação é considerada síncrona ou assíncrona.

Tanto os métodos HTTP quanto os formatos de documento são representados como entidades distintas para facilitar seu compartilhamento entre as operações REST definidas. Em ambos os casos, é suficiente a existência de um identificador e um nome associados à entidade.

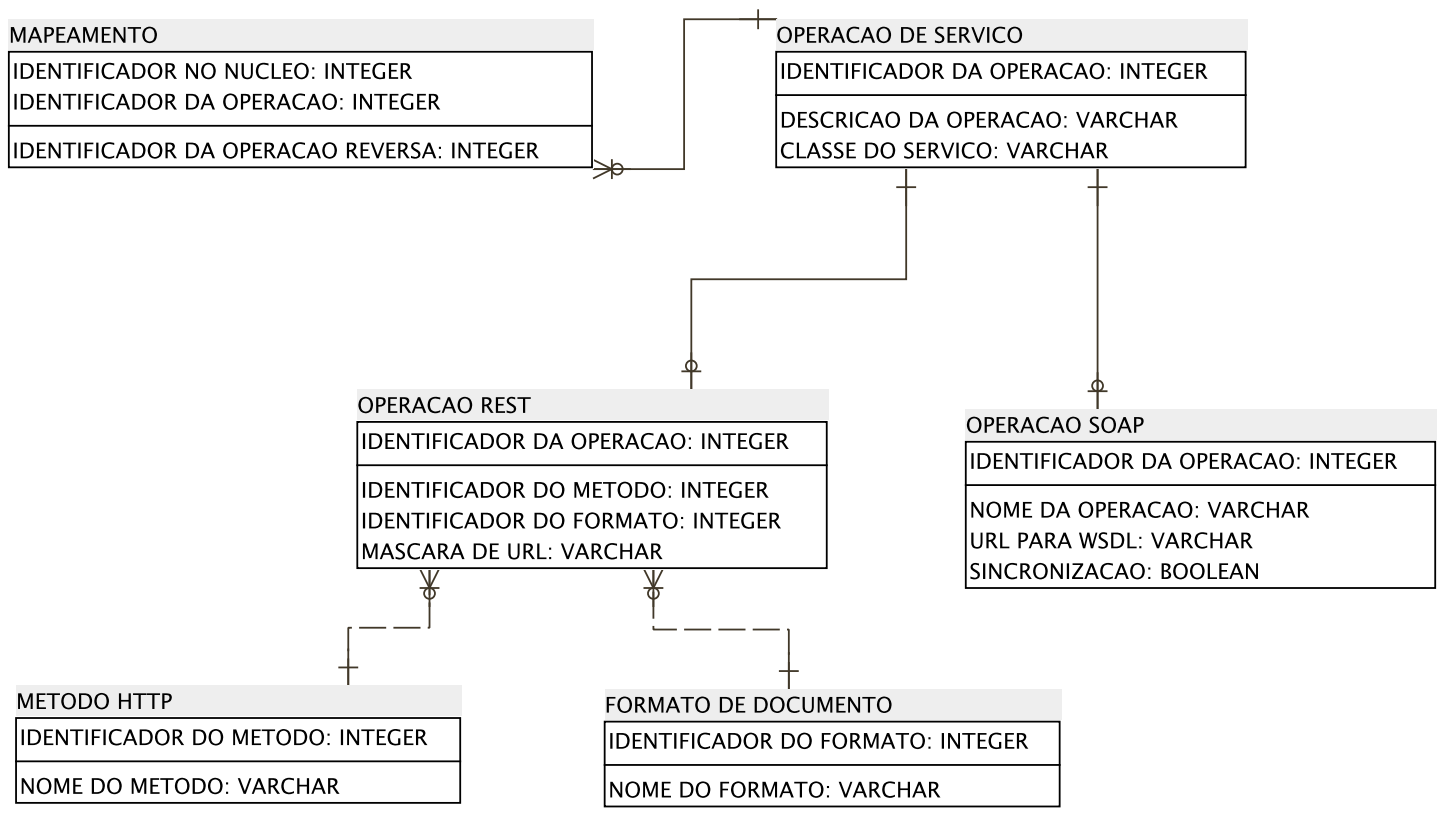

Figura 4.4: Principais entidades para integrar o módulo de extensão ao núcleo WED-flow.

Além das cinco entidades para representação dos dados de operações, é necessário que ocorra a integração ao modelo definido para o núcleo WED-flow. Sugere-se, com essa finalidade, a criação de uma entidade que promova o mapeamento entre os dados do último e os mantidos pelo módulo de extensão. Levam-se em consideração os seguintes atributos:

- Identificador da operação no núcleo WED-flow: chave que representa uma operação no modelo do núcleo, dado que as operações cadastradas junto ao núcleo podem ser Web ou não;

- Identificador da operação no módulo de extensão: chave que representa uma operação de serviço $W e b$ no modelo do módulo e que deve corresponder a uma operação cadastrada junto ao núcleo; 
- Identificador da operação reversa: chave opcional para indicar se existe e está cadastrada uma operação de serviço Web capaz de promover a compensação da operação em questão.

As seis entidades descritas constituem a base para o funcionamento do módulo de extensão e são representadas na Figura 4.4. Ainda é possível o uso de outras entidades para o controle interno de atividades pelo módulo.

Nota-se que, no modelo de dados apresentado para o módulo e sua integração com o núcleo, não há a representação de parâmetros de entrada ou saída necessários para a comunicação com os serviços Web. Tais informações devem ser transmitidas do núcleo WED-flow para o módulo de extensão, pois são definidas junto ao primeiro como parâmetros de funcionalidades quaisquer.

\subsubsection{Integração com o Núcleo WED-flow}

Uma vez integrados, o núcleo WED-flow e o módulo de extensão passam a cooperar para viabilizar a composição de serviços e, assim como o que proporciona para funcionalidades locais, o núcleo é habilitado a coordenar chamadas aos serviços Web de acordo com os eventos que identificar por meio da monitoração dos dados. É importante ressaltar que os termos núcleo e módulo são respectivamente empregados, a seguir, como referências ao núcleo WED-flow e ao módulo de extensão.

\section{Parâmetros de Entrada e Saída}

Para o núcleo, independente de uma funcionalidade ser local ou exposta por um serviço Web, a identificação dos valores de parâmetros de entrada ocorre da mesma maneira: por meio da consulta aos dados de domínios externos vinculados ao WED-flow seguida da preparação de acordo com o que é esperado pela funcionalidade. Analogamente, o tipo de resultado devolvido por uma operação, denominado parâmetro de saída, também deve ser de conhecimento do núcleo, bem como o que deve ser feito com ele.

Apesar de se esperar que os próprios serviços tenham acesso aos dados e sejam capazes de alterá-los, nada impede que suas operações impliquem em parâmetros de saída relevantes para a continuidade da execução de um processo de negócio. Uma vez que funcionalidades de diversos domínios podem ser combinadas, os parâmetros de saída obtidos podem ser úteis para relacionar os dados produzidos pelas operações. O registro de erros é outro exemplo em que se aplica o tratamento de respostas: normalmente não há razão para que um serviço armazene dados de erros de uma requisição, porém a informação, devolvida como resposta, pode ser útil para a continuidade ou o cancelamento da execução.

Os valores de parâmetros de entrada recebidos pelo módulo de extensão são preparados para que sejam devidamente transmitidos aos serviços Web. As respostas de operações também são tratadas antes de serem devolvidas ao núcleo, por isso é essencial que o módulo receba, junto aos valores de parâmetros de entrada, o tipo de resposta esperado para uma determinada operação, se houver. 
A Seção 4.3.4 provê informações específicas do tratamento de parâmetros por parte do módulo de extensão.

\section{Execução e Compensação de Operações}

As chamadas do núcleo WED-flow ao módulo de extensão ocorrem em duas situações distintas. A principal situação é a execução de uma operação, retratada pela seguinte sequência de passos:

1. O núcleo identifica um estado dos dados em que uma funcionalidade deve ser executada;

2. O núcleo verifica que a funcionalidade corresponde, pelo mapeamento, a uma operação de serviço $W e b$;

3. O núcleo extrai, dos dados a que tem acesso, os parâmetros que devem ser transmitidos ao módulo para que a operação seja invocada;

4. O módulo é acionado pelo núcleo, recebendo tanto o identificador da operação de serviço identificada quanto os valores dos parâmetros de entrada;

5. O módulo recupera as informações referentes à operação a ser invocada com base no identificador, bem como determina o tipo da operação;

6. O módulo realiza o processamento previsto para o tipo de operação encontrado e prepara os dados dos parâmetros de entrada para o envio;

7. O módulo estabelece contato com o serviço $W e b$ e solicita a execução da operação;

8. O módulo aciona o núcleo assim que conhece o resultado da execução.

A segunda situação em que o núcleo WED-flow e o módulo de extensão interagem é a compensação de uma operação. Durante a execução de um processo de negócio, é possível a ocorrência de algum resultado excepcional (por exemplo, uma falha) que demande a anulação de operações já realizadas. Duas alternativas são possíveis:

- Se houver uma operação de compensação cadastrada, o núcleo deve identificá-la por meio do mapeamento e solicitar sua execução ao módulo, de acordo com os passos da primeira situação de interação;

- Se não houver operação de compensação cadastrada, isso deve ser registrado pelo núcleo para posterior avaliação.

Apesar da existência de uma operação de compensação ser opcional para toda operação cadastrada, trata-se de uma propriedade bastante recomendada, pois viabiliza o tratamento automatizado e imediato de exceções. 


\section{Término de Execução de Operação}

O término da execução de uma operação, independente de seu tipo e de estar ou não relacionada a compensação, é gerenciado em conjunto com o núcleo WED-flow. Realizam-se duas principais operações:

- Avaliação: o WED-state corrente é verificado para determinar se os resultados ainda podem ser aceitos, bem como a própria resposta da operação pode passar por avaliação;

- Persistência: caso sejam válidos, os dados resultantes podem ser armazenados e também pode ocorrer a mudança para o próximo WED-state na execução do processo; caso contrário, não há persistência e opta-se pela compensação das atividades executadas.

\subsubsection{Funcionamento do Módulo de Extensão}

A descrição sobre como funciona o módulo implementado se divide em duas partes. A primeira é a atribuição de valores a parâmetros de entrada e saída, o que está diretamente relacionado à integração com o núcleo WED-flow. A segunda se refere aos algoritmos empregados para que ocorra a execução das operações de serviços $W e b$.

\section{Tratamento de Parâmetros}

Seja uma operação disponível em um serviço SOAP ou em um serviço REST, frequentemente há a necessidade de informar valores para parâmetros de entrada esperados para a sua execução. Uma vez que o conhecimento dos parâmetros e a identificação dos valores são responsabilidades do núcleo, cabe ao módulo de extensão ser capaz de gerenciá-los de diferentes formas, segundo a classe do serviço $W e b$ cuja operação deve ser invocada.

Uma operação arbitrária definida na interface de um serviço SOAP se assemelha a uma funcionalidade local: há um número esperado de parâmetros com ordenação e tipos pré-definidos; no entanto, tipos complexos empregados na comunicação com serviços dessa classe podem demandar a identificação dos parâmetros por seus nomes. O módulo deve ser capaz de tratar ambos os casos ao repassar os valores dos parâmetros como parte de um envelope SOAP (em formato XML), na chamada à operação.

Uma operação disponível na interface de um serviço REST, por outro lado, recebe os parâmetros de forma diferente: alguns valores podem ser informados junto ao endereço acessado, enquanto outros podem estar inclusos em um documento e formatados segundo o padrão esperado, como JSON ou XML. O módulo de extensão diferencia, portanto, os valores recebidos do núcleo WEDflow entre:

- Parâmetros de acesso: devem ser informados na ordem estabelecida pela máscara de URL da operação, já preparados para o preenchimento das lacunas da máscara; 
- Parâmetros de operação: devem ser informados como parte de uma estrutura composta por atributos, a qual é convertida pelo módulo em um documento no formato esperado pelo serviço $W e b$.

Parâmetros de acesso normalmente são úteis para a identificação de recursos, porém podem ser empregados para, por exemplo, autenticação junto a um serviço REST. Já a presença de parâmetros de operação depende do método HTTP em questão, dado que alguns implicam na transmissão de documentos e outros, não. No mínimo um tipo é utilizado na execução de uma operação REST, porém é possível a combinação dos dois tipos em uma só chamada.

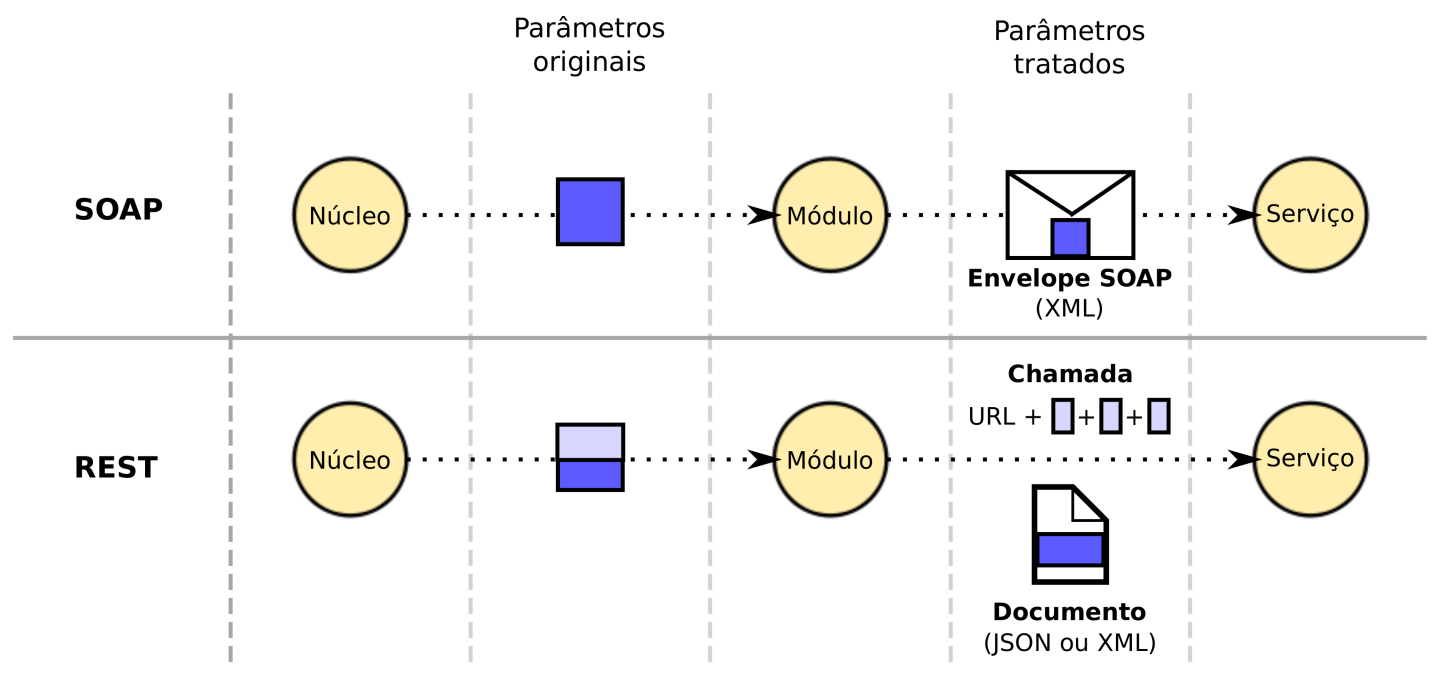

Figura 4.5: Tratamento de parâmetros de entrada pelo módulo de extensão ao invocar um serviço Web.

A Figura 4.5 contém os procedimentos aplicados sobre parâmetros de entrada nas transições entre núcleo WED-flow, módulo de extensão e serviços Web, de acordo com REST e SOAP.

O tipo esperado de resposta, se existir, deve ser informado na chamada do núcleo ao módulo, juntamente aos parâmetros de entrada. Sempre que um tipo de resposta é especificado, o módulo se compromete a tratar os dados devolvidos pela operação do serviço $W e b$ e então repassá-los ao núcleo; caso contrário, os dados são ignorados.

A resposta produzida por uma operação SOAP pode ser simples, como um texto, ou complexa, uma estrutura dotada de diversos atributos. Independente da complexidade da estrutura, espera-se que o tipo informado ao módulo pelo núcleo seja compatível com os dados extraídos do envelope SOAP de resposta. Já operações REST devolvem documentos em JSON ou XML, de acordo com o oferecimento do serviço em questão. Se especificado algum tipo de resposta, o documento devolvido pela respectiva operação REST deve ser convertido pelo módulo de extensão para esse tipo.

A Figura 4.6 ilustra as formas descritas de tratamento de respostas segundo as classes dos serviços envolvidos, retratando as interações de núcleo, módulo e serviços Web.

Tanto ao tratar parâmetros de entrada quanto os de saída, o módulo de extensão se responsabi- 


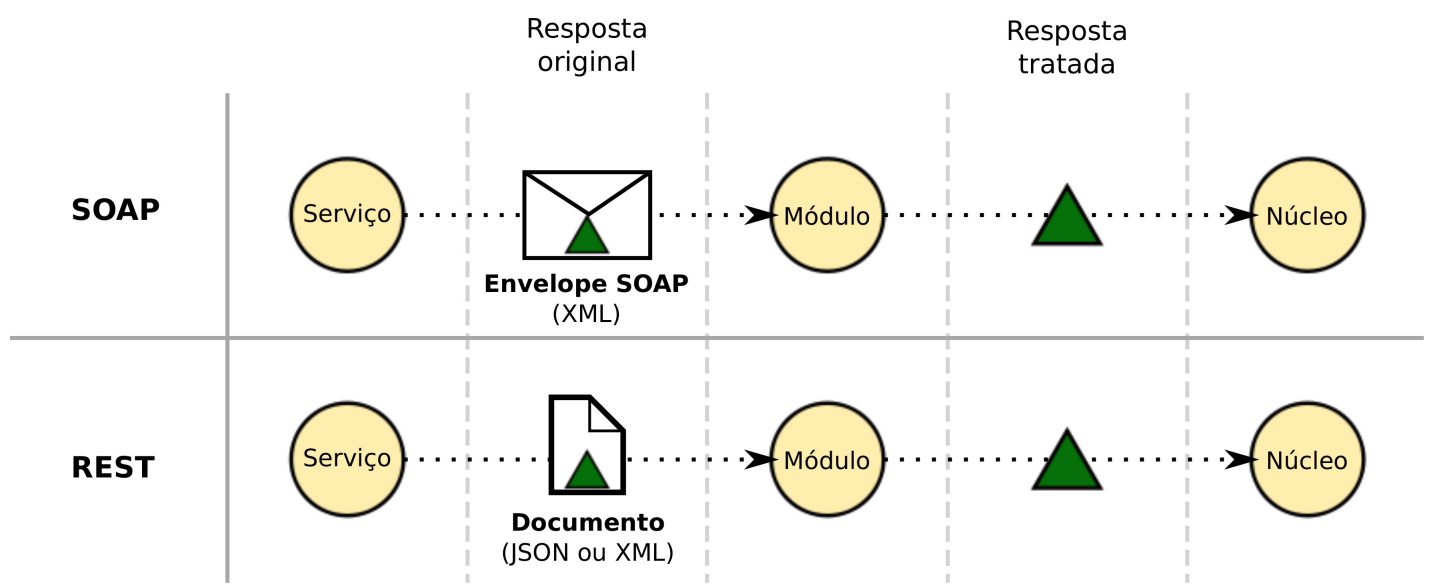

Figura 4.6: Tratamento de parâmetros de saída pelo módulo de extensão ao invocar um serviço Web.

liza por prover toda a estrutura necessária para o preenchimento de valores pelo núcleo WED-flow. Tipos complexos de parâmetros podem ser implementados junto ao módulo e utilizados pelo núcleo, evitando que o último precise armazenar qualquer conhecimento sobre como invocar uma operação de serviço $W e b$.

\section{Algoritmos para Execução de Operações}

O comportamento do módulo varia entre os três tipos de operação declarados na Seção 4.3.1. Em todas as situações apresentadas a seguir, considera-se a definição de um tempo limite $t_{\max }>0$ para concretizar o contato com cada serviço $W e b$ e ainda de um número máximo de chamadas $c_{\max }>0$, o qual permite trabalhar com tentativas falhas.

Os valores atribuídos aos limites não são mencionados nesta dissertação, pois não são relevantes e podem ser facilmente alterados na implementação de acordo com a necessidade. Supõe-se ainda que, caso ocorram falhas sem tratamento explícito pelos algoritmos, os problemas são registrados e a chamada ao serviço $W e b$ é cancelada.

O Algoritmo 4.1 possui os passos necessários para executar uma operação de serviço REST, suposta sempre como síncrona. Operações SOAP síncronas e SOAP assíncronas são respectivamente retratadas pelos algoritmos 4.2 e 4.3 .

Embora os procedimentos que antecedem a chamada sejam os mesmos para as variações síncrona e assíncrona de operações SOAP, a execução da operação é diferente na segunda variação: o módulo apenas dispara a execução da operação, sem aguardar seu término. A chamada ao serviço Web é, então, denominada chamada de disparo, e sua resposta deve indicar o início da execução.

Deve-se lembrar que, logo após os passos dos algoritmos referentes a operações síncronas, ocorre a transmissão de dados do módulo de extensão para o núcleo WED-flow. Já o algoritmo que corresponde às operações SOAP assíncronas é complementado por um tratamento diferente por parte do módulo, o que é abordado na próxima seção. 


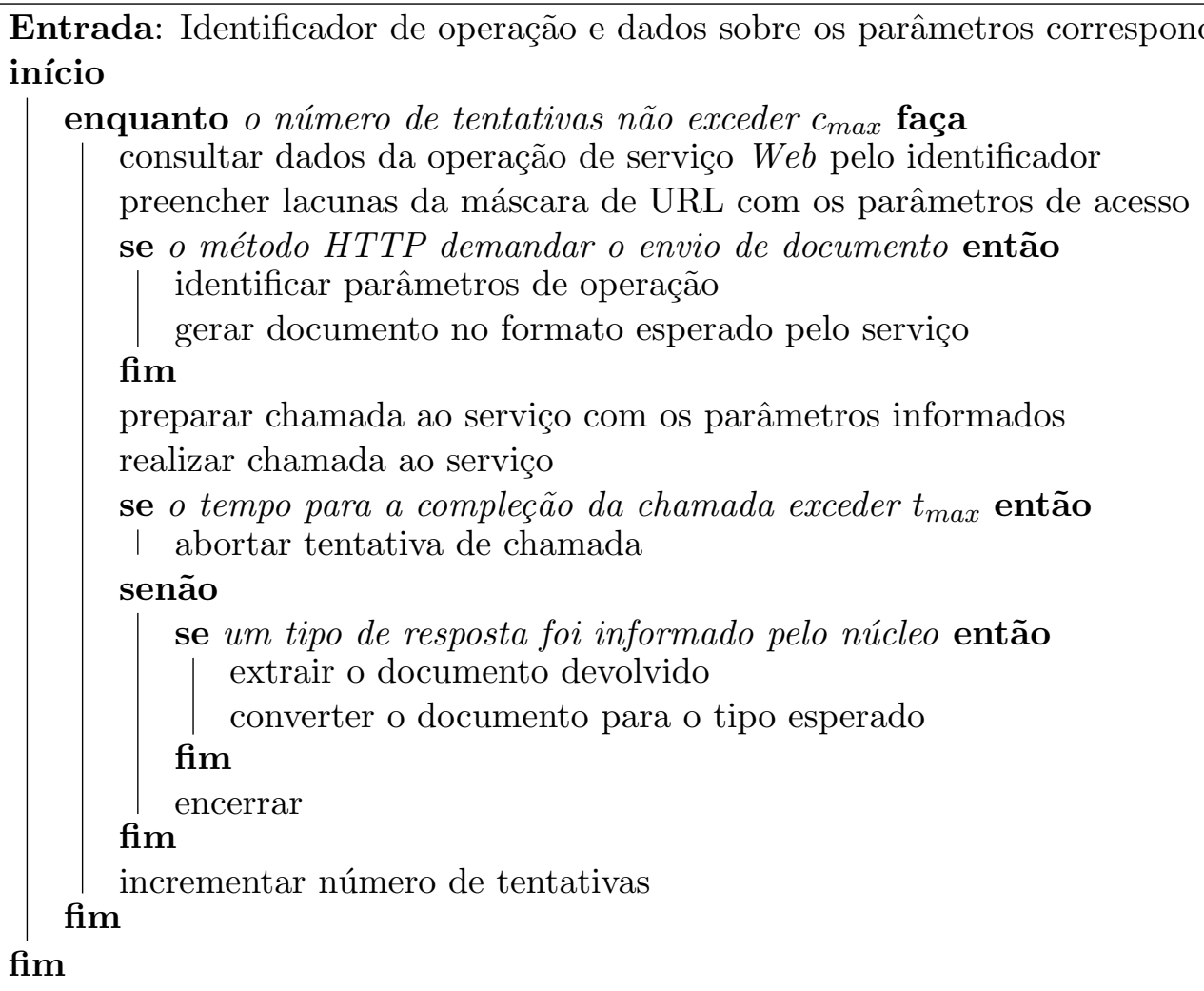

Algoritmo 4.1: Tratamento de operações REST pelo módulo de extensão.

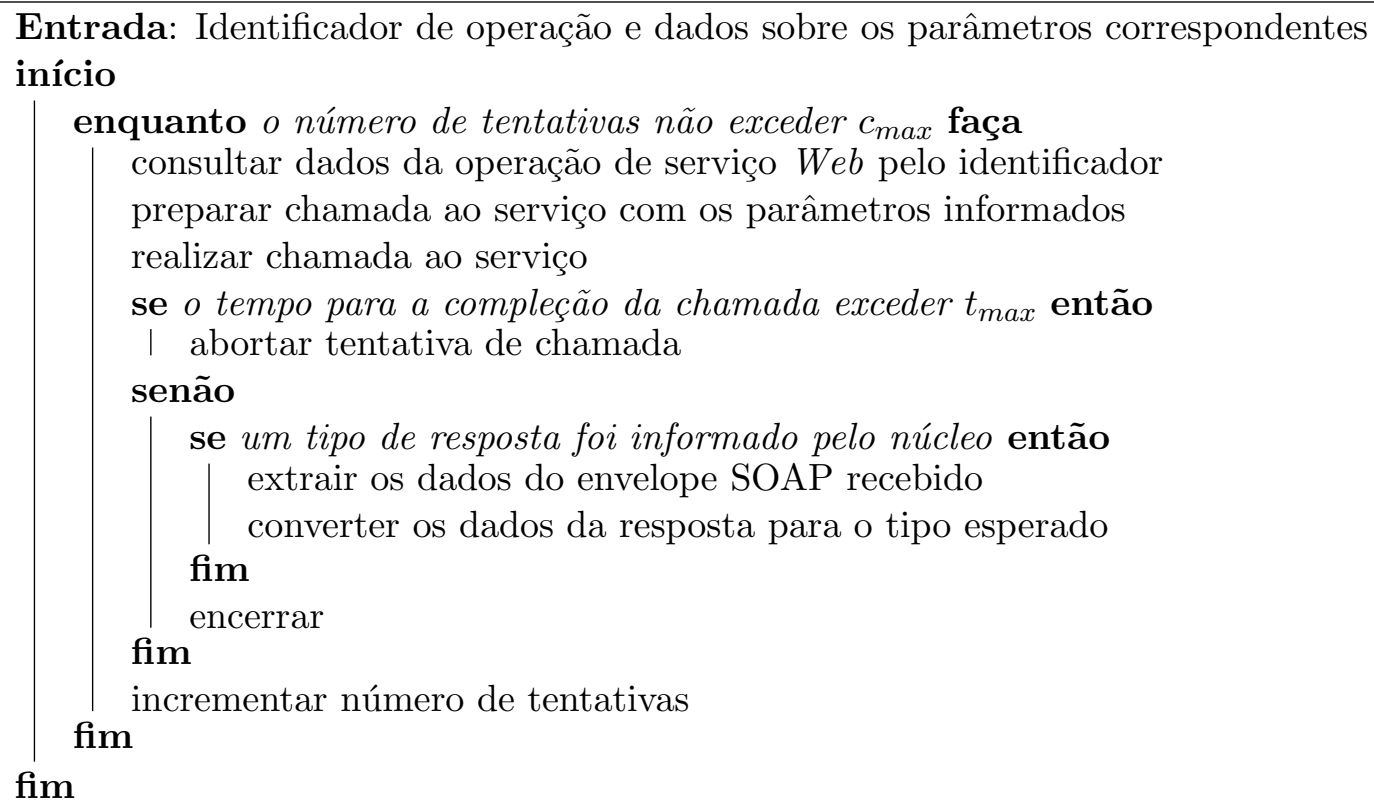

Algoritmo 4.2: Tratamento de operações SOAP síncronas pelo módulo de extensão. 


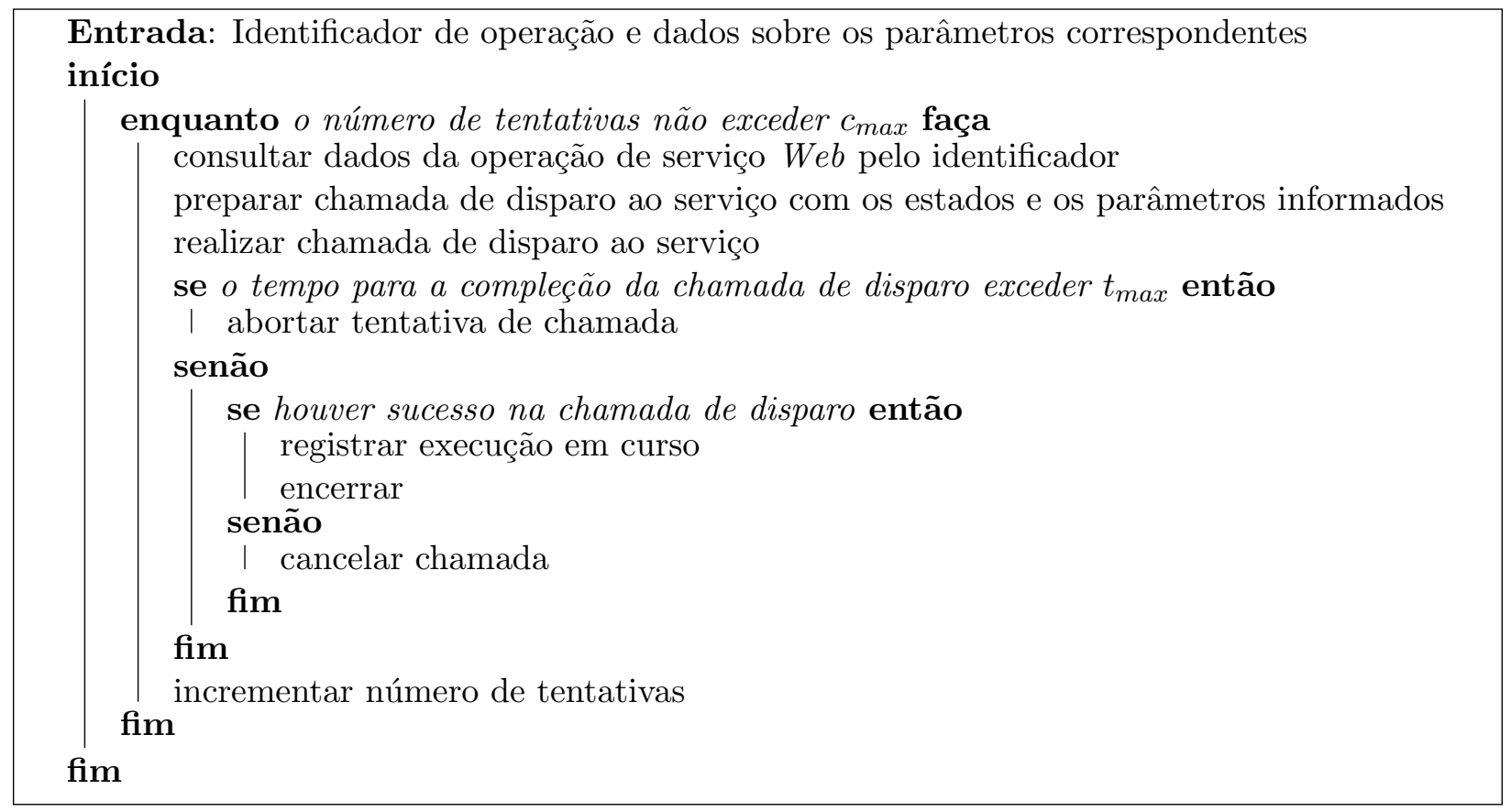

Algoritmo 4.3: Tratamento de operações SOAP assíncronas pelo módulo de extensão.

\subsubsection{Requisitos para os Serviços Web}

Dentre os três tipos de operações apresentados na Seção 4.3.1, somente um impõe requisitos que devem ser satisfeitos e, portanto, podem necessitar da adaptação de uma operação: a variação assíncrona para serviços SOAP.

A execução de operações assíncronas pressupõe que não deve haver a espera pelo retorno dessas chamadas, assim o módulo de extensão não detém o controle da execução a partir do momento em que identifica o sucesso na chamada de disparo. Toda operação assíncrona deve suprir essa perda por meio de duas funções:

1. Devolver uma resposta para a chamada de disparo que permita derivar se houve sucesso no início da execução;

2. Realizar uma chamada de retorno (comumente denominada callback) ao módulo de extensão assim que a execução terminar, seja após o sucesso ou devido à ocorrência de falha.

Com o intuito de que o módulo possa avaliar uma chamada de retorno e então registrar o término da respectiva execução, cada operação SOAP assíncrona deve estar relacionada a um receptor implementado junto ao módulo. Cada receptor é criado especificamente para atender ao retorno de uma operação, de modo a minimizar ou, se possível, eliminar a necessidade de adaptação de serviços $W e b$ que já desempenhem as funções mencionadas.

Apenas quando o módulo de extensão é notificado sobre o término da execução de uma operação, 
há a transmissão de eventuais dados da resposta para o núcleo WED-flow, da mesma forma que ocorre na execução de operações síncronas.

\subsection{Exemplo de Estudo}

O exemplo escolhido e elaborado para ilustrar o uso da abordagem WED-flow remete ao processo de negócio de aquisição online de produtos junto a uma empresa de e-commerce (comércio eletrônico). A modelagem apresentada nesta seção inclusive é implementada com serviços simplificados, visando validações práticas da abordagem proposta.

A empresa de e-commerce é responsável pela interação direta com o usuário final para a escolha de produtos e a criação de pedidos. Supõe-se que o controle e o reabastecimento de estoque sejam automaticamente realizados por outro sistema da empresa, não retratado explicitamente no exemplo. Suposto que o cadastro do comprador e o registro de pedidos ocorram por meio de um sistema próprio da empresa, os seguintes serviços $W e b$ são considerados:

- Processamento de pedido: define como proceder com o pedido e os produtos de acordo com o resultado do pagamento;

- Liberação de pedido: emite a nota fiscal para um pedido antes que seus itens se tornem disponíveis para entrega;

- Conclusão de pedido: registra o sucesso na venda e entrega dos itens.

As operações referentes a pagamentos de pedidos são delegadas pela empresa de e-commerce para um gateway de pagamento, isto é, outra empresa, prestadora de serviços, capaz de validar os dados fornecidos em uma tentativa de pagamento e também interagir com instituições financeiras. Os seguintes serviços Web são relacionados:

- Registro de transação financeira: cadastra no sistema os dados da tentativa de pagamento;

- Validação de dados do pagamento: determina se o comprador está apto a realizar transações, bem como avalia riscos associados ao meio de pagamento utilizado na transação;

- Pagamento: contacta uma instituição financeira, também alheia à representação nesse exemplo, visando o pagamento da transação.

O transporte dos produtos de um pedido também não é realizado pela empresa de $e$-commerce, mas por uma transportadora associada que disponibiliza um serviço $W e b$ de requisição de entrega para tal integração. A funcionalidade de confirmação de entrega, por sua vez, é realizada via interface administrativa.

Outros serviços ainda podem ser providos pelas organizações envolvidas no processo de negócio, embora não interfiram em sua execução. A transportadora, por exemplo, pode oferecer um serviço 
$W e b$ voltado ao rastreamento de pedidos. Todavia, somente a retirada dos produtos e sua entrega ao comprador são relevantes para a execução. Esse exemplo ratifica, ainda, como os monitores podem integrar não somente os serviços $W e b$ na execução, mas também funcionalidades internas a cada organização.

\subsubsection{Modelagem WED-flow}

O caminho normal para que uma compra online ocorra com sucesso é constituído pelos seguintes eventos:

1. O comprador se cadastra junto à empresa de e-commerce;

2. O comprador escolhe o meio de pagamento e submete seu pedido;

3. O pagamento é registrado;

4. Todos os dados do pagamento são validados;

5. O pagamento é efetivado junto a uma instituição financeira;

6. O pedido é processado e tem seus itens preparados;

7. O pedido é liberado para o envio;

8. O pedido é retirado pela transportadora;

9. O pedido é entregue ao comprador;

10. O pedido é dado como concluído pela empresa de e-commerce.

\begin{tabular}{|c|c|c|c|}
\hline Comprador & Pedido & Produto & Pagamento \\
\hline \multirow[t]{4}{*}{ Não cadastrado } & NĨ & Risnońul & \\
\hline & & & Não realizado \\
\hline & & & Registrado \\
\hline & & & Válido \\
\hline \multirow[t]{5}{*}{ - Eadastrado } & Processado & & \\
\hline & Liberado & & \\
\hline & Retirado & Vendido & \\
\hline & Entregue & & \\
\hline & Concluído & & \\
\hline
\end{tabular}

Figura 4.7: Normalização para o caminho normal da aquisição online de produtos. 
Diversas exceções podem ocorrer ao longo do caminho normal declarado, porém, para exemplificar a aplicação da WED-flow, apenas um foi escolhido: a identificação dos dados do pagamento como inválidos. Caso isso ocorra, o pagamento sequer é enviado para uma instituição financeira e o pedido é cancelado, o que se representa por meio dos eventos a seguir:

1. O comprador se cadastra junto à empresa de e-commerce;

2. O comprador escolhe o meio de pagamento e submete seu pedido;

3. O pagamento é registrado;

4. Todos os dados do pagamento são validados;

5. O pagamento não é efetivado por algum dado inválido encontrado;

6. O pedido é cancelado.

\begin{tabular}{|c|c|c|c|}
\hline Comprador & Pedido & Produto & Pagamento \\
\hline \multirow[t]{2}{*}{ Não cadastrado } & Não realizad & _- Dicnonível- & \\
\hline & & & Não realizado \\
\hline \multirow[t]{2}{*}{ Cadastrado } & Recebido & Reservado & Registrado \\
\hline & Cancelado & Disponível & \\
\hline
\end{tabular}

Figura 4.8: Normalização para o caminho de cancelamento por dados inválidos de pagamento.

Identificados os principais eventos referentes ao processo de negócio e separados entre eventos normais e de exceção, é preciso construir o modelo WED-flow a ser utilizado.

As classes de dados são quatro: o comprador, o pedido, o produto e o pagamento. O resultado do processo de normalização para o caminho normal e para o de exceção (cancelamento por dados inválidos de pagamento) são representados respectivamente nas figuras 4.7 e 4.8 . O modelo WED-flow para o caminho normal é ilustrado na Figura 4.9, de acordo com a notação gráfica descrita na Seção 2.3. O modelo WED-flow para o caminho de exceção referente ao cancelamento por dados inválidos de pagamento, por sua vez, é ilustrado na Figura 4.10.

\subsubsection{Simulação}

O fluxo completo para a conclusão de um pedido a partir da autenticação do usuário é ilustrado na Figura 4.11. A situação excepcional de cancelamento de pedido devido à identificação de dados inválidos pode ser derivada da mesma ilustração. Nesse caso, porém, o serviço Web de processamento de pedido impede que esse se concretize, cancelando-o e interrompendo a sequência de atividades. 


\begin{tabular}{|c|c|c|c|c|c|c|}
\hline & & $\begin{array}{c}\text { Comprador } \\
\text { id }=111\end{array}$ & $\begin{array}{l}\text { Pedido } \\
\text { id=222 }\end{array}$ & $\begin{array}{c}\text { Produto } \\
\text { id }=333\end{array}$ & $\begin{array}{c}\text { Pagamento } \\
\text { id }=444\end{array}$ & \\
\hline & WED-stateo & $\begin{array}{l}\text { Não } \\
\text { cadastrado }\end{array}$ & $\begin{array}{l}\text { Não } \\
\text { realizado }\end{array}$ & Disponível & $\begin{array}{l}\text { Não } \\
\text { realizado }\end{array}$ & \\
\hline & WED-state 1 & Cadastrado & $\begin{array}{l}\text { Não } \\
\text { realizado }\end{array}$ & Disponível & $\begin{array}{l}\text { Não } \\
\text { realizado }\end{array}$ & V \\
\hline & WED-statez & Cadastrado & Recebido & Reservado & $\begin{array}{l}\text { Não } \\
\text { realizado }\end{array}$ & VVL \\
\hline & WED-state 3 & Cadastrado & Recebido & Reservado & Registrado & \\
\hline Processo de Negócio: & WED-state $_{4}$ & Cadastrado & Recebido & Reservado & Válido & \\
\hline evento & WED-states & Cadastrado & Recebido & Reservado & Efetivado & \\
\hline & WED-state 6 & Cadastrado & Processado & Vendido & Efetivado & \\
\hline & WED-state 7 & Cadastrado & Liberado & Vendido & Efetivado & \\
\hline & WED-state 8 & Cadastrado & Retirado & Vendido & Efetivado & \\
\hline & WED-state 9 & Cadastrado & Entregue & Vendido & Efetivado & \\
\hline & WED-state 10 & Cadastrado & Concluído & Vendido & Efetivado & \\
\hline
\end{tabular}

Figura 4.9: Representação do modelo WED-flow para o caminho normal.

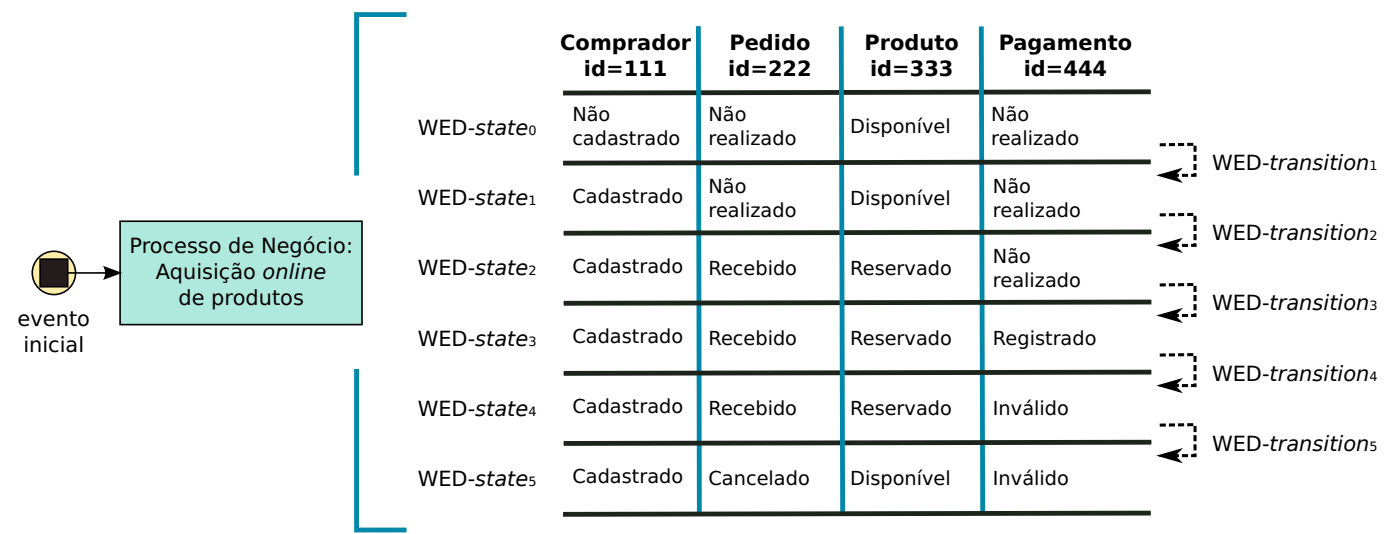

Figura 4.10: Representação do modelo WED-flow para o caminho de exceção.

\subsubsection{Implementação}

Além de aplicações $W e b$ implementadas com a linguagem de programação Java ${ }^{3}$ para representar os sistemas da empresa de e-commerce e da transportadora, os serviços $W e b$ relacionados na composição são artefatos produzidos como parte deste trabalho. A escolha dessa linguagem de programação para o desenvolvimento permite notar que a integração com o módulo criado não impõe Ruby como linguagem para a implementação. Também em Java, os serviços são especificados da seguinte forma:

\footnotetext{
${ }^{3}$ A especificação da linguagem Java está disponível em http://www.java.com.
} 


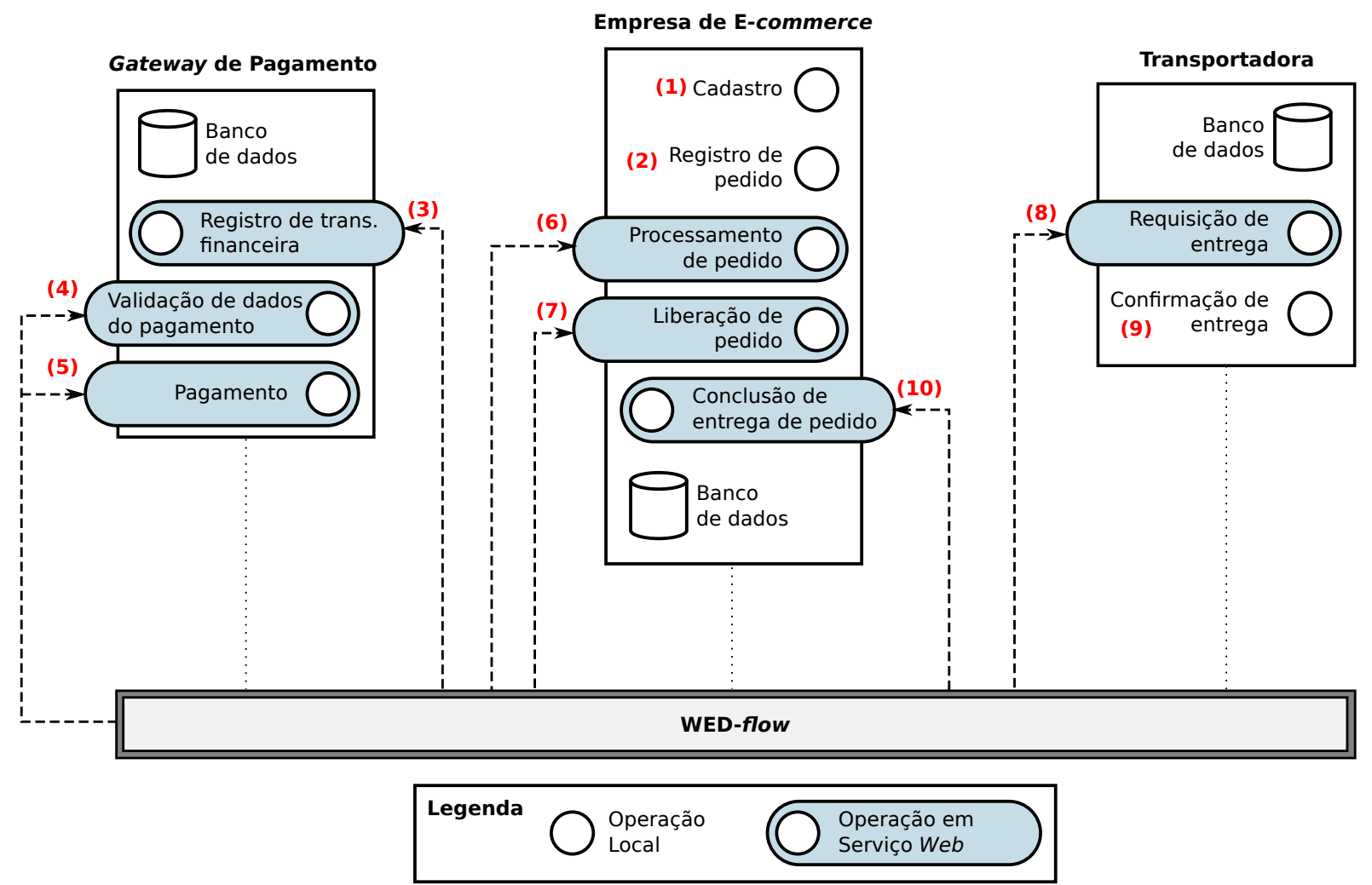

Figura 4.11: Simulação do processo de negócio de aquisição online de produtos.

\section{Empresa de E-commerce}

- Processamento de pedido: SOAP síncrono

- Liberação de pedido: REST

- Conclusão de entrega de pedido: REST

\section{Gateway de Pagamento}

- Registro de transação financeira: REST

- Validação de dados: SOAP síncrono

- Pagamento: SOAP assíncrono

\section{Transportadora}

- Requisição de entrega: REST

As três variedades de serviços $W e b$ aceitas para composição com WED-flow são representadas, para que o módulo implementado possa ser avaliado na prática em todas as situações. As aplicações Web, por sua vez, remetem à execução das funcionalidades locais. 


\subsection{Resultados Obtidos}

A composição de serviços $W e b$ por meio da WED-flow se dá pelo tratamento dos eventos que afetam os dados relacionados à execução do processo de negócio em questão. Como descrito na Seção 4.3, sobre a implementação da nova abordagem, os monitores são os responsáveis por identificar a ocorrência dos eventos.

Cada monitor avalia os dados continuamente, porém isso se dá de forma direta, uma vez que o acesso aos dados é local e sem dependência de outros componentes. Mudanças no estado da execução são, portanto, detectadas muito mais rapidamente do que se fosse necessária a comunicação via um protocolo de rede como o HTTP.

A realização de uma chamada via rede só ocorre quando um serviço Web precisa ser acionado; a operação exposta na interface do serviço, então, opera com os dados de forma local. Somente em casos de operação assíncrona ocorre uma segunda chamada dependente de protocolos de rede, a qual corresponde à chamada de retorno.

\subsubsection{Avaliação}

A composição de serviços Web com WED-flow é avaliada a seguir, de acordo com os critérios e conceitos propostos na Seção 3.1 e já empregados na avaliação dos cenários de comunicação referentes a coreografia e orquestração.

Segundo a abordagem proposta, os serviços $W e b$ da composição apenas aguardam uma chamada proveniente de algum monitor, por meio do módulo de extensão, para que iniciem suas atividades. Se consideradas somente as operações síncronas, não são necessárias consultas periódicas nem notificações de término, basta que os dados sejam alterados e um monitor poderá identificar isso em suas consultas. Por outro lado, se consideradas somente as operações assíncronas, toda chamada conduz a uma chamada de retorno, portanto uma atividade implica em duas chamadas dependentes de protocolos de rede.

A Figura 4.12 ilustra uma simulação da execução dos subprocessos descritos na Seção 3.1.1 e segundo a notação gráfica apresentada na Figura 3.1, suposta somente a presença de operações síncronas. A variação dotada apenas de operações assíncronas pode ser derivada da mesma figura, basta considerar uma chamada de retorno para cada chamada de execução realizada.

\section{Volume de Comunicação}

As consultas promovidas pelos monitores são locais, bem como as atualizações de estado da execução por parte dos serviços, portanto cada operação invocada na interface de um serviço $W e b$ executado remete a uma ou duas chamadas. O valor mínimo é assumido se a operação for síncrona, enquanto o máximo ocorre para uma operação assíncrona.

Dados todos os serviços acionados na composição, sejam o volume de comunicação mínimo 


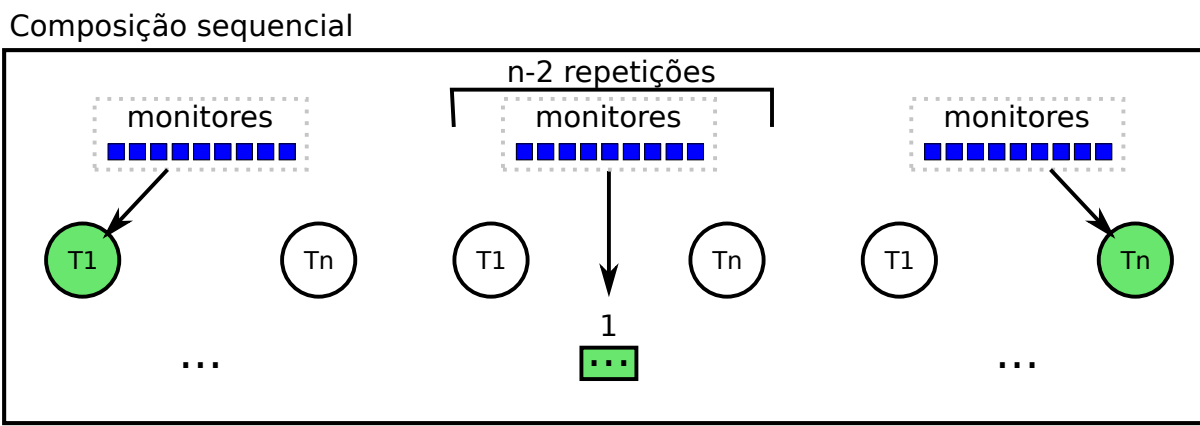

Composição alternativa

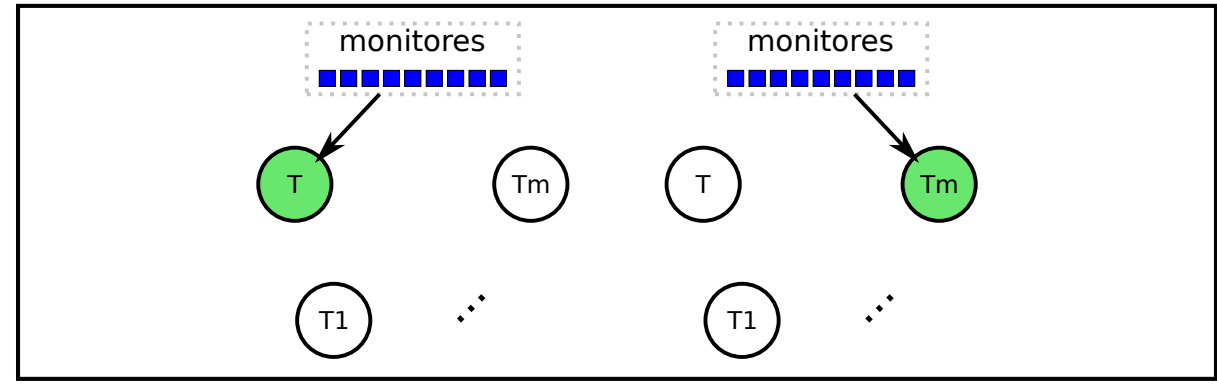

Entrelaçamento

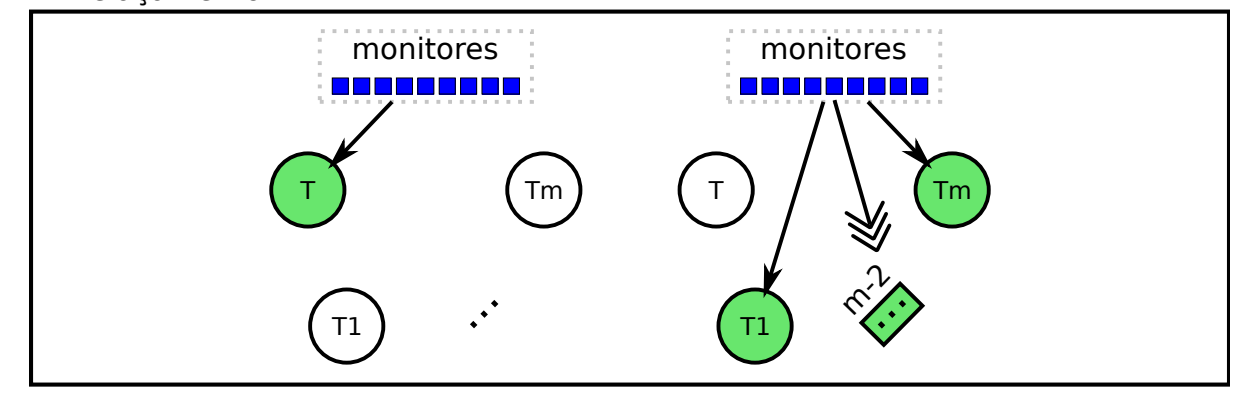

Figura 4.12: Simulação de comunicação segundo a WED-flow, somente com operações síncronas.

$V_{W E D m i n}$, o volume máximo $V_{W E D \max }$ e o volume real $V_{W E D}$. Pode-se afirmar que:

$$
\begin{array}{r}
V_{W E D \min }=\sum_{j \in E} 1=|E| \\
V_{W E D \max }=\sum_{j \in E} 2=2|E| \\
|E| \leq V_{W E D} \leq 2|E|
\end{array}
$$

É importante ressaltar que a maioria das operações oferecidas por serviços $W e b$ são síncronas, até porque operações assíncronas implicam em uma integração mais complexa a outros sistemas ou plataformas. O próprio módulo de extensão, por exemplo, precisa da implementação de receptores para compor operações assíncronas. Assim, $V_{W E D}$ está muito mais próximo de seu limite mínimo do que de seu limite máximo. 


\section{Aspectos Técnicos}

Uma vez implementado o módulo de extensão e integrado ao núcleo WED-flow, pouco resta para ser implementado na execução de operações síncronas de serviços Web: é suficiente gerar as estruturas necessárias para comportar os valores de parâmetros na comunicação entre núcleo e módulo; os serviços não precisam de qualquer alteração.

Demandas técnicas ocorrem somente na execução de operações assíncronas, uma vez que é preciso implementar os receptores de acordo com cada operação, e os serviços $W e b$ ainda devem prover uma forma de ocorrerem as chamadas de retorno. Existem serviços já habilitados a esse tipo de comportamento, porém os que não são dotados de tal capacidade precisam de adaptação.

Cabe aos serviços $W e b$, de forma geral, o requisito estabelecido na proposta de aplicação da WED-flow para a composição: cada serviço deve ser capaz de alterar o estado de seus respectivos dados, no que diz respeito à execução do processo de negócio.

\subsubsection{Comparação com Resultados das Configurações Propostas}

Na Seção 3.4, obtiveram-se resultados referentes à comparação dos cenários de comunicação propostos por este trabalho, com base nos critérios de volume de comunicação e aspectos técnicos. Os resultados, classificados em quatro configurações, são comparados nesta seção com o que é propiciado pela aplicação da WED-flow para a composição de serviços Web.

A comparação é feita da seguinte forma: para cada configuração, as propriedades dos cenários mais vantajosos são avaliadas em relação às da composição com WED-flow, mediante os mesmos

dois critérios. É mantida também a suposição de que cada operação executada corresponde a um serviço $W e b$ distinto, apenas por simplificação.

\section{Configuração com Notificações Globais e sem Feedback}

O cenário II, eleito como mais vantajoso, é uma forma de coreografia e possui o volume de comunicação $V_{2}=|E|(|C|-1)$. Desde que a composição contenha mais de um serviço $W e b$, o que de fato se espera, então é claro que $V_{W E D \min }=|E|$ apresenta resultados iguais ou melhores do que $V_{2}$.

Avaliando o pior caso para a abordagem WED-flow, com $V_{W E D \max }=2|E|$, deriva-se que o cenário II deixa de ser vantajoso para $|C| \geq 3$. Portanto, para composições com três ou mais participantes, o que engloba grande parte das composições, $V_{W E D m a x}$ mostra bons resultados. Conclui-se que a abordagem proposta tende a ser mais vantajosa do que as apresentadas para a configuração em questão.

No critério técnico, a composição com WED-flow com operações síncronas é bastante similar à do cenário II. Em ambas, os serviços Web são isentos da responsabilidade de consultar o estado da execução e há a necessidade de tratamento de situações atípicas, como falhas de comunicação. A 
adoção de retentativas de chamada é uma solução prática viável para as duas abordagens.

Supostas somente operações assíncronas, o aumento da complexidade técnica na abordagem proposta não chega a transpor a do cenário II. Isso se deve à própria natureza do último como uma coreografia, o que torna os serviços Web são mais complexos por precisarem conhecer a composição, uma vez que se comunicam entre si para dar continuidade à execução. Com a WED-flow, no pior caso os serviços precisariam ser capazes de enviar notificações (sempre para monitores, por meio do módulo de extensão), sem conhecer qualquer detalhe da execução do processo.

\section{Configuração com Notificações Globais e Feedback}

O cenário IV, único representante dessa configuração, é uma forma de orquestração cujo volume de comunicação é dado por $V_{4}=2|C|+|E|+\sum_{i \in C}\left[\frac{T}{\text { int }_{i}}\right]$, claramente maior do que $V_{W E D m i n}=|E|$ e, portanto, menos vantajoso no melhor caso para a abordagem proposta.

Para que o pior caso da abordagem WED-flow proporcione resultados melhores ou iguais aos do cenário IV, então deve valer que:

$$
\begin{array}{r}
2|E| \leq 2|C|+|E|+\sum_{i \in C}\left\lceil\frac{T}{\text { int }_{i}}\right\rceil \\
|E| \leq 2|C|+\sum_{i \in C}\left\lceil\frac{T}{\text { int }_{i}}\right\rceil
\end{array}
$$

Dado que a somatória presente na inequação equivale a, no mínimo, $|C|$, então o pior caso da WED-flow é uma boa opção para composições em que o número de serviços executados é inferior ao triplo do número de serviços existentes, proporção que parece bastante aceitável. Ademais, quanto maior o tempo de execução $T$, mais abrangente se torna a proporção.

Tecnicamente, apesar de, nas duas abordagens, os serviços $W e b$ não conhecerem a composição, ambas são bastante diferentes. O cenário IV é dotado de consultas periódicas por parte dos serviços, os quais também devem enviar notificações de término de atividade. Quando a execução de uma instância de processo termina, seja por sucesso ou falha, cabe ao orquestrador informar isso aos serviços da composição.

A composição com WED-flow não apresenta a tolerância a falhas própria das consultas periódicas, porém o uso de retentativas de chamada em situações atípicas consegue suprir essa necessidade sem sacrificar a vantagem no volume de comunicação. Nos demais aspectos, novamente a abordagem com WED-flow é vantajosa por permitir que a implementação dos serviços Web seja suficiente para as atividades que precisam exercer.

Mesmo no caso de operações assíncronas os serviços mostram ser menos complexos do que os avaliados no cenário IV. Basta notar que o envio de notificações de término, a principal demanda para operações assíncronas na abordagem proposta, é só uma das exigências impostas pelo cenário 
IV aos serviços da composição.

\section{Configuração com Notificações Diretas e sem Feedback}

O cenário III, eleito o mais vantajoso pelo critério do volume de comunicação, é uma coreografia e tem seu número de chamadas representado por $V_{3}=\sum_{i \in E} s u c_{i}$. Quanto aos aspectos técnicos, contudo, há impasse sobre qual é o mais vantajoso: o cenário III ou o cenário VI, referente a uma orquestração. Isso se deve à possibilidade de implementações do cenário III considerarem ou não o contexto da execução do processo como fator para que os sucessores de serviços sejam escolhidos.

O representante da abordagem de coreografia, quando aplicado a processos de negócio sem qualquer paralelismo, é tal que $V_{3}=|E|-1$, dado que todo serviço tem apenas um sucessor, exceto pelo último. Nesse caso, a composição com WED-flow em seu melhor caso é menos vantajosa por uma chamada. Nos demais casos, quando há serviços executados paralelamente pelo menos uma vez, o cenário III passa a ser menos vantajoso porque $V_{3}$ assume valores maiores ou iguais a $V_{W E D \min }=|E|$.

No pior caso, com $V_{W E D \max }=2|E|$, o cenário III é claramente mais vantajoso se considerados processos de negócio com pouco ou nenhum paralelismo entre as atividades executadas. Somente para processos com, em média, duas ou mais atividades executadas paralelamente é que a abordagem WED-flow passa a se destacar.

Quanto ao critério de aspectos técnicos, o cenário III é menos vantajoso do que a abordagem WED-flow independente do uso do contexto de uma execução para a escolha de sucessores dos serviços. A notificação de término, recurso mais complexo que uma operação pode implementar com WED-flow, sempre ocorre no cenário III. Porém, no último, ainda é preciso que cada serviço armazene algum conhecimento sobre a execução do processo, o que não é necessário na abordagem proposta.

Comparando tecnicamente o cenário VI à composição com WED-flow, tem-se que a desvantagem do primeiro está relacionada justamente às consultas periódicas: essas não só impõem o requisito de cada serviço apresentar uma interface para recebê-las como também são transportadas via rede. O uso da WED-flow isenta os serviços das consultas periódicas e cabe aos monitores avaliar o estado dos dados de forma contínua, porém local. Mesmo a variação com operações assíncronas não exige que os serviços exponham novas operações de consulta além das invocadas para a execução.

Visto que a composição de serviços Web com WED-flow se aproxima do cenário III no primeiro critério, com pequenas desvantagens, mas mostra ser mais vantajosa tecnicamente do que os cenários III e VI, então de forma geral pode-se afirmar que a abordagem constitui uma boa alternativa aos cenários dessa configuração. 


\section{Configuração com Notificações Diretas e Feedback}

Apenas o cenário V consta nessa configuração e, por ter seu volume de comunicação dado por $V_{5}=2|E|$, nota-se que $V_{W E D m i n}=|E|$ leva a valores menores e $V_{W E D m a x}=2|E|$ apresenta os mesmos resultados. Ademais, considerando a possibilidade de $V_{5}=|E|$ quando há garantia de que todas as operações são síncronas (Seção 3.3.5), verifica-se que as duas abordagens são bastante similares, não havendo desvantagens na composição com WED-flow.

Considerados os aspectos técnicos, o cenário $\mathrm{V}$, representando a abordagem de orquestração, isenta quase totalmente os serviços $W e b$ de uma complexidade técnica além da necessária para executar atividades. Exige-se apenas que notifiquem o término de suas atividades ao orquestrador, informando os mesmos identificadores de execução recebidos quando acionados.

Suposta a presença somente de operações síncronas, a composição com WED-flow é mais vantajosa segundo esse critério, uma vez que os serviços não precisam de adaptação para serem compostos. Já a variação de composição com operações assíncronas apresenta requisitos análogos aos do cenário V. Assim, a abordagem proposta também supera o cenário V com base no critério de aspectos técnicos.

\subsection{Considerações Finais}

A Tabela 4.1 é um resumo das considerações anteriores e apresenta os volumes de comunicação avaliados em relação ao da abordagem WED-flow.

\begin{tabular}{|l|l|}
\hline Volume de Comunicação & Nome \\
\hline$|E| \leq V_{W E D} \leq 2|E|$ & WED-flow \\
\hline$V_{2}=|E|(|C|-1)$ & $\begin{array}{l}\text { Cenário II } \\
\text { (Notificações Globais e sem Feedback) }\end{array}$ \\
\hline$V_{4}=2|C|+|E|+\sum_{i \in C}\left[\frac{T}{\text { int }_{i}}\right]$ & $\begin{array}{l}\text { Cenário IV } \\
\text { (Notificações Globais e Feedback) }\end{array}$ \\
\hline$V_{3}=\sum_{i \in E}$ suc $c_{i}$ & $\begin{array}{l}\text { Cenário III } \\
\text { (Notificações Diretas e sem Feedback) }\end{array}$ \\
\hline$V_{5}=2|E|$ & $\begin{array}{l}\text { Cenário V } \\
\text { (Notificações Diretas e Feedback) }\end{array}$ \\
\hline
\end{tabular}

Tabela 4.1: Volumes de comunicação considerados nas avaliações finais.

A composição de serviços Web por meio da WED-flow habilita uma abordagem que difere das tradicionais coreografia e orquestração. Em ambas, define-se quais os passos a serem seguidos para orientar a execução de processos de negócio. Já a composição com WED-flow utiliza o mapeamento dos estados de dados como orientação, sem definir explicitamente todos os possíveis fluxos de execução. Esses são derivados das alterações sofridas pelo estado dos dados.

Frente à coreografia, a abordagem proposta oferece a vantagem de serem utilizadas poucas chamadas via protocolos de rede, sem exigir que os serviços Web incorporem grande complexidade técnica além da necessária para a execução de suas respectivas atividades. Como visto entre os 
cenários apresentados para coreografia, a auto-organização dos serviços tende a gerar excesso de

chamadas na comunicação que estabelecem entre si. É possível eliminar chamadas desnecessárias em coreografias, porém isso implica no aumento da complexidade imposta a cada serviço devido ao maior conhecimento da composição pelos serviços.

A abordagem de orquestração, por sua vez, visa manter os serviços $W e b$ da composição com a menor complexidade técnica possível e, no melhor caso apresentado, os serviços apenas incrementam sua capacidade com o envio de notificações ao orquestrador. Assim, o volume de comunicação, que depende da configuração escolhida para a orquestração, pode vir a ser um valor bem próximo do proposto com a nova abordagem. Contudo, ainda se faz necessária a definição prévia de um modelo completo de BPM, fator comum às orquestrações e que se trata da tarefa mais complexa desse tipo de abordagem.

Um dos propósitos da WED-flow como abordagem é remover a restrição estabelecida pelos formalismos clássicos, e até mesmo por linguagens orientadas à programação, que torna necessária a especificação a priori de um modelo completo para viabilizar a execução de processos de negócio. Diversos conceitos podem ainda não estar claros em uma modelagem inicial, bem como novos comportamentos tendem a ser incorporados ao longo do tempo, de forma que um modelo pode facilmente se tornar obsoleto. A árdua representação e manutenção desse conhecimento junto a um orquestrador é, assim, uma desvantagem das orquestrações se relacionada à flexibilidade oferecida pela modelagem com WED-flow.

Para usufruir as vantagens da composição de serviços com WED-flow, todavia, é interessante, apesar de opcional, que os serviços tenham acesso a seus respectivos dados, em domínios externos, e os atualizem quando executados. Tanto na orquestração quanto na coreografia, nada impede que os serviços $W e b$ recebam parâmetros de entrada e devolvam um resultado processado, sem qualquer atualização do estado dos dados.

Por fim, vale ressaltar a capacidade composicional da abordagem WED-flow, tal qual a proporcionada por orquestrações e coreografias: um serviço $W e b$ pode representar uma subcomposição de serviços, orientados sob qualquer abordagem, desde que os requisitos especificados pela WED-flow sejam atendidos. É possível, portanto, a combinação de orquestração, coreografia e WED-flow na execução de um processo de negócio.

\subsubsection{Classes de Serviços Aceitas para Composição}

Um aspecto particularmente relevante da composição de serviços $W e b$ proposta por este trabalho é a viabilidade de se compor serviços adeptos da arquitetura REST, sem abandonar os serviços SOAP tradicionais.

Serviços REST trabalham com o estado de recursos, os quais são representações de dados. Cada operação HTTP implica diretamente na manipulação de dados, de modo que uma abordagem deve ser fortemente vinculada aos dados para que possa aceitar essa classe de serviços. Mostra- 
se bastante viável a composição de serviços REST por meio do reconhecimento das alterações de estado promovidas por suas operações, o que habilita a WED-flow como uma boa candidata a abordagem de composição.

Serviços SOAP, por sua vez, predominam em coreografias e orquestrações, tanto por se basearem em padrões já consolidados há bastante tempo quanto pela diversidade proporcionada: várias operações são disponibilizadas em interfaces de serviço e basta que produzam um determinado efeito dado um conjunto de parâmetros de entrada, independente de como se dá a relação com os dados. O uso de serviços SOAP é análogo a chamadas de diversos blocos de código em um sistema, então o resultado de uma série de chamadas provém dos resultados parciais obtidos em cada processamento local.

Embora a WED-flow recomende que operações sejam capazes de acessar e alterar os dados e o estado da execução, essa classe de serviços também é aceita para composições. De forma geral, somente serviços SOAP muito simples ou de propósito bastante genérico independem de leitura e armazenamento de dados (por exemplo, um serviço que recebe um texto como entrada e devolve o mesmo texto com alguma formatação). Funcionalidades próprias de domínios, tais como os apresentados no exemplo de uso, normalmente operam com os respectivos dados. Ademais, mesmo operações SOAP de longa duração são passíveis de composição por meio da abordagem proposta, se definidas como operações assíncronas. 


\section{Capítulo 5}

\section{Conclusão}

Neste capítulo é apresentado um resumo desta dissertação, bem como descritas suas contribuições e as limitações de seus resultados. São ainda introduzidos possíveis trabalhos futuros relacionados ao que foi produzido.

\section{$5.1 \quad$ Resumo}

Diversos são os conceitos e ferramentas de gerenciamento de processos de negócio propostos desde o advento dos formalismos clássicos, como as redes de Petri e as álgebras de processos, marcados pelo forte embasamento teórico para verificações. A WED-flow, uma das abordagens com tal finalidade, aplica o conceito de tratamento de eventos em prol da flexibilidade na modelagem de workflows: fluxos de controle não precisam ser completamente definidos a priori e alterações incrementais são possíveis por meio da definição de exceções.

Uma importante aplicação de técnicas e mecanismos de gerenciamento de processos de negócio é a composição de serviços $W e b$, dado o potencial desses serviços para a integração e o reuso de funcionalidades no desenvolvimento de aplicações distribuídas e heterogêneas. Entre as várias técnicas adotadas por ferramentas voltadas à composição constam os formalismos clássicos e também as linguagens orientadas à programação, como a BPEL.

Além da técnica empregada na coordenação dos serviços Web em uma composição, outra importante característica é a forma como se dá a organização dos participantes. Duas são as principais formas tradicionalmente adotadas: a coreografia e a orquestração. A abordagem de coreografia é marcada pelo fator colaborativo, de modo que os serviços da composição possuem conhecimento suficiente sobre o processo de negócio para que se auto-organizem. Por outro lado, em uma orquestração todo o conhecimento sobre o processo de negócio é centralizado em um componente denominado orquestrador, o qual exerce o papel de coordenação e aciona os serviços quando necessário.

Em coreografias, é necessário buscar um equilíbrio entre a quantidade de chamadas realizadas (volume de comunicação) e a complexidade técnica dos serviços participantes. Quanto menor o conhecimento presente em cada serviço, mais intensa tende a ser a comunicação necessária com os demais para que a execução de um processo possa ocorrer. Já o aumento do conhecimento 
lógico de cada participante, embora reduza o volume de comunicação, implica em serviços com implementações mais complexas.

Orquestrações, por outro lado, visam manter os serviços Web da composição com a menor complexidade técnica possível, uma vez que todo o conhecimento da execução se concentra no orquestrador. Uma vantagem disso é o maior controle das chamadas que devem ser realizadas aos participantes, mesmo sem aumentar a complexidade em suas implementações. Porém, centralizar toda a coordenação em um só componente torna necessária a adoção de algum mecanismo de gerenciamento de processos de negócio, o que implica na árdua tarefa de modelar o comportamento de todo o processo de negócio a priori e então revisar o modelo por completo sempre que uma alteração precisar ser promovida no processo, seja pela proposição de novos requisitos ou pela identificação de falhas na modelagem inicial.

Esta dissertação de mestrado propõe o uso da WED-flow como uma alternativa ou mesmo um complemento às coreografias e orquestrações na execução de processos de negócio. Adota-se como mecanismo de coordenação o tratamento de eventos por meio da monitoração do estado dos dados da execução, de modo a não ser necessário delegar o conhecimento lógico aos participantes nem haver a centralização de todo esse conhecimento junto a um componente mestre. O fluxo de execução, por sua vez, deixa de ser um requisito e passa a se tornar consequência das alterações promovidas no estado dos dados, o que proporciona maior flexibilidade na criação e manutenção de modelos.

\subsection{Contribuições}

Para apoiar a proposta de aplicar a WED-flow como abordagem de composição de serviços Web, bem como possibilitar sua posterior avaliação, foram apresentados cenários de comunicação, distribuídos entre quatro configurações. Cada configuração foi construída por meio da combinação de aspectos pré-definidos, entre eles a abordagem de composição: orquestração ou coreografia. Combinações inviáveis dos aspectos tiveram suas eliminações justificadas, de modo a restarem seis cenários para avaliação, metade para cada abordagem tradicional de composição.

Cada cenário de comunicação proposto passou, então, por um processo de avaliação com dois critérios: o volume de comunicação, referente à quantidade de chamadas a serviços $W e b$ necessárias ao longo de uma execução de processo de negócio, e os aspectos técnicos de implementação. Suposições, definições e conceitos foram estabelecidos para viabilizar a avaliação dos cenários e também a obtenção, para cada um, de uma expressão matemática para auxiliar no cálculo do volume de comunicação. Todos os cenários foram também simulados de acordo com amostras simples de processos de negócio, que podem ser compostas para originar a simulação de processos mais complexos.

Os cenários de cada configuração foram, por fim, avaliados entre si, de modo a se estabelecerem os mais vantajosos de suas respectivas configurações. Definiu-se, assim, um contexto no qual a abordagem proposta por este trabalho teria suas vantagens e desvantagens avaliadas. 
Esta dissertação apontou as razões pelas quais é considerada válida a proposta da WED-flow como abordagem de composição. Comparou, inclusive, suas características em relação ao NPWS, mecanismo de composição proporcionado por [40] e que promove a orquestração de serviços $W e b$ por meio de uma extensão de álgebra de processos como forma de gerenciar processos de negócio.

Realizou-se, então, a implementação de um módulo de comunicação com serviços Web para estender o potencial do núcleo WED-flow, ferramenta em desenvolvimento por [16] e responsável pelo gerenciamento propriamente dito de processos de negócio. A integração real não pôde ser promovida até o término deste trabalho, uma vez que o núcleo não foi concluído a tempo, porém seu comportamento pôde ser simulado.

O estudo de propriedades das classes SOAP e REST de serviços Web propiciou a diversificação dos serviços inclusos em composições compatíveis com a nova abordagem. O módulo de comunicação foi desenvolvido com a capacidade de se comunicar tanto com serviços SOAP quanto REST, levando ainda em consideração que operações SOAP podem ser síncronas ou assíncronas.

A abordagem proposta e implementada foi avaliada de acordo com os critérios previamente estabelecidos para a avaliação dos cenários de comunicação e, analogamente, obteve-se uma expressão matemática referente a seu volume de comunicação. Então, os resultados obtidos para a abordagem WED-flow foram comparados com aqueles identificados como os melhores de suas configurações, com o intuito de se estabelecer vantagens e desvantagens.

Por fim, este trabalho ainda apresentou um exemplo de estudo para a abordagem proposta, bem como sua implementação visando validações práticas do módulo desenvolvido.

\subsection{Limitações}

Os requisitos impostos pela abordagem WED-flow para a composição de serviços Web podem ser avaliados como limitações dos resultados obtidos. Por haver o bloqueio das atualizações de dados que pertencem a WED-states originados de sistemas externos ao WED-flow, alterações realizadas em um WED-state devem ser propagadas para os sistemas fontes.

Embora as operações síncronas expostas por serviços $W e b$ possam ser compostas sem qualquer adaptação, há o caso das operações assíncronas, que precisam estar habilitadas para o envio de chamadas de retorno ao módulo desenvolvido. Esse aspecto pode inviabilizar o ingresso de uma operação em composições com WED-flow, porém não foi identificada uma forma de integração livre de restrições.

Há ainda uma limitação técnica deste trabalho proveniente de sua proposta: a implementação realizada não é capaz de coordenar serviços $W e b$ por si só, pois tal função é exercida pelo núcleo WED-flow, contribuição de [16]. Dado que o módulo de comunicação com serviços Web é uma extensão do núcleo, o sucesso de sua aplicação a composições de serviços depende do bom funcionamento do último. 


\subsection{Trabalhos Futuros}

A conclusão deste trabalho é finalizada com propostas de alguns trabalhos que podem ser

realizados para complementá-lo. É importante ressaltar que existem trabalhos futuros associados ao núcleo WED-flow cujos resultados podem vir a ser interessantes para este trabalho, porém não estão diretamente relacionados à composição de serviços $W e b$ e, portanto, não são considerados.

\subsubsection{Gerenciamento das Informações de Serviços}

Interfaces gráficas muito simples foram desenvolvidas para permitir o cadastro e o gerenciamento de informações de serviços a serem compostos com o módulo desenvolvido. Ademais, atualmente as estruturas para a representação de parâmetros são definidas manualmente junto ao módulo de extensão.

A elaboração de uma aplicação mais apropriada para o cadastro, a manutenção e a extração de informações de serviços, bem como a automação da configuração de tipos complexos de parâmetros exigidos pelos serviços, certamente oferecem ganhos de usabilidade na preparação para o uso do módulo de comunicação e facilita a adoção da WED-flow como abordagem de composição.

\subsubsection{Tratamento de Questões de Segurança da Informação}

O módulo de extensão implementado não trata quaisquer questões de segurança nas informações trafegadas. Apesar da abstração desse fator não interferir nos resultados obtidos, é interessante que a aplicação prática da WED-flow a composições de serviços Web considere a possibilidade de operar com dados que não podem ser expostos durante a comunicação com os participantes.

Tratar questões de segurança da informação não implica somente em tornar o módulo de comunicação disponível em ambiente seguro, mas também avaliar as medidas que devem ser tomadas para que o módulo se comunique com serviços situados em outros ambientes seguros. 


\section{Referências Bibliográficas}

[1] Alarcon, R., Wilde, E., And Bellido, J. Hypermedia-driven restful service composition. ICSOC Workshops (2010). 5

[2] Alexopoulou, N., Nikolaidou, M., Anagnostopoulos, D., and Martakos, D. An event-driven modeling approach for dynamic human-intensive business. 393-404. 2

[3] Baeten, J. C. M. A brief history of process algebra. Theoretical Computer Science 335, 2-3 (2005), 131-146. 8

[4] Bergstra, J. A., And Klop, J. W. Process algebra for synchronous communication. Information and Control 60,1-3 (1984), 109-137. 13, 14

[5] Best, E., Devillers, R., and Koutny, M. A unified model for nets and process algebras. In Handbook of Process Algebra, J. A. Bergstra, A. Ponse, and S. A. Smolka, Eds. Elsevier Science Inc., Amsterdã, Holanda, 2001. 18

[6] Braghetto, K. R. Padrões de fluxos de processos em banco de dados relacionais. Master's thesis, Universidade de São Paulo, São Paulo, Brasil, 2006. 2, 18

[7] Cerami, E. Web Services Essentials. O’Reilly, 2002. 24

[8] Curbera, F., Khalaf, R., Leymann, F., and Weerawarana, S. Exception handling in the bpel4ws language. Proceedings of the 2003 International Conference on Business Process Management (2003). 5

[9] Decker, G., Kopp, O., Leymann, F., And Weske, M. Bpel4chor: Extending bpel for modeling choreographies. Proceedings International Conference on Web Services (2007). 4

[10] Dittrich, K. R., Gatziu, S., and Geppert, A. The active database management system manifesto: a rulebase of adbms features. RIDS95: Proceedings of the Second International Workshop on Rules in Database Systems (1995), 3-20. 2

[11] Fauvet, M.-C., Dumas, M., Benatallah, B., and Paik, H.-Y. Peer-to-peer traced execution of composite services. Proceedings of the 2nd International Workshop on Technologies for E-Services (2001), 103-117. 4

[12] Ferreira, J. E., Takai, O. K., Malkowski, S., and Pu, C. Reducing exception handling complexity in business process modeling and implementation: the wed-flow approach. Proceedings of CoopIS 2010: 18th International Conference on Cooperative Information Systems (2010). 2, 20, 21, 23, 24 
[13] Ferreira, J. E., Wu, Q., Malkowski, S., And Pu, C. Towards flexible event-handling in workflows through data states. IEEE 6th World Congress on Services (2010), 344-351. 2, 19, 20

[14] Fielding, R. T. Architectural styles and the design of network-based software architectures. PhD thesis, University of California, Irvine, 2000. 4, 25, 28

[15] Fokkink, W. Introduction to Process Algebra. Springer-Verlag New York, Inc., Secaucus, EUA, 2000. 7, 8, 13

[16] Garcia, M. O. Implementação do arcabouço wed-flow para controle de processos transacionais. Dissertação para Exame de Qualificação (2011). 6, 57, 62, 87

[17] Garcia-Molina, H., And Salem, K. Sagas. SIGMOD'87 Proceedings of the 1987 ACM SIGMOD International Conference on Management of Data (1987). 5

[18] HoAre, C. A. R. Communicating Sequential Processes. Prentice Hall, Nova Iorque, EUA, 1985. 13

[19] Hull, R., Benedikt, M., Christophides, V., And Su, J. E-services: A look behind the curtain. Proceedings of the 22nd ACM SIGMOD-SIGACT-SIGART Symposium on Principles of Database Systems (2003). 3

[20] IBM. Business process execution language for web services version 1.1. http://www.ibm. com/developerworks/library/specification/ws-bpel/, Feb. 2007. 3

[21] Jordan, D., And Evdemon, J. Web services business process execution language version 2.0. Tech. rep., OASIS Standard, 2007. 4, 31

[22] Kavantzas, N., Burdett, D., Ritzinger, G., Fletcher, T., and Lafon, Y. Choreography description language, version 1.0. Tech. rep., W3C, 2004. 4

[23] Leymann, F., Roller, D., And Schmidt, M. T. Web services and business process management. IBM Systems Journal 41, 2 (2002), 198-211. 1

[24] LiU, L., Pu, C., AND TANG, W. Continual queries for internet scale event-driven information delivery. IEEE Transactions on Knowledge and Data Engineering 11, 4 (1999), 610-628. 19

[25] Lomet, D., Barga, R., Mokbel, M., Shegalov, G., Wang, R., And Zhu, Y. Immortal $\mathrm{db}$ : Transaction time support for sql server. SIGMOD'05: Proceedings of the 2005 ACM SIGMOD international conference on Management of data (2005), 939-941. 19

[26] Mecella, M., Presicce, F. P., And Pernici, B. Modeling e-service orchestration through petri nets. Proceedings of the Third International Workshop on Technologies for E-Services (2002), 38-47. 3

[27] Menamin, S. M. M., And Palmer, J. F. Essential Systems Analysis. Yourdon, 1984. 2

[28] Milner, R. A Calculus of Communicating Systems. Springer-Verlag New York, Inc., Secaucus, EUA, 1982. 13, 14, 15

[29] Moller, F. The importance of the left merge operator in process algebras. Proceedings of the 17th International Colloquium on Automata, Languages and Programming (1990), 752-764. 14 
[30] Montali, M., Pesic, M., van der Aalst, W. M. P., Chesani, F., Mello, P., and Storari, S. Declarative specification and verification of service choreographies. ACM Transactions on the Web 4, 1 (2010). 4

[31] Müller, D., Reichert, M., And Herbst, J. Data-driven modeling and coordination of large process structures. On the Move to Meaningful Internet Systems 2007: CoopIS, DOA, ODBASE, GADA, and IS (2007), 131-149. 2

[32] Murata, T. Petri nets: Properties, analysis and applications. Proceedings IEEE 77, 4 (1989), 541-580. 8, 9

[33] Nigam, A., And Caswell, N. S. Business artifacts: an approach to operation specification. IBM Journal 42 (2003), 428-445. 2

[34] (OMG), O. M. G. Business process modeling notation (bpmn) specification, final adopted specification. Tech. rep., 2006. 4

[35] Pautasso, C. Restful web service composition with bpel for rest. Data $\&$ Knowledge Engineering 68 (2009). 5

[36] Peltz, C. Web services orchestration and choreography. Computer 36, 10 (2003), 46-52. 31, 32

[37] Pfitzner, K., Decker, G., Kopp, O., And Leymann, F. Web service choreography configurations for bpmn. Proceedings of the 3rd International Workshop on Engineering Serviceoriented Applications: Analysis, Design and Composition (2007). 4

[38] Pires, P. F., Benevides, M. R. F., And Mattoso, M. Building reliable web services compositions. Proceedings of the Workshop on the Web, Web-Services, and Database Systems 2002 (2002). 4

[39] Purer, K. Web service composition in drupal. Master's thesis, Vienna University of Technology, Vienna, Austria, 2011. 5

[40] Rodrigues, M. C., Malkowski, S., And Ferreira, J. E. Implementing rigorous web services with process algebra: Navigation plan for web services. SAC'09: Proceedings of the 2009 ACM symposium on Applied Computing 2 (2009), 625-631. 3, 16, 60, 87

[41] Roman, E., Sriganesh, R. P., and Brose, G. Mastering Enterprise JavaBeans. Wiley, 2004. 24

[42] Schäfer, M., Dolog, P., ANd Nejdl, W. An environment for flexible advanced compensations of web service transactions. ACM Transactions on the Web 2, 2 (2008), 1-36. 5

[43] Schuler, C., Schuldt, H., And Schek, H.-J. Supporting reliable transactional business processes by publish/subscribe techniques. Proceedings of the 2nd International Workshop on Technologies for E-Services (2001), 118-131. 4

[44] SpIEs, B. Web services, part 1: Soap vs rest. http://ajaxonomy.com/2008/xml/ web-services-part-1-soap-vs-rest, May 2008. 29, 30

[45] VAN DER AALST, W. M. P. The application of petri nets to workflow management. The Journal of Circuits, Systems and Computers 8, 1 (1998), 1-53. 11, 13 
[46] VAn Der Aalst, W. M. P. Pi calculus versus petri nets: Let us eat humble pie rather than further inflate the pi hype. Tech. rep., Twente University, Holanda, 2004. 4, 19

[47] VAn Der Aalst, W. M. P., AND Pesic, M. Towards a truly declarative service flow language. Web Services and Formal Methods, Third International Workshop (2006). 4

[48] van der Aalst, W. M. P., ter Hofstede, A. H. M., and Weske, M. Business process management: A survey. Proceedings of International Conference on Business Process Management (2003). 8

[49] van Der Aalst, W. M. P., And van Hee, K. Workflow Management: Models, Methods, and Systems. MIT Press, Cambridge, EUA, 2004. 8, 9, 10, 11

[50] Vidyasankar, K., And Vossen, G. Multi-level modeling of web service compositions with transactional properties. Journal of Database Management 22 (2011), 1-31. 3

[51] W3C. Web service choreography interface (wsci) 1.0. http://www.w3.org/TR/wsci/, Jan. 2011. 31

[52] W3C. Web services architecture. http://www.w3.org/TR/ws-arch/, Jan. 2011. 25, 26

[53] W3C. Web services glossary. http://www.w3.org/TR/ws-gloss/, Jan. 2011. 24

[54] WfMC. Terminology \& glossary (document number wfmc-tc-101). http://www.wfmc.org/ standards/docs/TC-1011_term_glossary_v3.pdf, Jan. 2011. 1

[55] WfMC. The workflow reference model (document number tc00-1003). http://www.wfmc. org/standards/docs/tc003v11.pdf, Jan. 2011. 1

[56] Zhao, H., And Doshi, P. Towards automated restful web service composition. ICWS '09 Proceedings of the 2009 IEEE International Conference on Web Services (2009). 5

[57] Zuliane, D., Oikawa, M. K., Malkowski, S., Alcazar, J. P., and Ferreira, J. E. The riverfish approach to business process modeling: Linking business steps to control-flow patterns. Lecture Notes of the Institute for Computer Sciences, Social Informatics and Telecommunications Engineering 10 (2009), 179-193. 2, 4 